\title{
Hormônios reguladores do metabolismo energético e repercussões na atividade funcional dos fagócitos mononucleares do colostro de puérperas com excesso de peso pré-gestacional
} Tassiane Cristina Morais

Tese apresentada ao Programa de Pós-Graduação em Saúde Pública para obtenção do título de Doutor em Ciências.

Área de Concentração: Saúde, Ciclos de vida e Sociedade

Orientador: Prof. Dr. Luiz Carlos de Abreu

São Paulo - SP 


\section{Hormônios reguladores do metabolismo energético e repercussões na atividade funcional dos fagócitos mononucleares do colostro de puérperas com excesso de peso pré-gestacional}

Tassiane Cristina Morais

Tese apresentada ao Programa de Pós-Graduação em Saúde Pública da Faculdade de Saúde da Universidade de São Paulo para obtenção do título de Doutor em Ciências.

Área de Concentração: Saúde, Ciclos de vida e Sociedade

Orientador: Prof. Dr. Luiz Carlos de Abreu

Versão Revisada

São Paulo - SP

2019 
Autorizo a reprodução e divulgação total ou parcial deste trabalho, por qualquer meio convencional ou eletrônico, para fins de estudo e pesquisa, desde que citada a fonte.

Catalogação da Publicação

Ficha elaborada pelo Sistema de Geração Automática a partir de dados fornecidos pelo(a) autor(a) Bibliotecária da FSP/USP: Maria do Carmo Alvarez - CRB-8/4359

Morais, Tassiane Cristina

Hormônios reguladores do metabolismo energético e repercussões na atividade funcional dos fagócitos mononucleares do colostro de puérperas com excesso de peso pré-gestacional / Tassiane Cristina Morais; orientador Prof. Dr. Luiz Carlos de Abreu. -- São Paulo, 2019. $86 \mathrm{p}$.

Tese (Doutorado) -- Faculdade de Saúde Pública da Universidade de São Paulo, 2019.

1. adiponectina. 2. colostro. 3. leptina. 4. melatonina. 5. obesidade. I. de Abreu, Prof. Dr. Luiz Carlos, orient. II. Título. 
Dedico este trabalho para todos os meus ancestrais, em especial para a minha bisavó paterna Lúcia que teve sua vida abreviada após um parto e não gozou da possibilidade de embalar, ninar e amamentar seu bebê. Ela não deteve do direito de fazer parte da memória de sua filha, provavelmente, pelo simples fato de ser mulher. Assim, dedico este trabalho a todas as mães de Maria. 


\section{AGRADECIMENTOS}

Agradeço a Deus pela estrada percorrida e por ser uma fonte infinita de força e esperança que nos impulsiona a seguir em frente.

Agradeço a minha mãe, Suely Estela da Silva Morais, e a meu pai, Pedro Morais (In memoriam), que me deram a vida e todas as ferramentas necessárias para amadurecer e ter a coragem de sair para trilhar meu próprio caminho. Com vocês eu descobri o que é amar e receber o amor real, de modo incondicional. Eu os amo e tenho imensa gratidão!

Agradeço a toda minha família, em especial a minha tia Solimar da Silva quem abriu as portas de sua casa e me recebeu com todo o seu amor e carinho, fato fundamental para me sentir em casa nesta cidade tão querida. Meus agradecimentos a minha avó Elydia Campi Silva, ao meu irmão Rodrigo Roberto Morais, minha cunhada Milene Bordin, a minha irmã Tame Renata Morais e meus sobrinhos Carlos Caique Morais do Nascimento, Larissa Mayra Morais do Nascimento e Vitor Hugo Morais do Nascimento, vocês são a minha base e o meu porto seguro! Espero que com o passar dos anos nossos laços se fortaleçam cada vez mais e nossas relações sejam sempre baseada na cumplicidade e amor.

Agradeço ao meu amigo, namorado e grande parceiro, Ricardo Morais Freitas, que veio como um lindo presente de primavera que adentrou estações e coloriu meus dias junto ao final dos experimentos desta pesquisa. Gratidão por compartilhar comigo segredos e virtudes, pelo seu lindo coração e sua capacidade de amar, eu o amo.

Meus agradecimentos para Leila Santos e Vanessa Ribeiro que foram minhas "amigas irmãs" nesta fase de doutorado. Agradeço pela companhia, amizade, apoio, ombro amigo, incentivo, pelos sonhos compartilhados e memórias vividas, meus sinceros agradecimentos. Agradeço também a Maria Elizangela Ramos Junqueira por toda amizade, fé, otimismo, conselhos, amparo, constante incentivo, por sua capacidade de ver além e abrir meus olhos 
para novas perspectivas. Agradeço ao meu amigo Rafael Souza Pessoa, pela sua sensibilidade, pelas gotas de lavanda para ansiedade, por todos os seus conselhos, pela ajuda nos experimentos e por simplesmente ser você. Gratidão meu amigo!

Agradecimentos ao Cleiton Fiório por todas as risadas durante os almoços, por saber acolher seus amigos sem julgamentos, mostrando a praticidade para se resolver um problema. Agradeço também a Agatha Gameiro, a Denize Rupolo Dall Agnol e a todos os outros amigos que não foram aqui citados, mas que fizeram parte da minha história. Os anos de doutorado foram acompanhados de muitas vivências que extrapolaram o espaço acadêmico, foi uma fase rica, agregada a muita busca e amadurecimento pessoal.

Um agradecimento a Dr. ${ }^{a}$ Mahmi Fujimori que foi uma das pioneiras nesta linha de pesquisa e abriu as portas para que hoje possamos estar avançando neste campo de conhecimento.

Um agradecimento em especial a meu orientador Prof. Dr. Luiz Carlos de Abreu, por ter aceitado conduzir este projeto de doutorado. Meus agradecimentos por toda confiança e autônomia dada a mim para o desenvolvimento deste trabalho. Admiro-o pela sua audácia de sempre extrapolar sua zona de conforto, buscando novas parcerias e projetos de âmbitos nacionais ou internacionais e por sua visão em agrupar talentos e formar grupos. Meus agradecimentos pelos seus conselhos, por ter contribuído com minha maturidade como cientista e principalmente pelo constante incentivo de ir além.

Agradeço também a Prof ${ }^{a}$ Dr. $^{a}$ Adenilda Cristina Honório-França que em muito colaborou para o desenvolvimento deste trabalho. Sua experiência e conhecimento foram fundamentais para o enriquecimento desta pesquisa. Agradeço por toda sua dedicação, ousadia, humildade, ética, amor ao tema e a seus alunos. Gratidão pelo acolhimento dado, pelas orientações transmitidas e por toda confiança e liberdade que a mim foi conferida. Aprendi muito com suas orientações que também foram essenciais para meu amadurecimento 
no campo das ciências. Meus agradecimentos pelo constante apoio e incentivo nesta caminhada, tenho imensa admiração pelo seu trabalho e pela sua pessoa. Gratidão!

Agradeço ao Prof. Dr. Eduardo Luzia França, a quem tenho imensa gratidão e grande admiração por sua simplicidade, sua forma de fazer ciência, pela grandiosidade de seus pensamentos e por respeitar a individualidade de cada aluno. Suas contribuições foram fundamentais, não só para a constituição desse trabalho, mas como para meu reconhecimento da minha própria vocação. Um Professor que sempre ensinou que cada um tem seu tempo, que devemos sonhar grande, mirar no alvo para além do que queremos!

Agradeço aos membros da Banca, em especial ao Prof. Dr. Claudio Leone, pelo aceite em fazer parte desta Banca de defesa de doutorado e que gentilmente contribuiu para a melhoria deste trabalho desde o processo de qualificação desta pesquisa. Meus agradecimentos por compartilhar o conhecimento com os alunos de forma simples, interessante e gentil. Agradeço por ser um Professor acessível e que mesmo após a aposentadoria continua com seus trabalhos, contribuindo com o desenvolvimento da ciência nesta instituição de ensino.

Um agradecimento especial também a Prof. ${ }^{a}$ Dr. ${ }^{a}$ Isabel C. E. Sorpreso por suas contribuições visando a melhoria desta tese e pelo incentivo em aprofundar a temática tratada em futuras pesquisas. Meus agradecimentos principalmente por fazer parte desta Banca e trazer a força do seu feminino para a discussão de um tema fundamental para a saúde de muitas crianças e mulheres. Meus singelos agradecimentos.

Agradeço também as minhas parceiras de pesquisa Ocilma B. de Quental e Blanca Blanca E.G. Daboin pelas colaborações prestadas e por terem despertado em mim, novamente, um olhar mais humano perante a saúde materno-infantil.

Agradeço aos colegas do Laboratório de Delineamentos e Escrita Científica, do Centro Universitário Saúde ABC, e aos colegas, professores e funcionários da Faculdade de Saúde 
Pública da Universidade de São Paulo, locais em que eu aprendi muitos ensinamentos ao longo dos anos. Meus agradecimentos também aos colegas dos Laboratórios de Cronoimunomodução e de Imunologia da Relação Materno-Infantil, da Universidade Federal do Mato-Grosso-UFMT, em especial ao Aron, Bruno, Carol, Elton, José Nivaldo (pelo café e otimismo diário), Renata Araújo, Rubian, Taisline, Patrícia e as professoras: Danny Laura Gomes Fagundes, Lucélia Campelo de Albuquerque Moraes e Patrícia Fernandes Massmann. Gratidão pela ajuda e sugestões prestadas.

Agradeço especialmente a Fundação de Amparo a Pesquisa do Estado de São Paulo por ter fomentado este trabalho com Auxílio a Pesquisa (Processo auxílio 2015/19922-0) e a bolsa de doutorado (Processo Fapesp n²015/01051-3), recursos essenciais para execução desta pesquisa.

Meus agradecimentos a todas as doadoras de colostro por compartilharem parte deste momento do puerpério e da amamentação, por acreditarem na ciência e colaborarem na tentativa de construírem um mundo melhor.

Meus agradecimentos finais a todos que contribuíram com este trabalho e que por ventura não foram aqui citados. Uma tese de doutorado não se faz sozinha, este trabalho também é resultado da confiança e da força de cada um de vocês. Meus sinceros agradecimentos! 
"La loba, a velha, Aquela Que Sabe, está dentro de nós. Ela viceja na mais profunda alma-psique das mulheres, a antiga e vital Mulher Selvagem. Ela descreve sua casa como um lugar no tempo no qual o espírito das mulheres e o espírito dos lobos se encontram - o lugar onde a mente e os instintos se misturam, onde a vida profunda da mulher embasa sua vida rotineira. É o ponto em que o Eu e o Tu se beijam, o lugar onde as mulheres correm com os lobos"

-Clarissa Pinkola Estés- 
MORAIS, TC. Hormônios reguladores do metabolismo energético e repercussões na atividade funcional dos fagócitos mononucleares do colostro de puérperas com excesso de peso prégestacional [tese]. São Paulo: Faculdade de Saúde Pública da Universidade de São Paulo; 2019.

\section{RESUMO}

A promoção a amamentação representa uma importante estratégia de saúde pública no manejo do sobrepeso e obesidade mundial. É possível que os hormônios reguladores do metabolismo energético, como a adiponectina, leptina e melatonina do colostro humano, possa beneficiar o sistema imunológico do lactente e minimizar os impactos ocasionados pelo excesso de peso materno pré-gestacional. Esses hormônios também possuem ação imunomoduladora, assim, mudanças nas suas concentrações podem comprometer a atividade funcional das células mononucleares $(\mathrm{MN})$ do colostro humano e contribuir para o aumento de infecções neonatais. Por isto, o objetivo desta pesquisa foi analisar a atividade funcional dos fagócitos MN do colostro de mulheres com excesso de peso pré-gestacional, na ausência e presença de adiponectina, leptina e melatonina. As amostras de colostro foram coletadas de 109 doadoras saudáveis e foram divididas em dois grupos: grupo controle e grupo com excesso de peso. $\mathrm{O}$ colostro foi centrifugado para obtenção do botão celular e sobrenadante. O sobrenadante foi utilizado para dosagem de melatonina, quantificada por ELISA. As células MN foram utilizadas no ensaio de fagocitose, por citometria de fluxo, e a produção de espécies reativas de oxigênio (EROS), cálcio intracelular e apoptose foram realizadas por fluorimetria. Foram consideradas diferenças significativas quando $\mathrm{p}<0,05$. O colostro de mulheres com excesso de peso prégestacional apresentou uma maior concentração de melatonina $(\mathrm{p}<0,05)$. Os fagócitos $\mathrm{MN}$ do grupo excesso de peso teve um menor índice de fagocitose $(\mathrm{p}<0,05)$, no entanto, os estímulos foram capazes de restaurar a atividade fagocítica para este grupo $(p<0,05)$. A adiponectina+leptina foi o estímulo que desenvolveu uma resposta mais efetiva, com restauração dos níveis de EROS, manutenção do cálcio intracelular e elevação do índice de apoptose para o grupo com excesso de peso $(\mathrm{p}<0,05)$. Os dados em conjunto reforçam a hipótese de que amamentação é benéfica para a saúde da criança, e a manutenção dos níveis endógenos maternos de adiponectina, leptina e melatonina são essenciais para intensificar a proteção do colostro. Assim, políticas públicas que apoiam o controle de peso pré-gestacional devem ser encorajadas.

Palavras-chave: adiponectina, colostro, fagócitos, leptina, melatonina, obesidade. 
MORAIS, TC [Hormones regulating energy metabolism and repercussions on the functional activity of phagocytes from colostrum of pre-gestational overweight women] [Thesis]. São Paulo: Faculdade de Saúde Pública da Universidade de São Paulo; 2019. Portuguese.

\begin{abstract}
Breastfeeding promotion represents an important public health iniciative in worldwide overweight and obesity management strategies. It is possible that the hormones regulating energy metabolism, such as adiponectin, leptin and melatonin of human colostrum can benefit the infant's immune system and minimize the impacts caused by pre-gestational maternal overweight. As these hormones also have immunomodulatory action, changes in their concentrations can affect the functional activity of mononuclear cells of human colostrum and contribute to the increase of neonatal infections. Therefore, the aim of this study is to analyze the functional activity of colostrum mononuclear phagocytes in women with pregestational overweight, with absence or presence of adiponectin, leptin and melatonin. Colostrum samples collected from 109 healthy donors were divided into two groups: the control group and the high body mass index (BMI) group. Colostrum samples were centrifuged to obtain the cell button and supernatant. The supernatant was used for melatonin dosing performed by ELISA, mononuclear cells used to phagocytosis assay, by flow cytometry and production of reactive species of oxygen, intracellular calcium and apoptosis assays were performed by fluorimetry using plate reader. Statistically significant differences were considered when $\mathrm{p}<0.05$. Colostrum of pre-gestational high BMI group had higher concentration of melatonin $(\mathrm{p}<0.05)$. Mononuclear phagocytes of high BMI group had a lower index of phagocytosis $(p<0.05)$. However, the stimuli restored the phagocytic activity for high BMI group $(\mathrm{p}<0.05)$. Adiponectin+leptin was the stimulus that developed a more effective response, with restoration of reactive oxygen species levels, maintenance of intracellular calcium and elevation of apoptosis index $(\mathrm{p}<0.05)$ in the high BMI group. These data reinforce that breastfeeding is beneficial to child's health and maintaining maternal endogenous levels of adiponectin, leptin and melatonin may increase colostrum protection. Thus, public policies that support pregestational weight control should be encouraged.
\end{abstract}

Keywords: adiponectin; colostrum; leptin; melatonin; phagocytes; obesity. 


\section{SUMÁRIO}

1 INTRODUÇÃO.................................................................................................................. 17

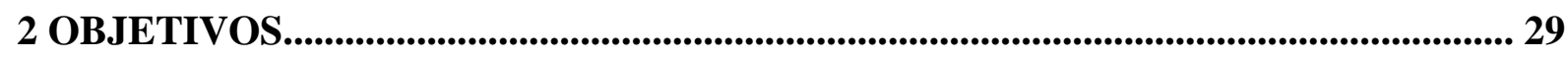

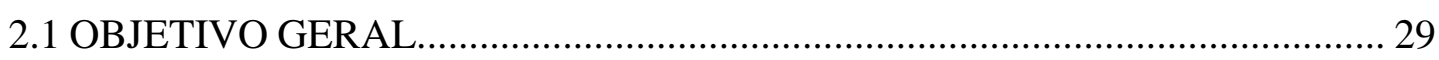

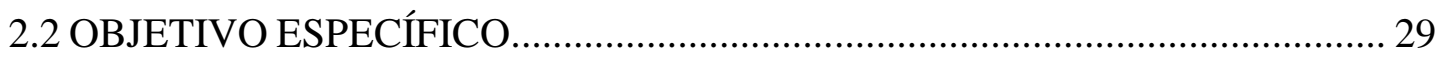

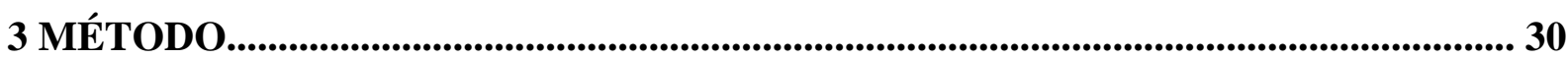

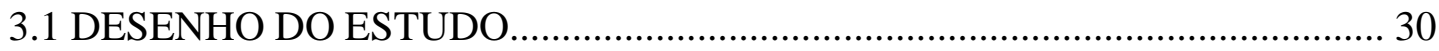

3.2 SUJEITOS E TAMANHO AMOSTRAL ............................................................. 31

3.3 CRITÉRIOS DE INCLUSÃO, EXCLUSÃO E DESCONTINUIDADE............... 32

3.4 DEFINIÇÃO DAS VARIÁVEIS........................................................................... 33

3.5 MÉTODOS DE COLETA E AVALIAÇÃO........................................................... 33

3.5.1 Estado Nutricional Pré-Gestacional......................................................... 33

3.5.2 Idade Gestacional................................................................................ 34

3.5.3 Procedimento para Obtenção de Células Mononucleares do Colostro..... 35

3.5.4 Dosagem da Melatonina........................................................................ 36

3.5.5 Estímulos Utilizados......................................................................... 36

3.5.6 Ensaio de Fagocitose......................................................................... 36

3.5.7 Análises de Espécies Reativas de Oxigênio................................................... 37

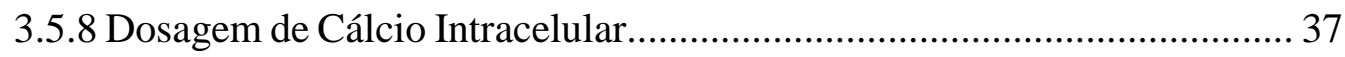

3.5.9 Ensaio de Apoptose................................................................................ 38

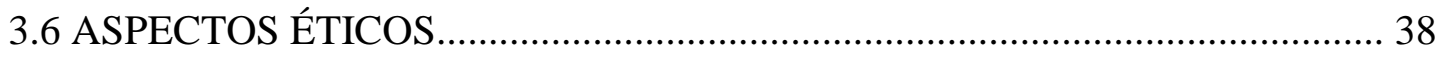

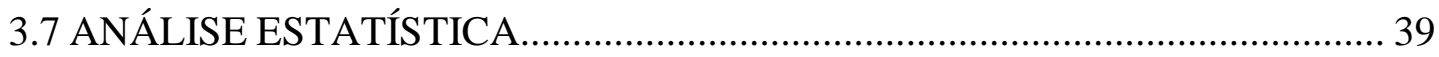

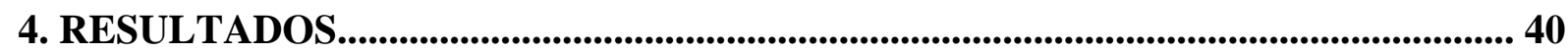

4.1 CARACTERIZAÇÃO DA POPULAÇÃO ESTUDADA....................................... 40 
4.2 DOSAGEM DA MELATONINA NO SOBRENADANTE DO COLOSTRO.....41

4.3 ANÁLISES DAS CÉLULAS MONONUCLEARES DO COLOSTRO.............. 41

5 DISCUSSÃ

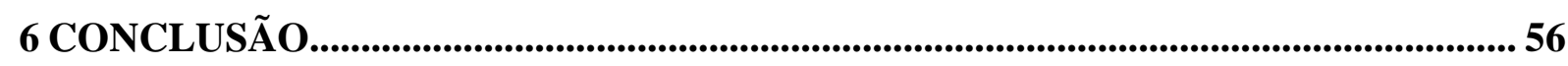

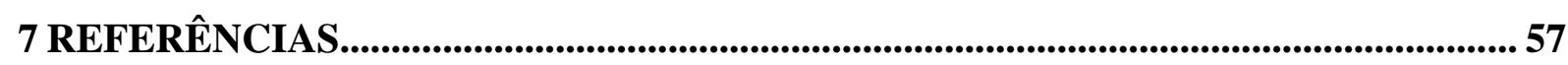

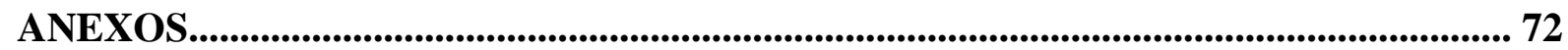

ANEXO 1 - QUESTIONÁRIO.................................................................. 73

ANEXO 2 - TERMO DE CONSCENTIMENTO LIVRE ESCLARECIDO............. 77

ANEXO 3 - PARECER CONSUBSTANCIADO DO COMITÊ DE ÉTICA............ 79

ANEXO 4 -VALORES BRUTOS DAS MÉDIAS E DESVIO PADRÃO DOS RESUlTADOS DE FAGOCITOSE, ESPÉCIES REATIVAS DE OXIGÊNIO, NÍVEIS DE CÁLCIO INTRACELULAR E

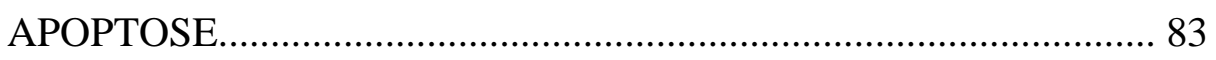

CURRÍCULO LATTES................................................................................................. 84

ARTIGO PUBLICADO............................................................................................................. 86 


\section{LISTAS DE TABELAS}

Tabela 1 -

Tabela $2-$
Caracterização da população estudada 40

Média e desvio padrão dos dados apresentados nos gráficos da sessão Resultados, referentes a atividade funcional dos fagócitos do colostro humano, segundo o estado nutricional pré-gestacional. 


\section{LISTAS DE FIGURAS}

Figura $1-$

Hipótese do estudo

Figura 2 -

Esquematização das etapas desenvolvidas pela pesquisa

Figura 3 -

Separação de fases e de população celular do colostro humano

Figura 4 Níveis de melatonina em $\mathrm{pg} / \mathrm{mL}$ no sobrenadante do colostro humano segundo o IMC pré-gestacional

Figura 5 Índice de fagocitose das células mononucleares do colostro humano de acordo com o IMC materno pré-gestacional

Figura $6-$ Liberação de espécie reativas de oxigênio pelos fagócitos do colostro segundo o excesso de peso materno

Figura 7 Níveis de cálcio intracelular liberados no processo de fagocitose das células mononucleares do colostro em função o estado nutricional materno pré-gestacional.

Figura $8-$ Índice de apoptose dos fagócitos MN do colostro humano em função o estado nutricional materno pré-gestacional 


\section{LISTAS DE ABREVIATURAS}

AdipoRs - Receptores de adiponectina

AMP cíclico - Monofosfato cíclico de adenosina

ANOVA - Análise de Variância

Bcl-2 - B-cell lymphoma protein 2

BSA - Albumina do soro bovino

DHR 123 - Dihidrorhodamina 123

DP - Desvio padrão

ELISA - Ensaio de imunoabsorção enzimática

EROS - Espécies reativas de oxigênio

$\mathrm{Fc} \alpha \mathrm{R}$ - Receptor do fragmento Fc da imunoglobulina alfa

FITC - Isotiocianato de Fluoresceina

FLUO-3 AM - Fluo-3/acetoxymethyl ester

HBSS - Hank’s Balanced Salt Solution

IkB - Quinase do inibidor kappa B

IMC - Índice de massa corporal

JAK/STAT- Janus Kinase/Transdutores de Sinal e Ativadores de Transcrição

$\mathrm{Kg}$ - Quilograma

$\mathrm{m}^{2}-$ Metros ao quadrado

LepRs - Receptores de leptina

M1 - Macrófagos de fenótipo M1 da via clássica

M2 - Macrófagos de fenótipo M2

$\mathrm{MN}$ - Mononucleares 
MT1 - Receptor de melatonina do tipo 1

MT2 - Receptor de melatonina do tipo 2

MT3 - Receptor de melatonina do tipo 3

Myd88 - Fator de diferenciação mielóide 88

NF-kB - Fator nuclear kappa beta

pg/mL - Picogramas por mililitros

RZR/ROR $\alpha$ - Receptores órfãos do ácido retinóico

TLR - Receptores Toll-like

TCLE - Termo de Consentimento Livre e Esclarecido 


\section{INTRODUÇÃO}

O sobrepeso (IMC 25,0 a $29,9 \mathrm{Kg} / \mathrm{m}^{2}$ ) e a obesidade (IMC $\geq 30,0 \mathrm{Kg} / \mathrm{m}^{2}$ ) é um complexo problema de saúde pública de proporções epidêmicas dado que, a maior parte da população mundial reside em países em que o excesso de peso mata mais pessoas que o baixo peso (WHO, 2018).

De acordo com a Federação Mundial de Obesidade, a obesidade é considerada uma doença crônica complexa, recorrente e progressiva. Por isso, ressalta-se a necessidade de ações com enfoque na prevenção e controle desta epidemia mundial (BRAY et al., 2017). No entanto, é altamente desafiador o desenvolvimento de estratégias eficazes para o controle do excesso de peso corporal, devido a sua complexa etiologia que envolve diversos fatores, tais como: fatores genéticos, ambientais, fisiológicos, culturais, políticos, socioeconômicos e até mesmo as forças de mercado (MITCHELL e SHAW, 2015; RALSTON et al., 2018).

Destaca-se que os custos diretos e indiretos do manejo da obesidade representam $21 \%$ do total dos gastos médicos, principalmente devido a associação de comorbidades (CAWLEYA e MEYERHOEFERD, 2012; SEVERIN et al., 2019), gerando assim, custos consideráveis para o indivíduo e para a comunidade (HAFEKOST et al., 2013).

O excesso de peso eleva o risco para o desenvolvimento de comorbidades, tais como: asma, desordens musculoesqueléticas e do sono, diabetes mellitus do tipo 2, disfunções hepáticas e renais, doenças cardiovasculares, infertilidade e até mesmo câncer (câncer de mama, de endométrio, de vesícula biliar, de ovário, próstata, rim, fígado e colón) (MANNA e JAIN, 2015; ROGERO e CALDER, 2018; WHO, 2018). Por isso, por volta de 2,8 milhões de pessoas morrem a cada ano, decorrente das consequências do sobrepeso e da obesidade. Essas mortes 
poderiam ser evitadas por intermédio de medidas preventivas ao excesso de peso corporal (WHO, 2018).

Ressalta-se que, na maioria dos países, o sexo feminino é o público mais acometido pelo sobrepeso e a obesidade (NG et al., 2014).

No Brasil, o Estudo Longitudinal de Saúde do Adulto (ELSA-Brasil), um estudo de coorte com 15.105 servidores públicos de 35 a 74 anos de idade, descreveu que os homens brasileiros foram os mais acometidos pelo sobrepeso do que as mulheres. No entanto, a obesidade foi mais frequente no sexo feminino (PINTO et al., 2018). Esse fato, em especial, tem potencial de ocasionar impactos na saúde das gerações futuras (MITCHELL e SHAW, 2015), pois as mulheres obesas estão cada vez mais expostas a um risco elevado de complicações metabólicas e desfechos gestacionais adversos, tanto para mulher quanto para a criança (STEWART et al., 2007; RAMSAY et al., 2012; CATALANO E SHANKAR, 2017).

O excesso de peso gestacional, além de estar correlacionado a diabetes gestacional e pré-eclâmpsia, pode acarretar transtornos tais como: elevação na pressão arterial, macrossomia fetal, aumento de parto por via cesárea, aumento da morbidade perinatal e elevação nas taxas de natimortalidade e mortalidade infantil (DONG et al., 2013; MISSION et al., 2015; MITCHELL e SHAW, 2015; CNATTINGIUS e VILLAMOR, 2016).

O estado nutricional materno desempenha um papel importante na saúde da criança, inclusive na predisposição para distúrbios metabólicos. Geralmente, as mulheres com excesso de peso apresentam maior probabilidade de terem filhos que desenvolvam a obesidade (WHITAKER, 2004; DONG et al., 2013). Pois o acúmulo dos metabólitos de lipídios, resultante da obesidade materna, é capaz de ativar na criança uma série de cascatas de sinalização envolvidas com o estresse metabólico, o que ocasiona complicações que surgirão mais tarde na vida adulta (DONG et al., 2013). 
Destaca-se que o período da gestação e do puerpério representa um oportunidade para intervenção, identificação da obesidade e redução de suas possíveis consequências adversas, dado que, a própria gestação pode atuar como desencadeante da obesidade, ou como agravante. Por isso, a prática ideal seria iniciar as atividades profiláticas ao excesso de peso desde o período anterior a concepção, com incentivo a perda de peso antes da gravidez e ao controle do ganho de peso gestacional (MATTAR et al., 2009; LEE et al., 2015; MISSION et al., 2015; CNATTINGIUS e VILLAMOR, 2016). Além do mais, o período que precede a amamentação, também é o momento de ser encarado como uma fase de oportunidade para implementação de mudanças no estilo de vida e na dieta. Essas, beneficiam a curto e a longo prazo as mulheres com sobrepeso e obesidade, assim como seus filhos (MITCHELL e SHAW, 2015).

Enfatiza-se que a promoção ao incentivo a um estilo de vida saudável e ao controle do peso corporal, deveria ocorrer desde dos estágios iniciais da vida (BRAY et al., 2017). Pois a nutrição nesses estágios iniciais é fundamental para o desenvolvimento da programação nutricional e metabólica do indivíduo. Nesse sentido, o leite humano é o alimento mais recomendado para o recém-nascido (DIETERICH et al., 2013; BADILLO-SUÁREZ et al., 2017).

O leite materno proporciona inúmeros benefícios, inclusive proteção ao desenvolvimento de alterações metabólicas, como obesidade e diabetes (BINNS et al., 2016; BADILLO-SUÁREZ et al., 2017). Dessa maneira, a amamentação representa um importante caminho com capacidade real de ocasionar impactos na redução do excesso de peso, com alcance no binômio mãe-filho (MAYER-DAVIS et al., 2006; DIETERICH et al., 2013; SHARMA et al., 2014; BINNS et al., 2016; BADILLO-SUÁREZ et al., 2017; HORTA et al., 2018). Entretanto, a obesidade está associada à interrupção precoce da amamentação. As mulheres com elevado índice de massa corporal, possuem maiores taxas de cessação da amamentação exclusiva (KRONBORG et al., 2013; MARSHALL et al., 2018). 
Ademais, estudos relatam que as alterações metabólicas, consequentes do excesso de peso materno, acarretam em mudanças nos constituintes do colostro e leite humano, modificando assim a oferta, via amamentação, de diferentes concentrações de hormônios reguladores do apetite e do metabolismo energético, tais como: a adiponectina e leptina. Impactando em eventuais repercussões no desenvolvimento infantil (BRONSKY et al., 2011; ANDREAS et al., 2014; FUJIMORI et al., 2017; GRIDNEVA et al., 2018; KRATZSCH et al., 2018).

A adiponectina e leptina desempenham papel na programação nutricional das crianças. Essas adipocinas, juntamente com outros hormônios do leite materno, auxiliam na regulação do balanço energético e modulam vias neuroendócrinas envolvidas na regulação do peso corporal. No entanto, os mecanismos não são totalmente esclarecidos. Sabe-se que um tempo maior de amamentação diminui o risco para o desenvolvimento da obesidade (DONERAY et al., 2009; SAVINO et al., 2009; NEWBURG et al., 2010; BRONSKY et al., 2011; MITROVA et al., 2014).

Realça-se que a obesidade é caracterizada por um aumento no percentual do tecido adiposo, que é considerado um grande órgão com propriedades plásticas e endócrinas (CINTI, 2018). Esse tecido, tem sido historicamente classificado em tecido adiposo branco anabólico e tecido adiposo marrom catabólico (LEE, MOTTILLO e GRANNEMAN, 2014). Há um grande esforço dedicado ao desenvolvimento de terapias baseadas no próprio tecido adiposo, com enfoque na plasticidade das células desse tecido, visando a conversão do tecido adiposo branco que é acumulador de gordura, em tecido adiposo marrom que dissipa energia (MONTANARI, POŠĆIĆ e COLITTI, 2017).

O tecido adiposo marrom requer uma vasculatura para fornecer oxigênio, gasto de energia para ser queimado e um meio de ativação termogênica (LEE, MOTTILLO e 
GRANNEMAN, 2014). Enquanto que as principais atividades metabólicas do tecido adiposo branco, inclui a lipogênese, lipólise e secreção de adipocinas (PROENÇA et al., 2014).

Adipocinas é a denominação geral utilizada para as citocinas ou hormônios que são secretados pelos adipócitos, sendo que as mais abundantes são: a adiponectina e a leptina (MARSEGLIA et al., 2015; PARK, 2018).

A adiponectina e leptina desenvolvem papel primordial no processo de regulação da saciedade, elas inibem a alimentação, por diferentes mecanismos, atuando em seus respectivos receptores (AdipoRs e LepRs) localizados em neurônios no hipotálamo (SUN et al., 2016). Essa é uma região do cérebro que promove a regulação do processo de homeostase energética, envolvendo a ação de diversos hormônios e a atividade de neurônios das regiões límbicas e do córtex cerebral, que atuam no controle do apetite e peso corporal (AHIMA e ANTWI, 2008; AUSTIN e MARKS, 2009; COCCURELLO e MACCARRONE et al., 2018). Além do mais, a adiponectina e leptina possuem outras ações fisiológicas, como as descritas a seguir.

A adiponectina possui propriedades anti-inflamatórias, antidiabéticas, antiaterogênicas e angiogênicas. A insuficiência dessa adipocina ocasiona a resistência da insulina e o desenvolvimento de inflamação metabólica (MOUZON e CATALO, 2013). Ademais, ela tem sido implicada na adaptação fisiológica da gravidez normal, como também nas complicações obstétricas (NIEN et al., 2007). Em grávidas, seus níveis elevados estimulam a absorção de glicose no músculo esquelético materno, reduzindo a disponibilidade de nutrientes para o feto. Por isso, os baixos níveis circulantes de adiponectina, observados em gestantes obesas, estão associados ao aumento do crescimento fetal (AYE et al., 2013).

A leptina também está envolvida em inúmeros processos fisiológicos, incluindo o processo de homeostasia, regulação de funções neuroendócrinas, angiogênese, formação óssea, reprodução, homeostase da glicose, metabolismo de ácidos graxos (MANZAR e HUSSAIN, 2011; NEWMAN e GONZALEZ-PEREZ, 2014) e hipertensão relacionada com a obesidade. 
Além do mais, a exposição para uma hiperleptinemia no início da vida pode predispor a criança a ter uma hipertensão de início precoce, uma hiperfagia e até mesmo disfunções cardíacas (TAYLOR et al., 2014). Essa adipocina também está envolvida em processos inflamatórios e respostas imunológicas (MANZAR e HUSSAIN, 2011; MIEHLE et al., 2012; NEWMAN e GONZALEZ-PEREZ, 2014).

A proporção entre os níveis destas adipocinas (leptina/adiponectina) é um indicador para o desenvolvimento de obesidade e síndrome metabólica, dado que é verificado em indivíduos com sobrepeso e obesidade uma redução nas concentrações endógenas de adiponectina e aumento nos níveis de leptina (KONSOULOVA et al., 2016; van ZYL et al., 2017). Assim, é de extrema importância a manutenção do equilíbrio entre os níveis de adiponectina e leptina, bem como o estudo de componentes bioativos com potencial de restaurar os níveis alterados dessas adipocinas. Nessa esfera, destaca-se o hormônio melatonina.

A melatonina é uma indolamina produzida principalmente pela glândula pineal, secretada seguindo variações circadianas e que desempenha um papel fundamental na regulação temporal dos ritmos biológicos (REITER, 1992; CIPOLLA-NETO et al., 2014; KATO et al., 2015; PEVET et al., 2017). Ela controla os níveis endógenos de adiponectina e leptina e possui um importante papel na patogênese da obesidade e síndrome metabólica, atuando tanto como um agente protetor, como na reversão das desordens ocasionadas pela obesidade (CORBALÁN-TUTAU et al., 2014; KATO et al., 2015; SZEWCZYK-GOLEC, WOSNIAK e REITER, 2015; CARDINALI e HARDELAND, 2017).

Evidências científicas destacam que os níveis séricos da melatonina podem estar reduzidos em indivíduos obesos e a compensação dos déficits dessa indolamina está associada a efeitos positivos na dislipidemia e na obesidade. Por isso, a melatonina representa um potencial alvo de abordagem para o controle do excesso de peso e das doenças metabólicas associadas (AGIL et al., 2011; TAN et al., 2011; SATO et al., 2013; SZEWCZYK-GOLEC, 
WOSNIAK e REITER, 2015; CHOJNACKI et al., 2016; GROSSHANS et al., 2016; LIU et al., 2017; FERNÁNDEZ VÁZQUEZ, REITER e AGIL, 2018).

As ações anti-obesogênica da melatonina e os seus efeitos na redução do peso corporal abrange muitos mecanismos e ações (CIPOLLA-NETO et al., 2014). Sabe-se que a melatonina faz a regulação da massa corporal e do balanço energético, seguindo variações circadianas, com elevação em sua concentração no período noturno (ZHANG et al., 1994; CAGNACCI et al., 2002; ALONSO-VALE et al., 2005). Os receptores MT2, os quais são sítios de ligação da melatonina estão presentes nas células do tecido adiposo (BRYNDON et al., 2001). Proporcionando assim, a capacidade da mesma de controlar os ritmos circadianos dos tecidos adiposos periféricos, resultando em mudanças no peso corporal (LIU et al., 2017). Além do mais, essa indolamina pode recrutar o tecido adiposo marrom, de modo termogênico, assim como, possui potencial de inibir a adipogênese (ALONSO-VALE et al., 2009; FERNÁNDEZ VÁZQUEZ, REITER e AGIL, 2018).

É essencial destacarmos que a melatonina está presente no colostro e leite materno, com flutuações rítmicas temporais com pico de concentração no período noturno (PONTES et al., 2006; PONTES et al., 2007; HONORIO-FRANÇA et al., 2013; KATZER et al., 2016). Por isso, a melatonina via amamentação desempenha um papel importante na sincronização do neonato com o ritmo biológico materno e eleva a capacidade de leucócitos do colostro de proteger frente a infecções (ILLNEROVÁ e BURESOVÁ, 1993; FRANÇA et al., 2010; MORCELI et al., 2013).

Enfatiza-se que ainda há lacunas no conhecimento científico que tange o impacto do excesso de peso materno nos níveis da melatonina no colostro e leite humano. Mas, sabe-se que esse hormônio diminui o risco de ocorrência de obesidade precoce (FIGUEROA e AGIL, 2011). Dessa forma, o incentivo a amamentação a livre demanda pode contribuir para a redução no nível de obesidade das futuras gerações. Assim, a promoção ao aleitamento materno, pode 
representar um novo caminho de intervenção, visando a criação de contemporâneas abordagens que utilizem esse consagrado alimento, de modo a intensificar os benefícios para a saúde da mãe e da criança. Inclusive, no combate a infecções infantis (FRANÇA et al., 2011a, 2011b; MORCELI et al., 2013; FAGUNDES et al.; 2018) e frente a epidemia da obesidade (MAYERDAVIS et al., 2006; DIETERICH et al., 2013; HORTA et al., 2018).

Dentro do contexto abordado, é imprescindível dar ênfase ao fato de que a melatonina, assim como a adiponectina e leptina, possuem capacidade de modular as respostas imunológicas, destacando assim a interação entre as vias do metabolismo e do sistema imunológico (OHASHI, 2010; CERMAKIAN, WESTFALL e KIESSLING, 2014; LUO e LIU, 2016; FRANCISCO et al. 2018).

A adiponectina, leptina e melatonina, além de ativarem leucócitos, desencadeiam o início de uma importante função da resposta imunológica, que é a progressão do processo inflamatório, que tem como função primária a destruição dos micro-organismos invasores. Mecanismo esse, que pode sofrer alterações decorrentes da obesidade e síndrome metabólica (SANCHEZ-POZO et al., 2003; SHIRSHEV e ORLOVA, 2005; MORCELI et al., 2013; CERMAKIAN, WESTFALL e KIESSLING, 2014; OHASHI, 2010; LUO e LIU, 2016; FRANCISCO et al. 2018; ROGERO e CALDER, 2018).

Na presença de micro-organismos invasores, os leucócitos do colostro são fundamentais para a proteção do lactente. Essas células estão presentes no colostro e leite humano em quantidades variáveis, dependendo do estágio de lactação, entre elas, destacam-se os macrófagos e os linfócitos (FIELD, 2005; CHIRICO e GASPARONI, 2006; ISLAM et al., 2006).

Os macrófagos e linfócitos são células mononucleares, que dão respostas seletivas ao sistema imunológico e representam, nos humanos, as principais células desse sistema (POURAHMAD e SALIMI, 2015). 
Os macrófagos estão presentes em todos os tecidos dos vertebrados e desempenham papéis-chave no reconhecimento e eliminação bacteriana, bem como na polarização da resposta imunológica inata e adaptativa. Dado que, essas células fagocitam bactérias e secretam mediadores pró-inflamatórios e antimicrobianos (HIRAYAMA et al., 2017).

No colostro, a presença de microrganismos estimula os macrófagos, via receptores FcaR (FRANÇA et al., 2011b), que englobam a partícula invasora e durante o processo de fagocitose, há o desenvolvimento da atividade microbicida, estresse oxidativo e consequente aumento da liberação de espécies reativas de oxigênio (EROS) (FRANÇA-BOTELHO et al., 2006; FRANÇA et al., 2011a; MORCELI et al., 2013; FAGUNDES et al. 2018).

As EROS são moléculas que podem ou não conter elétrons não pareados, tais como: ânion superóxido $\left({ }^{\circ} \mathrm{O}_{2}\right)$, peróxido de hidrogênio $\left(\mathrm{H}_{2} \mathrm{O}_{2}\right)$ e radical hidroxila $\left({ }^{\circ} \mathrm{OH}\right)$ (DJORDJEVIC, 2004; McMURRAY et al., 2016). A liberação de EROS é um dos últimos eventos no decorrer da resposta imunológica inata e tem função essencial para o processo de morte do microrganismo invasor (DJORDJEVIC, 2004). A ativação da atividade microbicida, via EROS, é um provável mecanismo de proteção adicional para os lactentes, frente a eventuais infecções no decorrer dessa fase da vida, que pode persistir até o sistema imunológico do bebê estiver desenvolvido (FRANÇA et al., 2011a; MORCELI et al., 2013; FAGUNDES et al.; 2018).

Em relação aos linfócitos, esses são células do sistema imunológico, de aparência uniforme e com funções variadas, tais como: produção de anticorpos, morte direta mediada por células infectadas por vírus e células tumorais e regulação da resposta imunológica. Os linfócitos incluem as células: linfócitos B, linfócitos T e células "natural killer" (LAROSA e ORANGE, 2008).

No colostro a maioria dos linfócitos são as células T, mas os linfócitos B e as células natural killer também são encontrados. Essas células, no colostro, apresentam uma ampla 
função, atuam através de uma fina rede de interação e influenciam a resposta imunológica inata e a adaptativa, principalmente pela produção de citocinas e secreção de imunoglobulinas (FIELD, 2005; CIARDELLI et al., 2008; FRANÇA et al., 2010; TREND et al., 2015; ISLAM et al., 2006). Assim, o leite humano além de promover no lactente a imunidade passiva, ele também modula diretamente o desenvolvimento do sistema imunológico da criança (GAROFALO e GODMAN, 1999).

Apesar de haver estudos na literatura científica que descrevem os constituintes do colostro humano, o impacto proveniente de alterações metabólicas do excesso de peso materno ainda é um caminho pouco explorado, principalmente no que tange a atividade funcional das células deste primordial alimento.

Mas, sabe-se que o sobrepeso e a obesidade materna acarreta em mudanças nos constituintes bioquímicos e imunológicos do colostro, alterando as concentrações de glicose, conteúdo de calorias, gorduras e de Imunoglobulina A secretória (FUJIMORI et al., 2015). Além de modificar as concentrações de hormônios imunomoduladores como a adiponectina e leptina (ANDREAS et al., 2016; FUJIMORI et al. 2017; FIELDS et al., 2017).

Nessa conjuntura, hipotetizou-se que as alterações hormonais do colostro decorrentes do excesso de peso materno pré-gestacional, refletem na atividade funcional das células mononucleares do colostro, comprometendo a proteção do lactente. 
Figura 1 - Hipótese do estudo

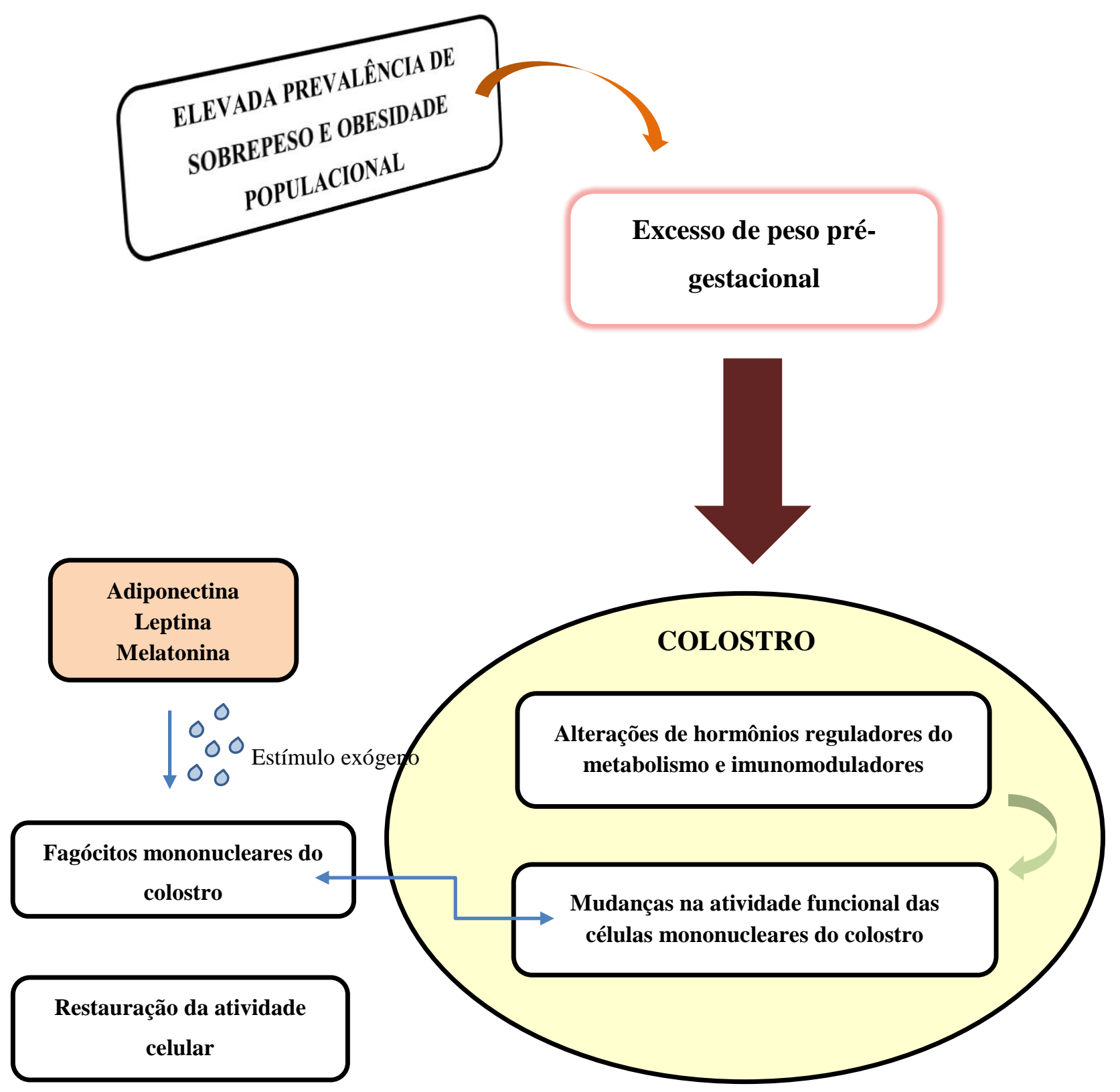

Dentro do exposto, observa-se o enredamento envolvido na temática. Assim, enfatizase que a obesidade não é simplesmente sobre peso corporal ou imagem corporal. Trata-se de um assunto altamente complexo e de múltiplos determinantes. Por isso, são necessários o desenvolvimento de novas narrativas que possam colaborar para uma construção de uma resposta mais abrangente a obesidade (RASTON et al., 2018). 
O colostro e leite humano representam esse novo caminho. Pois as avaliações das repercussões dos hormônios reguladores do metabolismo energético, sob atividade das células mononucleares do colostro, são peças essenciais para o embasamento de eventuais estratégicas que protejam a saúde materno-infantil. Por isso, o objetivo desse estudo foi avaliar a ação da adiponectina, leptina e melatonina sob as células mononucleares do colostro humano, em função do excesso de peso da mulher, no período pré-concepção.

Espera-se que os resultados desse estudo possam colaborar com futuras pesquisas no campo de ciências de implementação, principalmente com pesquisas que utilizem o próprio colostro ou leite humano, via amamentação em horários estratégicos, como ferramenta para a redução da incidência e prevalência da obesidade. Sendo assim, um econômico e sustentável caminho para ações benéfica frente ao impacto do sobrepeso e obesidade. 


\section{OBJETIVO}

\subsection{OBJETIVO GERAL:}

Avaliar a ação da adiponectina, leptina e melatonina na atividade funcional dos fagócitos mononucleares do colostro, segundo o índice de massa corporal (IMC) prégestacional.

\subsection{OBJETIVO ESPECÍFICO:}

$\checkmark$ Descrever os níveis de melatonina no colostro humano segundo o IMC materno prégestacional;

$\checkmark$ Analisar nos fagócitos mononucleares do colostro de mulheres com sobrepeso e obesidade, a fagocitose e o burst oxidativo com estímulo da adiponectina, da leptina e da melatonina;

$\checkmark$ Analisar os mecanismos intracelulares de modulação dos fagócitos mononucleares do colostro na presença da adiponectina, leptina e melatonina, através da liberação do cálcio intracelular e indução de apoptose. 


\section{MÉTODO}

\subsection{DESENHO DO ESTUDO}

Figura 2 - Esquematização das etapas desenvolvidas pela pesquisa.

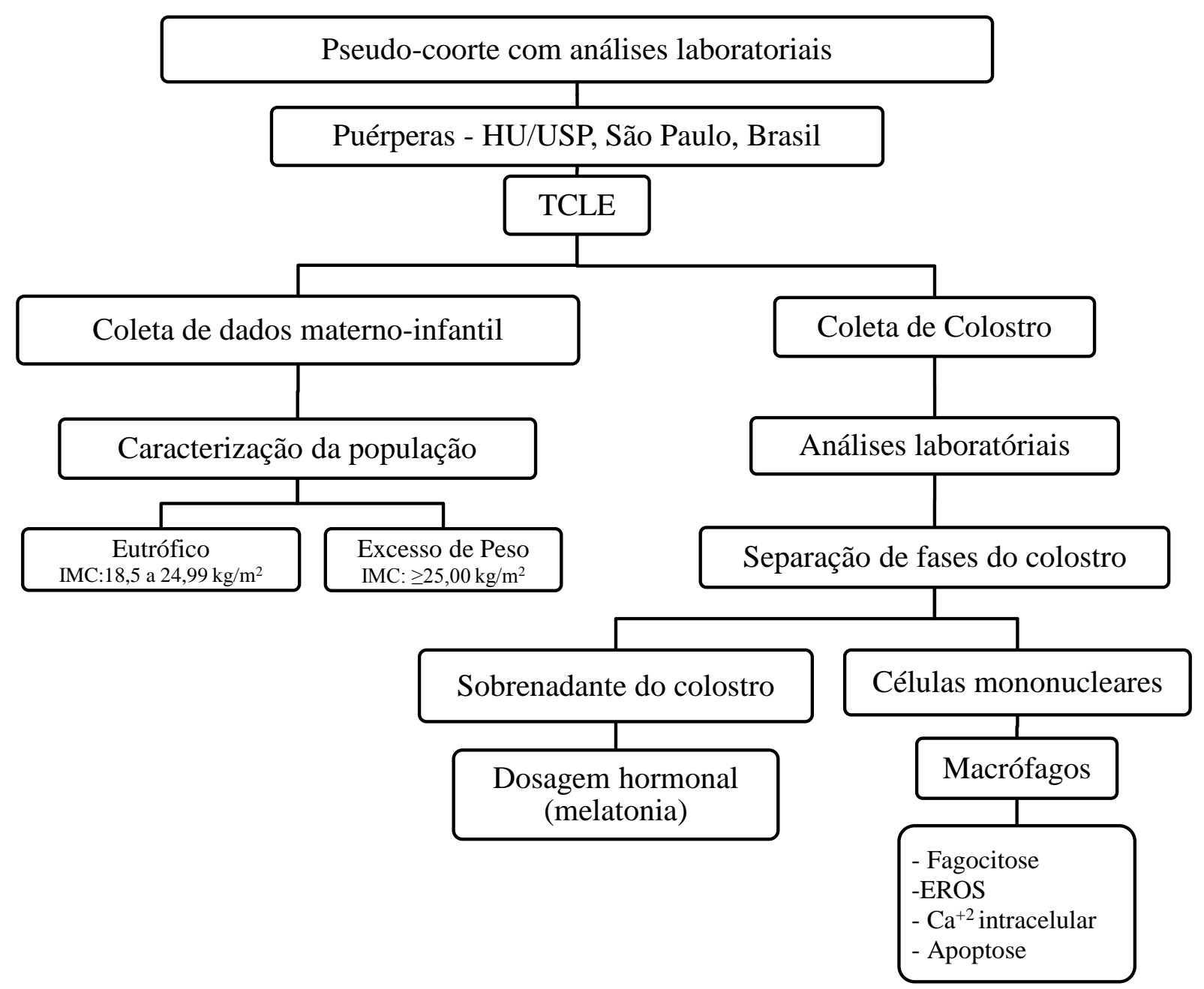


Foi realizado um estudo do tipo pseudo-coorte, seguido de análises laboratoriais considerando-se o estado nutricional materno pré-gestacional (eutrófico e excesso de peso).

As mulheres participantes tiveram parto no Hospital Universitário (HU) da Universidade de São Paulo, São Paulo - SP, no período de 2016 a 2017. As mulheres foram informadas sobre os objetivos da pesquisa e consultadas sobre a disponibilidade em responder a um questionário (anexo 1) e em doar uma amostra de colostro. A coleta foi realizada por ordenha manual, nos intervalos entre duas mamadas, no período diurno, correspondente as primeiras 48 a 72 horas após o parto.

Para as análises das amostras, o projeto contou com estrutura e equipamentos disponíveis no Laboratório de Imunologia da Relação Materno-Infantil e o de Cronoimunomodução, da Universidade Federal do Mato-Grosso-UFMT, localizados no Campus Universitário do Araguaia.

\subsection{SUJEITOS E TAMANHO AMOSTRAL}

As amostras de colostro foram obtidas de nutrizes que realizaram seus partos no Hospital Universitário (HU) da Universidade de São Paulo, São Paulo, SP, no período de 2016 e 2017. Os colostros coletados foram classificados de acordo com o IMC materno prégestacional e divididos em dois grupos: grupo eutrófico (IMC entre 18,5 a 24,9 kg/m²) e grupo excesso de peso $\left(\mathrm{IMC} \geq 25,0 \mathrm{~kg} / \mathrm{m}^{2}\right)$.

O tamanho amostral proposto nesse estudo foi baseado em amostra de conveniência. O estudo foi constituído por 109 puérperas, distribuídas em: 48 mulheres no grupo eutrófico e 61 no grupo excesso de peso. O Poder do teste foi calculado de acordo com os critérios citados por 
Armitage e Berry (1987). O poder do Teste utilizado neste estudo foi de $80 \%$, considerando o nível de significância de 5\%, o número amostral usado em cada experimento e as diferenças encontradas entre os grupos.

\subsection{CRITÉRIOS DE INCLUSÃO, EXCLUSÃO E DESCONTINUIDADE}

Foram elegíveis como possíveis doadoras as nutrizes caracterizadas nos grupos experimentais: puerpéras com peso pré-gestacional normal (grupo eutrófico) e com sobrepeso ou obesidade pré-gestacional (grupo excesso de peso), sendo estabelecidos os seguintes critérios de inclusão: idade de 18 a 35 anos; peso pré-gestacional conhecido ou medido até o final da $13^{\mathrm{a}}$ semana gestacional; idade gestacional no parto entre 37 a $41^{6 / 7}$ semanas; reações sorológicas negativas para hepatite, HIV e sífilis; ter realizado assistência pré-natal; não ter restrição alimentar; assinatura do Termo de Consentimento Livre e Esclarecido.

Critérios de exclusão: diabetes gestacional, doença hipertensiva da gravidez, gravidez gemelar, malformações fetais e parto antes da $36^{\mathrm{a}}$ semana de gestação.

Critérios de descontinuidade: desistência da mãe após aceite, escassez de colostro, mastite ou rachaduras no seio. 


\subsection{DEFINIÇÃO DAS VARIÁVEIS:}

As seguintes variáveis foram investigadas: presença (sim) ou ausência (não) de tabagismo, diabetes mellitus (prévia ou gestacional), anemia, consumo de álcool, hipertensão arterial; idade gestacional, em semanas completas; IMC pré-gestacional (peso normal e excesso de peso) e IMC na última consulta de pré-natal; ganho de peso total durante a gestação, categorizado em insuficiente, adequado e excessivo.

Foram variáveis independentes do estudo: Grupos experimentais: eutrófico (controle) e excesso de peso classificado de acordo com o IMC pré-gestacional. As variáveis dependentes do estudo foram: determinação da atividade funcional dos fagócitos mononucleares do colostro.

\subsection{MÉTODOS DE COLETA E AVALIAÇÃO}

\subsubsection{Estado Nutricional Pré-Gestacional}

Para determinar o estado nutricional pré-gestacional, foi utilizado o índice de massa corporal pré-gestacional. A definição do IMC pré-gestacional foi obtida por meio da fórmula: índice de massa corpórea $=$ peso pré-gestacional $(\mathrm{kg}) /$ altura $\left(\mathrm{m}^{2}\right)$. Foi utilizado o peso prégestacional referido pela gestante durante a primeira consulta de pré-natal, ou, na ausência dessa informação, foi utilizado o peso obtido em alguma consulta realizada até a $13^{a}$ semana de gestação. Segundo a Organização Mundial da Saúde, o peso aferido nesse período tem sido 
utilizado como proxy do peso pré-gestacional, possibilitando uma estimação do estado nutricional pré-gestacional.

A classificação do IMC foi definida de acordo com o "Institute of Medicine dos Estados Unidos" (IOM, 2009), utilizando como referência as seguintes categorias: baixo peso (IMC $<18,5 \mathrm{~kg} / \mathrm{m} 2$ ); eutrófica (IMC entre 18,5 a 24,9 kg/m²); sobrepeso (IMC entre 25,00 a $29,99 \mathrm{~kg} / \mathrm{m}^{2}$ ) e obesidade (IMC $\geq 30 \mathrm{~kg} / \mathrm{m}^{2}$ ). Para os experimentos foram utilizadas a classificação de eutrófica (IMC entre 18,5 a $24,9 \mathrm{~kg} / \mathrm{m}^{2}$ ) e excesso de peso (IMC $\geq 25,0 \mathrm{~kg} / \mathrm{m}^{2}$ ).

O peso no momento da coleta e a altura foram mensurados em duplicata de acordo com protocolo padronizado (FRISANCHO, 1990). A altura adotada foi a referida na primeira consulta de pré-natal, confirmada pela que altura aferida com estadiômetro da marca Seca ${ }^{\circledR}$ com precisão de $1 \mathrm{~mm}$ e capacidade de $205 \mathrm{~cm}$.

\subsubsection{Idade Gestacional}

A idade gestacional foi calculada utilizando, primeiramente, o resultado da ultrasonografia com data inferior a 20 semanas. Para gestantes que tiverem ultrassonografia maior que 20 semanas, a idade gestacional foi calculada fazendo-se a média entre a idade informada pela ultra-sonografia e aquela calculada pela data da última menstruação. Para as gestantes que não possuírem ultra-sonografia, a idade gestacional foi calculada somente a partir da data da última menstruação. 


\subsubsection{Procedimento para Obtenção de Células Mononucleares do Colostro}

Foram coletados aproximadamente $5 \mathrm{~mL}$ de colostros, no período diurno, até 72 horas após o parto. As amostras foram centrifugadas por $10 \min \left(160 \mathrm{~g}, 4^{\circ} \mathrm{C}\right)$ para separação de fases: pellet celular, sobrenadante e gordura. A população celular foi separada por gradiente de concentração, Ficoll-Paque (Pharmacia, Uppsala, Sweden). As células mononucleares foram ressuspendidas em meio 199 (Gibco, Grand Island, USA), ajustadas para concentração de $1 \times 10^{6}$ células por $\mathrm{mL}$ e o sobrenadante foi armazenado para posterior dosagem hormonal (FRANÇA et al., 2011a; MORCELI et al., 2013; FAGUNDES et al., 2018).

Figura 3 - Separação de fases e de população celular do colostro humano.

(A)

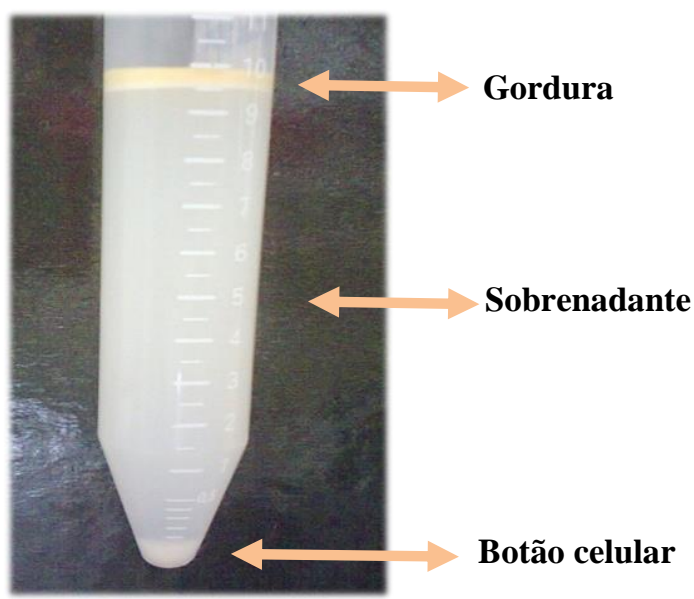

(B)

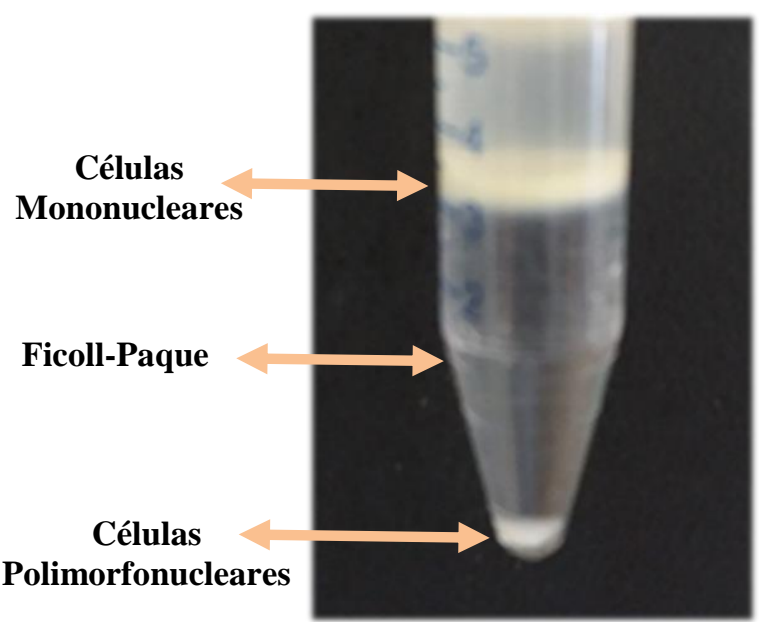

(A)Colostro humano após a centrifugação para separação de fases. (B) Botão celular diluído em tampão, após a centrifugação com Ficool-Paque para obtenção das células mononucleares. 


\subsubsection{Dosagem da Melatonina}

A melatonina foi quantificada no sobrenadante do colostro humano, por meio do kit de ELISA da Immuno-Biological Laboratories (IBL, Hamburg). A melatonina do sobrenadante foi extraída por cromatografia de afinidade e concentrada por "speed-vacuum", seguindo as orientações do fabricante. Os resultados foram descritos em $\mathrm{pg} / \mathrm{mL}$ de acordo com descrito por Pontes e colaboradores (2006) e Honório-França e colaboradores (2013).

\subsubsection{Estímulos Utilizados}

Para as análises as células mononucleares foram tratadas na presença e na ausência dos hormônios: adiponectina humana (Sigma, ST Loius, USA), leptina humana (Thermo Fisher, Carlsbad, USA) e melatonina (Sigma, ST Loius, USA) na concentração de 100ng/mL. Constituindo os seguintes grupos de tratamento: células tratadas com meio 199 (controle negativo), adiponectina, leptina, melatonina, adiponectina+leptina e leptina+metatonina.

\subsubsection{Ensaio de Fagocitose}

As células mononucleares foram incubadas (por $2 \mathrm{~h}$, a $37^{\circ} \mathrm{C}$ e sob agitação contínua) com Zymosan pHrodo Green ${ }^{\circledR}$ (Thermo Fisher, Carlsbad, USA), na presença e ausência dos estímulos, de acordo com as instruções do fabricante. O pHrodo Green ${ }^{\circledR}$ emitem fluorescência 
verde em $\mathrm{pH}$ ácido durante o processo de fagocitose. Após o período de incubação, foram analisados 10 mil eventos por citometria de fluxo, utilizando FACSCalibur ${ }^{\circledR}$ (BD Biosciences, San Jose, USA).

3.5.7 Análises de Espécies Reativas de Oxigênio

A dihidrorhodamina 123 (DHR 123) é um composto que emite fluorescência no interior celular após ser oxidado pelas espécies reativas de oxigênio. A intensidade de fluorescência emitida é proporcional a produção das espécies reativas de oxigênio. Sendo esse método mais sensível para detecção de $\mathrm{OH}$. e $\mathrm{H}_{2} \mathrm{O}_{2}$. Por isto, os fagócitos foram incubados com DHR123 $(5 \mu / \mathrm{mL})$ (Sigma, ST Loius, USA), na presença e ausência dos estímulos e de $0,5 \mathrm{mg} / \mathrm{mL}$ Zymosan A (Sigma, ST Loius, USA), seguindo protocolo padronizado para o tipo de experimento (LIEBERMAN et al. 1996; RICHARDSON et al. 1998; RADOGNA et al., 2009a). A intensidade de fluorescência foi medida em no leitor de placa Fluoroskan Ascent $\mathrm{FL}^{\circledR}$, com os filtros de $485 \mathrm{~nm}$ excitação e $538 \mathrm{~nm}$ de emissão. Os resultados foram expressos em intensidade de fluorescência de DHR 123.

3.5.8 Dosagem de cálcio intracelular

As células foram incubadas na ausência ou presença de Zymosan A (Sigma, ST Loius, USA) e dos estímulos. Sendo adicionado $5 \mu \mathrm{L}$ de solução de Fluo-3 AM (Sigma, ST Loius, USA) e incubado por 2 horas a $37^{\circ} \mathrm{C}$ (BURCHIEL et al., 2000; FAGUNDES et al. 2018). As 
células foram lavadas e ressuspendias em HBSS (Hank's Balanced Salt Solution) contendo BSA. A intensidade de fluorescência foi medida pelo leitor de placa Fluoroskan Ascent FL ${ }^{\circledR}$, com os filtros de $485 \mathrm{~nm}$ excitação e 538nm de emissão. Os resultados foram expressos em intensidade de fluorescência do Fluo 3 AM.

\subsubsection{Ensaio de Apoptose}

As células mononucleares (na concentração de $1 \times 10^{6}$ células $/ \mathrm{mL}$ ) foram previamente incubados por 2 horas, na presença ou ausência de $0.5 \mathrm{mg} / \mathrm{mL}$ Zymosan A from Saccharomyces cerevisiae (Sigma, ST Loius, USA) e dos estímulos. A apoptose, foi analisada utilizando FITC Annexin V (BD Biosciences, Erembodegem, Belgium). A intensidade de fluorescência foi medida pelo leitor de placa Fluoroskan Ascent $\mathrm{FL}^{\circledR}$, usando os filtros de $485 \mathrm{~nm}$ excitação e 538nm de emissão. Os resultados foram expressos em intensidade de fluorescência do FITCAnnexin V.

\subsection{ASPECTOS ÉTICOS}

As considerações éticas foram baseadas no uso do material biológico para fins científicos, com sigilo da identidade da nutriz, livre de coação ou conflito de interesses da instituição ou de pessoas envolvidas na pesquisa. As coletas respeitaram os protocolos técnicos do serviço envolvido. As nutrizes foram previamente informadas e o material somente foi coletado, ou utilizado, sob o consentimento em formulário específico (Termo de Consentimento Livre e Esclarecido - TCLE) (Anexo 2), conforme resolução 466/2012 do Conselho Nacional 
de Saúde. Esse trabalho foi aprovado pelo Comitê de Ética em Pesquisa da Faculdade de Saúde Pública, juntamente com o do Hospital Universitário da USP (CAAE 46643515.0.3001.0076) (Anexo 3).

\subsection{ANÁLISE ESTATÍSTICA}

A análise estatística foi executada respeitando os pressupostos determinados pelos resultados, características e comportamento das variáveis de estudo, dependendo da distribuição normal ou não normal dos dados. Os resultados foram apresentados como média ( \pm desvio padrão) ou mediana. Foram utilizados o teste de normalidade Shapiro-Wilk ou D’Agostino e para a comparação entre os grupos foi utilizado o Teste de Mann-Whitney ou a análise de Variância (ANOVA) seguido pelo teste de Tukey. Foram consideradas diferenças significativas quando $\mathrm{p}<0,05$. 


\section{RESULTADOS}

\subsection{CARACTERIZAÇÃO DA POPULAÇÃO ESTUDADA}

Houve diferença estatística $(\mathrm{p}<0,05)$ entre o IMC pré-gestacional e o IMC ao final da gestação entre os grupos eutróficos e excesso de peso, essas e outras caraterísticas maternoinfantil foram descritas na Tabela 01.

Tabela 01- Caracterização da população estudada.

\begin{tabular}{|c|c|c|}
\hline Variáveis & $\begin{array}{c}\text { Eutrófico } \\
\mathrm{n}=\mathbf{4 8}(\mathbf{1 0 0 , 0 0 \% )})\end{array}$ & $\begin{array}{l}\text { Excesso de Peso } \\
n=61(100,00 \%)\end{array}$ \\
\hline Idade (anos) (Média \pm DP) & $24,77 \pm 5,2$ & $26,72 \pm 5,16$ \\
\hline Número de Gestação (Média $\pm D P$ ) & $2,08 \pm 1,08$ & $2,36 \pm 1,17$ \\
\hline Número de Paridade (Média $\pm D P$ ) & $1,85 \pm 0,95$ & $2,06 \pm 1,08$ \\
\hline Número de Abortos (Média $\pm \mathrm{DP}$ ) & $0,23 \pm 0,56$ & $0,33 \pm 0,57$ \\
\hline Peso Materno Pré-Gestacional (Média $\pm D P$ ) & $54,86 \pm 6,72$ & $77,39 \pm 10,51$ \\
\hline Altura materna em metros (Média $+D P)$ & $1,58 \pm 0,06$ & $1,61 \pm 0,06$ \\
\hline Peso Gestacional Final (kg) (Média $\pm D P)$ & $66,88 \pm 7,76$ & $86,95 \pm 9,68$ \\
\hline IMC Pré-Gestacional em kg/m² (Média $\pm D P$ ) & $21,78 \pm 1,88$ & $29,64 \pm 3,46^{\#}$ \\
\hline IMC ao Final da Gestação kg/m² (Média $\pm D P)$ & $26,68 \pm 2,57$ & $33,57 \pm 3,45^{\#}$ \\
\hline Ganho de peso gestacional & $12,09 \pm 4,39$ & $9,99 \pm 4.98^{\#}$ \\
\hline \multicolumn{3}{|l|}{ Tipo de Parto } \\
\hline Normal & $32(66,67 \%)$ & $30(49,18 \%)$ \\
\hline Cesárea & $15(31,25 \%)$ & $27(44,26 \%)$ \\
\hline Fórceps & $1(2,08 \%)$ & $4(6,56 \%)$ \\
\hline Idade Gestacional em semanas (Média \pm DP) & $38,81 \pm 1,26$ & $39,08 \pm 1,23$ \\
\hline \multicolumn{3}{|l|}{ Sexo do bebê } \\
\hline Feminino & $25(52,08 \%)$ & $28(44,00 \%)$ \\
\hline Masculino & $23(47,92 \%)$ & $33(56,00 \%)$ \\
\hline Peso ao Nascer em gramas (Média $\pm D P$ ) & $3141,25 \pm 337,38$ & $3336,64 \pm 427,62$ \\
\hline Estatura em centímetros (Média $\pm D P$ ) & $48,33 \pm 1,48$ & $48,91 \pm 2,01$ \\
\hline \multicolumn{3}{|l|}{ Classificação do Recém-Nascido } \\
\hline Pequeno para Idade Gestacional & $3(6,25 \%)$ & $7(11,47 \%)$ \\
\hline Adequado para Idade Gestacional & $43(89,58 \%)$ & $52(85,25 \%)$ \\
\hline Grande para Idade Gestacional & $2(4,17 \%)$ & $2(3,28 \%)$ \\
\hline \multicolumn{3}{|l|}{ Apgar } \\
\hline 1 minuto (Mediana/ máximo-minimo) & $8(7-10)$ & $8(7-10)$ \\
\hline 5 minutos (Mediana/ máximo-minimo) & $10(8-10)$ & $10(8-10)$ \\
\hline 10 minutos (Mediana/ máximo-minimo) & $10(9-10)$ & $10(9-10)$ \\
\hline Perímetro Cefálico em cm (Média \pm DP) & $34,11 \pm 1,29$ & $33,94 \pm 3,64$ \\
\hline Perímetro Torácico em cm (MédiaさDP) & $32,80 \pm 1,39$ & $33,03 \pm 3,60$ \\
\hline Perímetro Abdominal em cm (Média \pm DP) & $31,88 \pm 2,22$ & $32,10 \pm 3,47$ \\
\hline
\end{tabular}




\subsection{DOSAGEM DA MELATONINA NO SOBRENADANTE DO COLOSTRO}

Foram descritos os níveis de melatonina do sobrenadante do colostro de mulheres eutróficas e com excesso de peso pré-gestacional (Figura 4). As concentrações médias de melatonina foram maiores $(27,14 \pm 2,26 \mathrm{pg} / \mathrm{mL})$ no grupo excesso de peso, quando comparado ao controle $(15,60 \pm 2,66 \mathrm{pg} / \mathrm{mL})(\mathrm{p}<0,05)$. Os níveis de adiponectina e de leptina do colostro não foram dosados, dado que seus valores são claramente descritos na literatura científica em função do IMC materno.

Figura 4 - Níveis de melatonina em $\mathrm{pg} / \mathrm{mL}$ no sobrenadante do colostro humano segundo o IMC pré-gestacional.

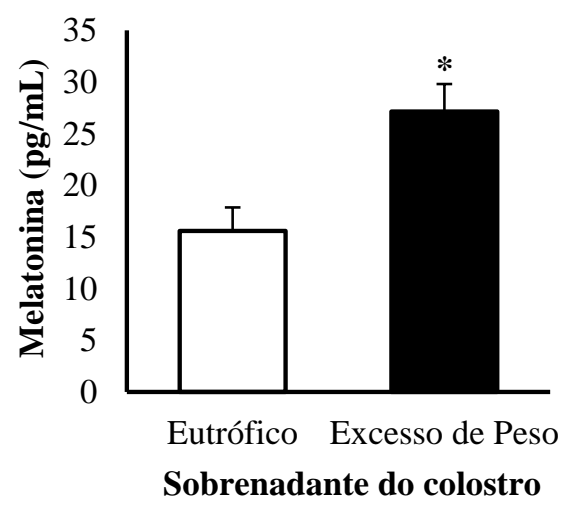

Os dados foram avaliados pelo Teste de Mann-Whitney, os resultados foram expressos em média \pm DP $(\mathrm{n}=10$ por grupo), indicado como a seguir: *Diferença estatística $(\mathrm{p}<0,05)$ em relação ao grupo controle.

\subsection{ANÁLISES DAS CÉLULAS MONONUCLEARES DO COLOSTRO}

O percentual de fagocitose das células mononucleares do colostro segundo o estado nutricional materno no período pré-gestacional é descrito na Figura 5. 
Figura 5 - Índice de fagocitose das células mononucleares do colostro humano de acordo com o IMC materno pré-gestacional.

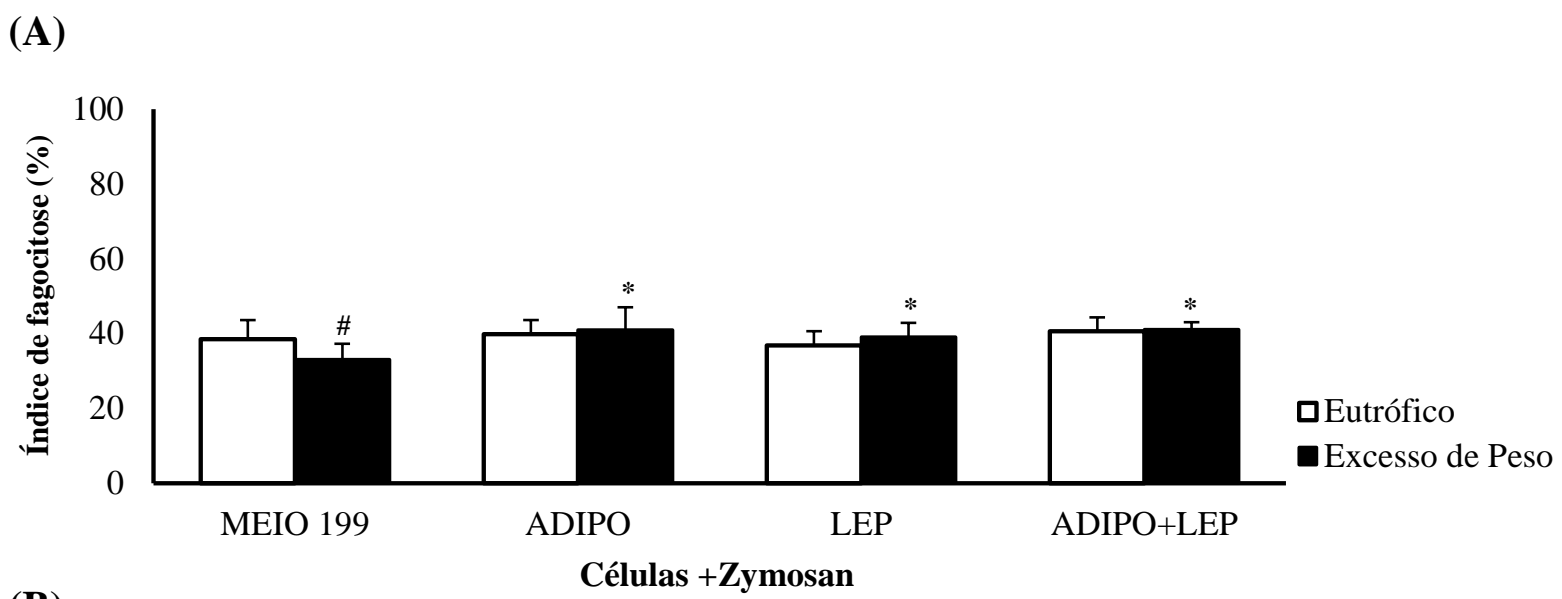

(B)

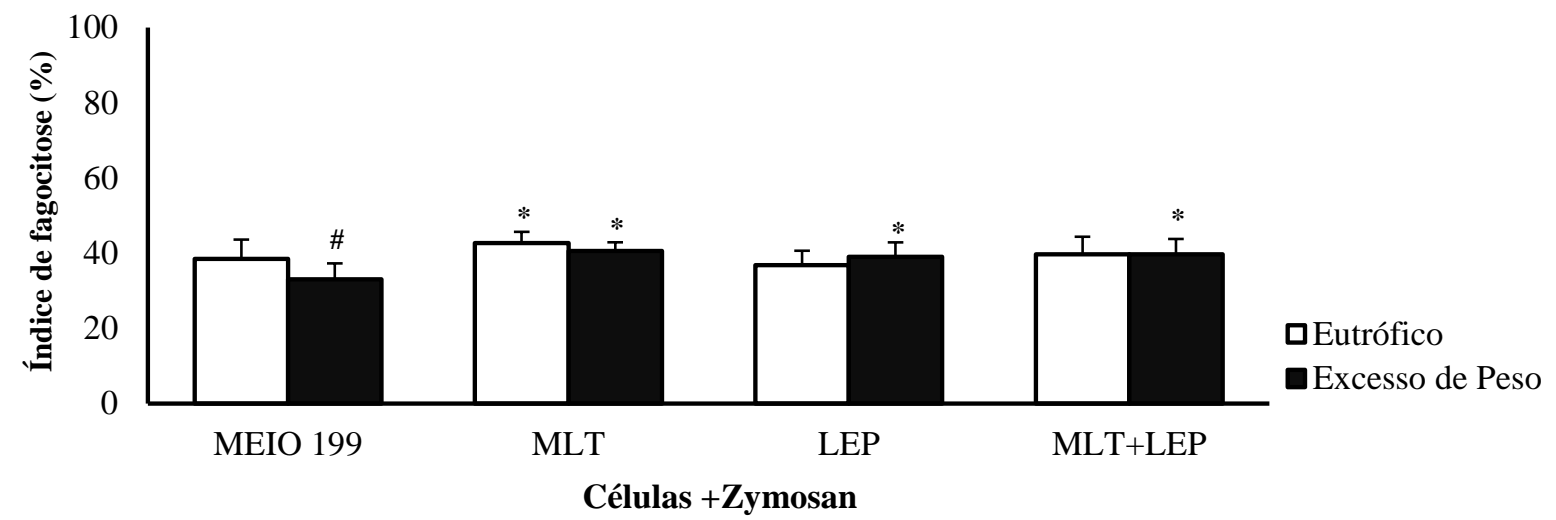

(C)

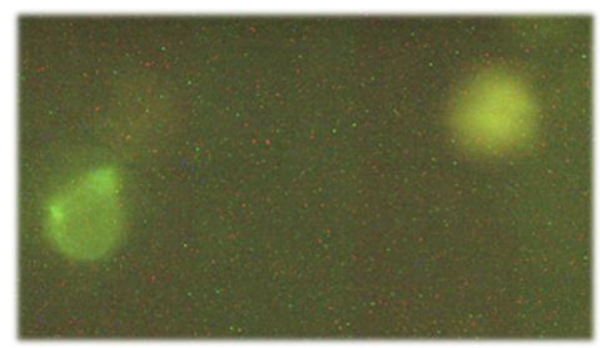

(A) Percentual de fagocitose das células MN na presença ou ausência de adiponectina e/ou leptina ou (B) tratadas na presença ou ausência de melatonina e/ou leptina. (C) Imagem de microscopia de fluorescência da fagocitose de partícula de Zymosan pHrodo ${ }^{\circledR}$ Green pelas células MN (aumento: 100x). Os resultados foram avaliados por ANOVA e teste de Tukey, os dados foram expressos em média \pm DP ( $n=10$ por tratamento), indicado como a seguir: *Diferença estatística $(\mathrm{p}<0,05)$ em relação ao mesmo grupo tratado com meio 199 (controle). "Diferença estatística $(\mathrm{p}<0.05)$ intragrupo considerando o mesmo tratamento. 
Os fagócitos MN do colostro de mulheres com excesso de peso pré-gestacional apresentaram redução no índice de fagocitose $(\mathrm{p}<0,05)$ (Figura 5). No entanto, os hormônios adiponectina e leptina restauraram o percentual de fagocitose apenas para o grupo com elevado IMC materno $(\mathrm{p}<0,05)$ (Figura 5A), enquanto que a melatonina elevou o índice de fagocitose tanto para o grupo eutrófico, quanto para o grupo excesso de peso $(\mathrm{p}<0,05)$ (Figura 5B). A associação dos hormônios adiponectina+leptina (Figura 5A) e melatonina+leptina (Figura 5B) restabeleceu o índice de fagocitose das células MN do grupo com excesso de peso, para valores similares ao do grupo eutrófico $(\mathrm{p}<0,05)$.

Durante o processo de fagocitose as células liberaram espécies reativas de oxigênio, conforme descrito na Figura 6. Nas células não tratadas, os níveis de espécies reativas de oxigênio foram menores para o grupo excesso de peso em relação ao grupo eutrófico $(p<0,05)$. Apenas a leptina aumentou as concentrações de radicais livres para o grupo excesso de peso $(\mathrm{p}<0,05)$ (Figura 6A). No entanto, a ação em conjunto das adipocinas adiponectina+leptina elevou os níveis de radicais livres para o grupo excesso de peso, restaurando os níveis de EROS a valores semelhantes ao do grupo eutrófico $(\mathrm{p}<0,05)$ (Figura 6A). Enquanto que, a leptina não elevou os níveis de EROS na presença de melatonina $(\mathrm{p}<0,05)$ (Figura 6B). 
Figura 6 - Liberação de espécie reativas de oxigênio pelos fagócitos do colostro segundo o excesso de peso materno.

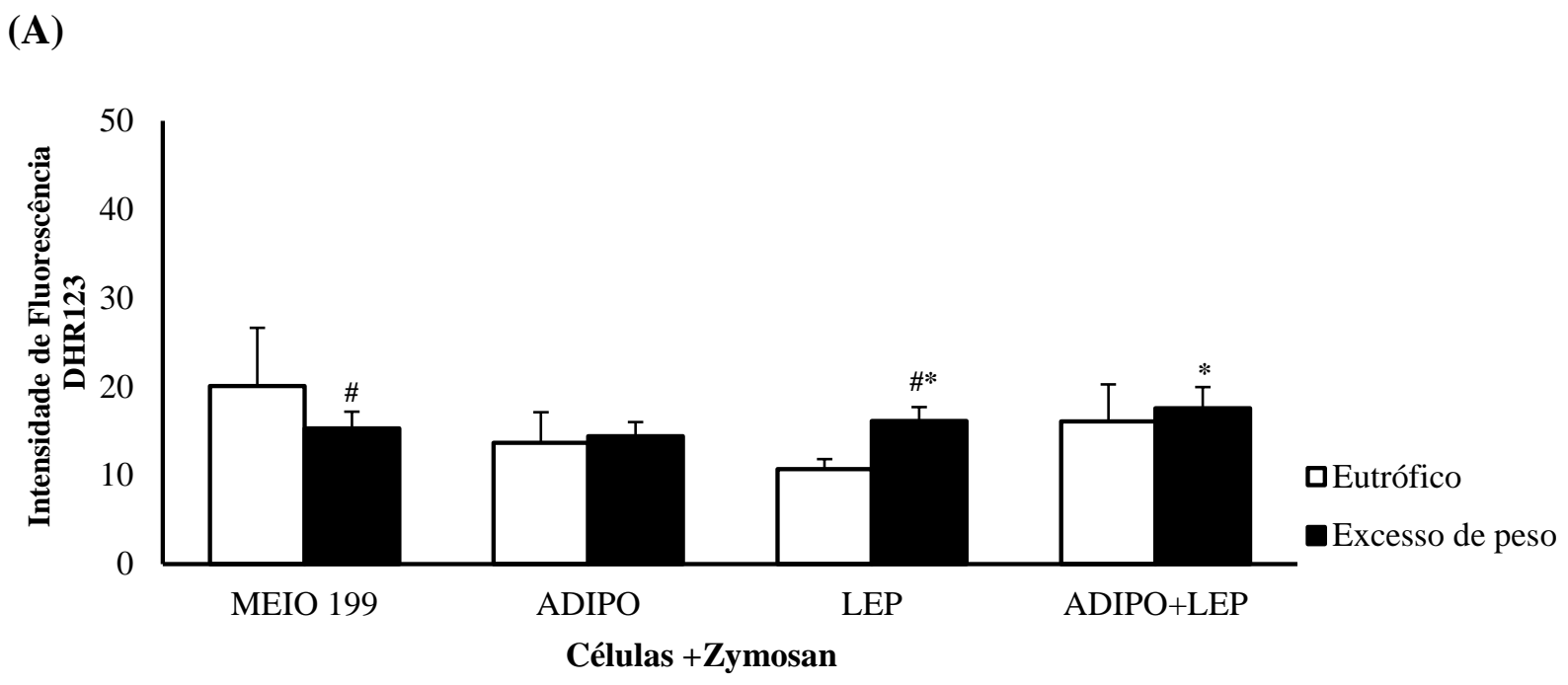

(B)

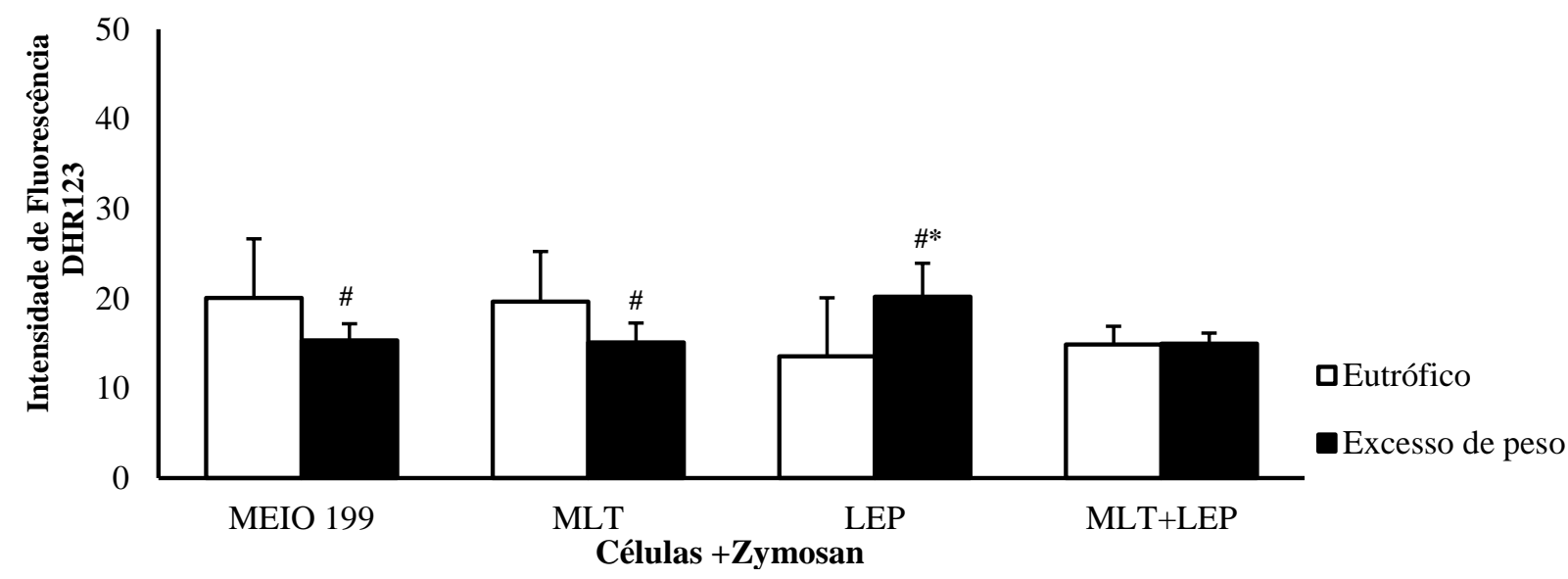

Liberação de espécies reativas de oxigênio pelos fagócitos MN na presença ou ausência de partículas de Zymosan e dos hormônios: (A) adiponectina e/ou leptina ou (B) melatonina e/ou leptina. Os resultados foram avaliados por ANOVA e teste de Tukey, os dados foram expressos em média \pm DP ( $\mathrm{n}=10$ por tratamento), indicado como a seguir: *Diferença estatística $(\mathrm{p}<0,05)$ em relação ao mesmo grupo, tratado com meio 199 (controle). ${ }^{*}$ Diferença estatística $(\mathrm{p}<0,05)$ intragrupo considerando o mesmo tratamento. 
O excesso de peso materno anterior a gestação não influenciou a liberação de cálcio intracelular pelos fagócitos MN do colostro humano ( $p>0,05$ ), como ilustrado na Figura 7. Mas, a adiponectina elevou $(\mathrm{p}<0,05)$ e a leptina reduziu os níveis de cálcio intracelular apenas para o grupo excesso de peso (Figura 7A). A melatonina, não alterou as concentrações de cálcio intracelular em nenhum dos grupos estudados ( $>00,05)$ (Figura 7B).

Figura 7 - Níveis de cálcio intracelular liberados no processo de fagocitose das células mononucleares do colostro em função o estado nutricional materno pré-gestacional.

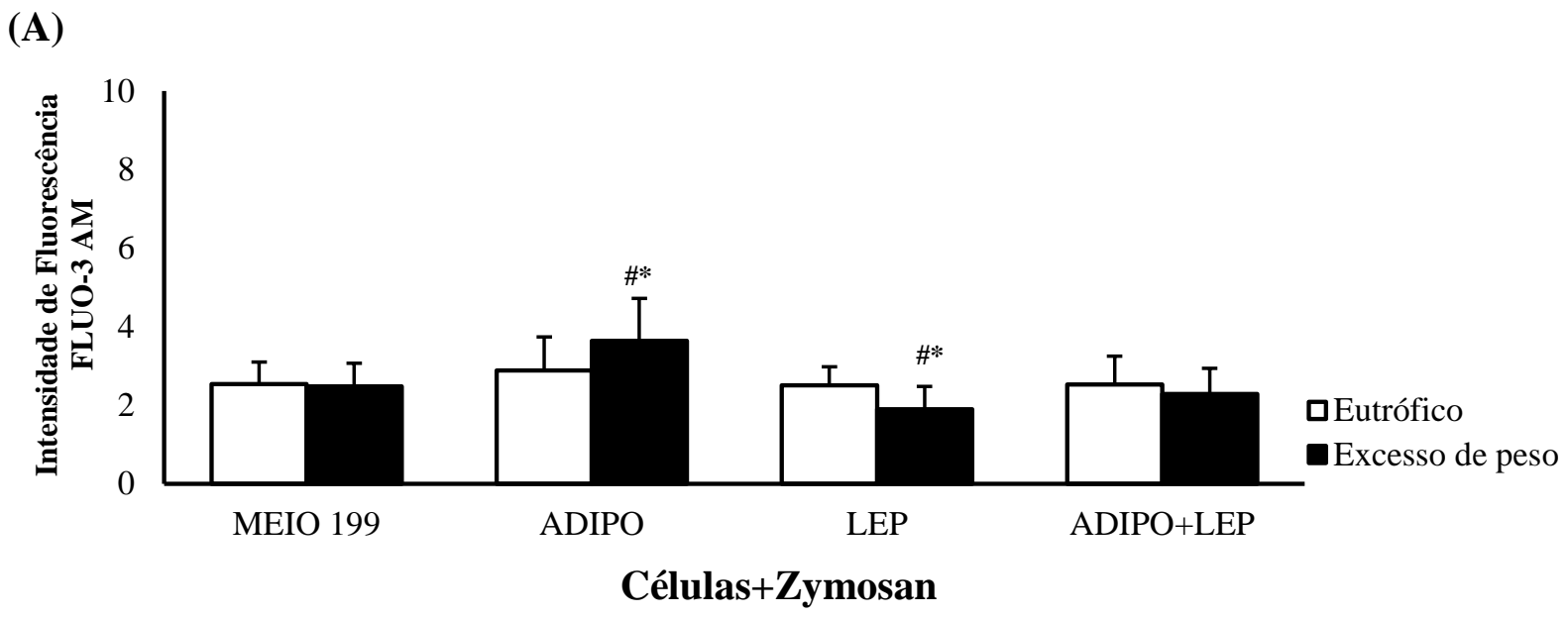

(B)

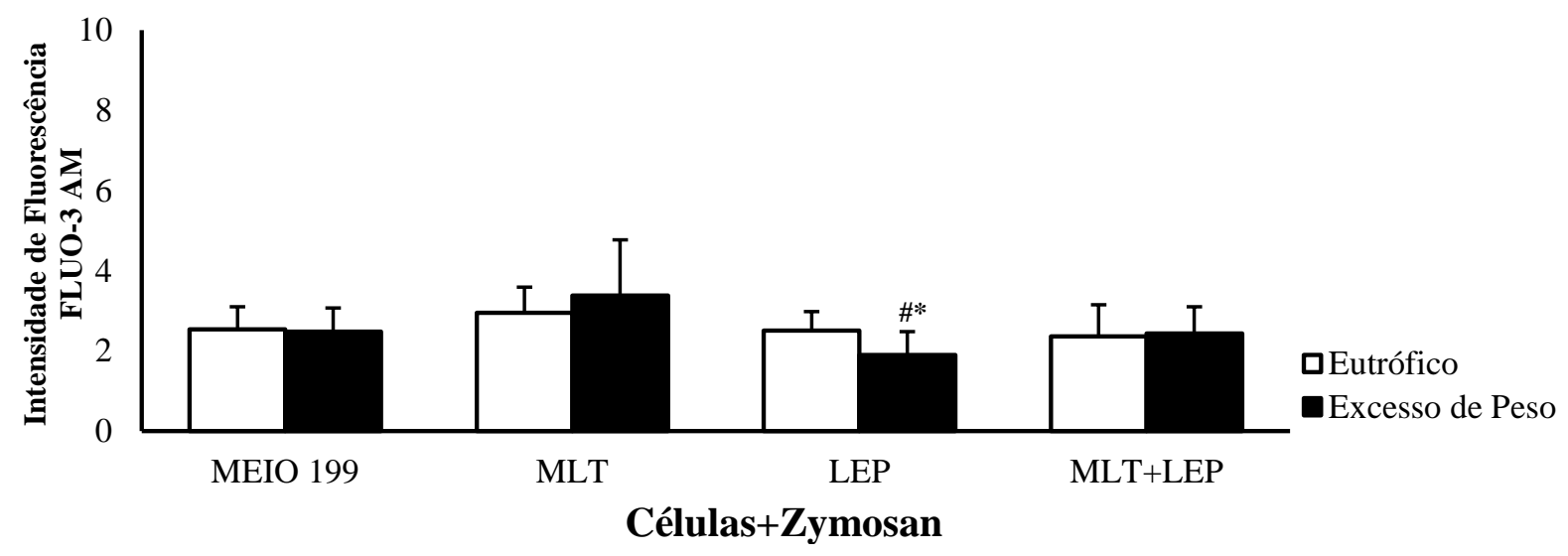

Cálcio intracelular liberados pelos fagócitos MN do colostro humano na presença ou ausência de partículas de Zymosan e dos hormônios: (A) adiponectina e/ou leptina ou (B) melatonina e/ou leptina. Os resultados foram avaliados por ANOVA e teste de Tukey, os dados foram expressos em média $\pm \mathrm{DP}(\mathrm{n}=10$ por tratamento), indicado como a seguir: "Diferença estatística $(p<0,05)$ em relação ao mesmo grupo tratado com meio 199 (controle). \#Diferença estatística $(\mathrm{p}<0,5)$ intragrupo considerando o mesmo tratamento. 
O elevado IMC materno pré-gestacional não alterou o índice de apoptose dos fagócitos mononucleares do colostro humano (Figura 8). No entanto, o efeito sinérgico da adiponectina+leptina aumentou os níveis de apoptose para o grupo com excesso de peso prégestacional $(\mathrm{p}<0,05)$ (Figura 8A). Enquanto que, a melatonina reduziu o índice de apoptose para o grupo excesso de peso em relação ao controle $(\mathrm{p}<0,05)$. A associação da melatonina+leptina, não alterou os níveis de cálcio intracelular ( $p>0,05)$ (Figura 8B).

Figura 8 - Índice de apoptose dos fagócitos MN do colostro humano em função o estado nutricional materno pré-gestacional.

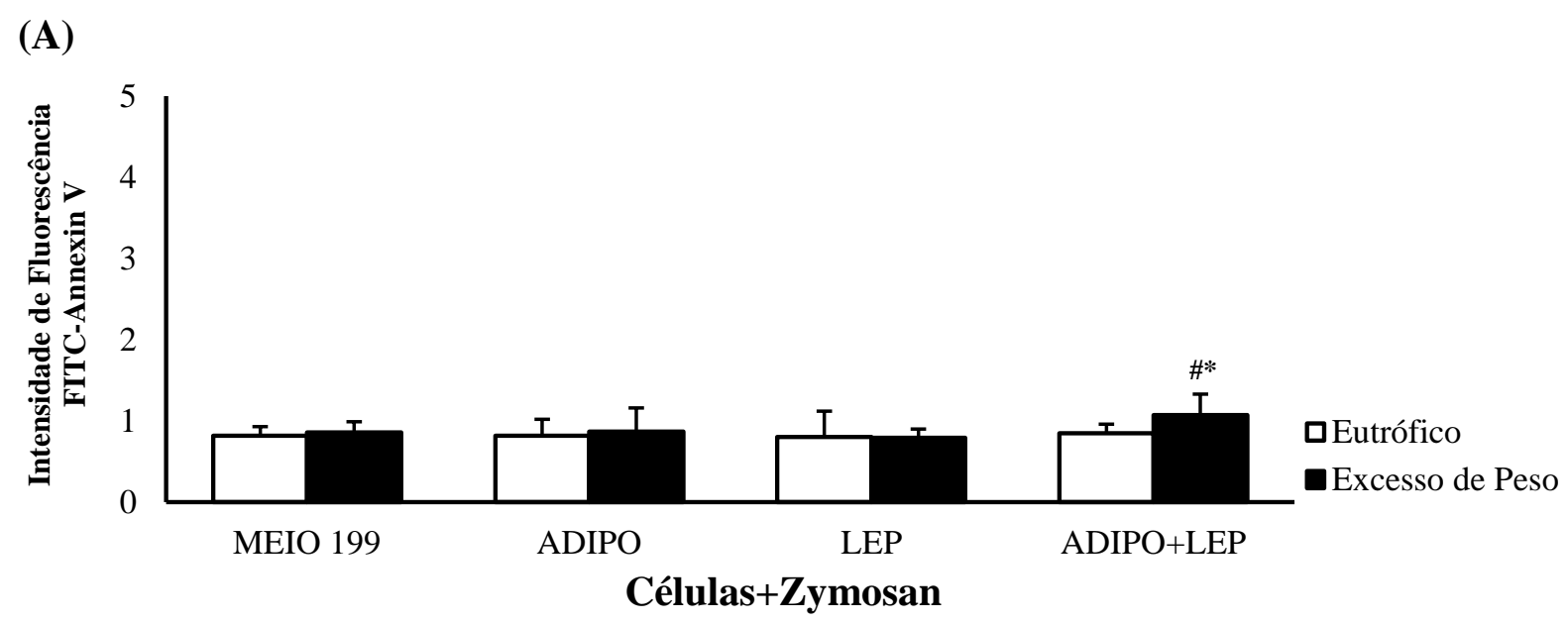

(B)

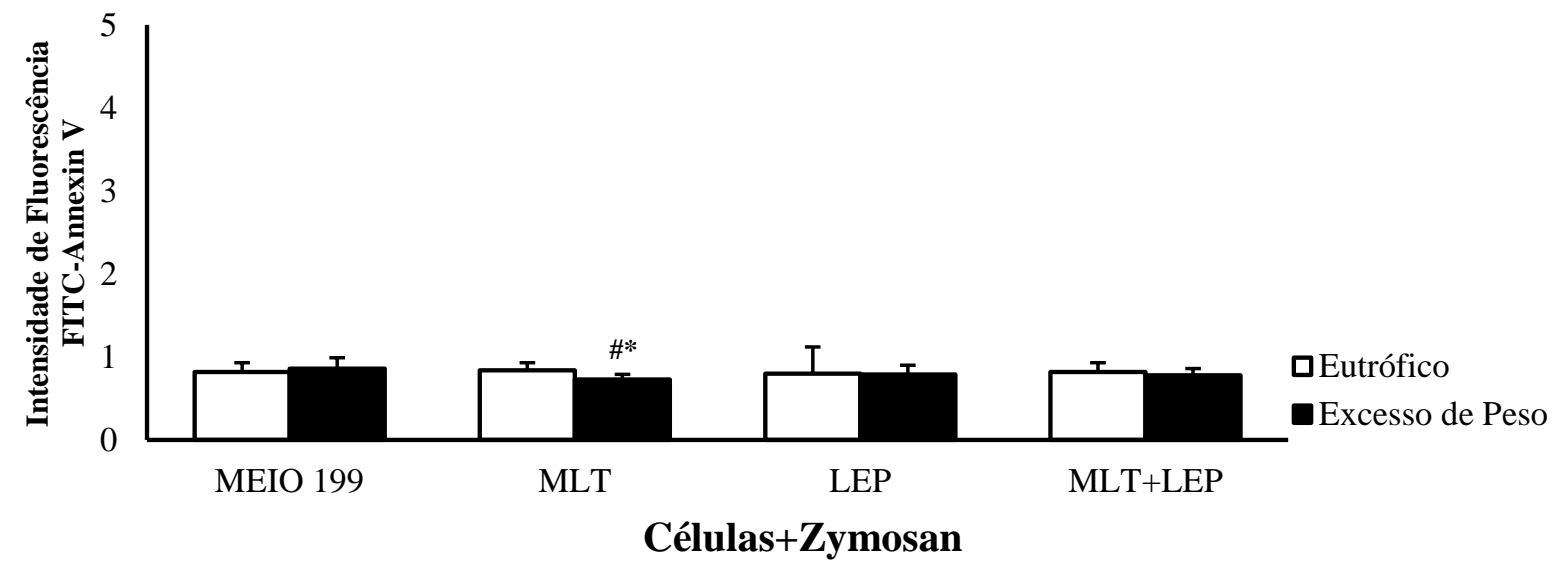

Índice de apoptose dos fagócitos MN do colostro na presença ou ausência de partículas de Zymosan e dos hormônios: (A) adiponectina e/ou leptina ou (B) melatonina e/ou leptina. Os resultados foram avaliados por ANOVA e teste de Tukey, os dados foram expressos em média \pm DP ( $n=10$ por tratamento), indicado como a seguir: "Diferença estatística $(\mathrm{p}<0,05)$ em relação ao mesmo grupo tratado com meio 199 (controle). "Diferença estatística $(\mathrm{p}<0,05)$ intragrupo considerando o mesmo tratamento. 


\section{DISCUSSÃo}

A partir dos resultados desta pesquisa, observou-se que os fagócitos do colostro tiveram menor índice de fagocitose em função do excesso de peso pré-gestacional. Esse fato ilustra que o impacto da obesidade materna para a criança não se finaliza com o nascimento. É possível que o nível de adiposidade materna altere as concentrações dos constituintes do leite humano e assim, modifique inclusive a programação do apetite dos lactentes (KUGANANTHAN et al., 2017), dado que a amamentação também representa um link metabólico entre as mães e seus bebês (SAVINO et al., 2012).

As adipocinas do leite humano influenciam no lactente o desenvolvimento dos constituintes corpóreos durante o primeiro ano de vida, que é um período crítico da programação nutricional infantil (GRIDNEVA et al., 2018). Dessa forma, a desregulação nos níveis das adipocinas nos estágios iniciais da vida pode elevar o risco de desenvolvimento de obesidade e distúrbios metabólicos nas fases posteriores dos ciclos de vida (KRATZSCH et al., 2018). Por isso, torna-se cada vez mais essencial a avaliação de como o IMC materno e os hormônios associados às doenças metabólicas estão relacionadas aos componentes bioativos do leite humano (YOUNG et al., 2017).

A origem das adipocinas do leite materno é difícil de ser uniformemente definida, visto que as suas concentrações são dependentes de inúmeros fatores, elas podem ser influenciadas pelos níveis séricos ou ser oriundas dos tecidos periféricos e até mesmo do próprio tecido mamário (KRATZSCH et al., 2018). Outro fator importante que também influencia nas concentrações das adipocinas do leite humano é o estado nutricional materno, esse altera mudanças nos níveis de adipocinas, tais como: adiponectina e leptina (FUJIMORI et al., 2017; KRATZSCH et al., 2018). 
As concentrações da adiponectina e da leptina no colostro e leite humano, em função do estado nutricional materno são divulgadas na literatura científica (SAVINO et al., 2012; ANDREAS et al., 2016; FUJIMORI et al., 2017; CHAN et al., 2018; GRIDNEVA et al., 2018; KRATZSCH et al., 2018). Aparentemente, o excesso de peso materno pode estar associado ao aumento das concentrações da adiponectina (MARTIN et al., 2006; FUJIMORI et al., 2017) e da leptina no colostro e leite humano (ANDREAS et al. 2016; DE LUCA et al. 2016; FIELDS et al., 2017; FUJIMORI et al., 2017, CHAN et al., 2018).

Essas alterações possivelmente, descrevem um mecanismo materno-infantil de controle do excesso de peso corpóreo, pois no primeiro ano de vida, a medida que os níveis de adiponectina do leite se elevam, o peso do lactente e a circunferência abdominal diminuem significativamente. Ilustrando assim, o efeito regulador da amamentação, via adiponectina, sob a adiposidade infantil no primeiro ano de vida (MOHAMAD et al., 2018). Semelhante também acontece com a leptina.

Os níveis de leptina tendem a aumentar em função da elevação da adiposidade, de modo a controlar a homeostase energética, limitando o desenvolvimento da obesidade (AHIMA et al. 1996). As elevadas concentrações de leptina no leite materno também estão associadas a redução da relação peso/comprimento no primeiro ano de vida da criança (CHAN et al., 2018).

Embora os estudos acima citados abordem os mecanismos materno-infantil que influenciam o controle do peso corpóreo, via adipocinas da amamentação, ainda há lacunas no conhecimento que engloba a temática tratada; principalmente, no que faz referência a variação de marcadores do ritmo circadiano, como a melatonina do colostro ou leite humano segundo o estado nutricional materno.

Temos que destacar que nos mamíferos, há uma sinalização entre este importante marcador do ritmo circadiano - a melatonina - e o metabolismo de lipídios, sendo assim, um hormônio eficaz na prevenção e tratamento da obesidade (AGIL et al., 2011; LIU et al., 2018). 
Esse fato, torna ainda mais instigante a constatação descrita nos resultados desta atual pesquisa, no que se refere ao aumento dos níveis de melatonina no colostro do grupo excesso de peso $(27,14 \mathrm{pg} / \mathrm{mL})$, em relação ao grupo eutrófico $(15,60 \mathrm{pg} / \mathrm{mL})$, ambos coletados no período diurno.

Pesquisas descrevem níveis variados da melatonina no colostro coletado no período diurno: 4,16 pg/mL (PONTES et al., 2006), 4,2 pg/mL (PONTES et al., 2007), aproximadamente 15 pg/mL (HONORIO-FRANÇA et al., 2013) e 1,5 pg/mL (KATZER et al., 2016). As divergências nos valores descritos na literatura, possivelmente deve-se as características próprias de cada população estudada, pois a melatonina é um marcador do ritmo circadiano e seus níveis variam de acordo com as características sazonais (KARAMITRI e JOCKERS, 2019).

Apesar de haver lacunas no conhecimento a respeito das concentrações da melatonina no colostro segundo o excesso de peso materno, sabe-se que no sangue, os níveis de melatonina estão reduzidos em indivíduos obesos (SATO et al. 2013; CHOJNACKI et al. 2016).

Desta forma, é possível inferirmos que a elevação nos níveis de melatonina no colostro de mulheres com excesso de peso, também representa um dos possíveis mecanismos protetores do aleitamento materno ao desenvolvimento do sobrepeso e obesidade no lactente. Ela é responsável, em partes, pela regulação do fluxo de energia através da ativação do tecido adiposo marrom. Assim, as reduções nos níveis de melatonina podem levar a uma cronodisrupção e desencadear a obesidade (CIPOLLA-NETO et al., 2014).

Por isto, a promoção da amamentação a livre demanda, o que inclui o incentivo a amamentação noturna- período no qual há uma maior concentração de melatonina no colostro e leite humano- (HONORIO-FRANÇA et al., 2013; KATZER et al., 2016), poderia ser considerada também uma ferramenta nas campanhas públicas que visam a redução do sobrepeso e obesidade populacional. 
É fundamental lembrarmos que os hormônios adiponectina, leptina e melatonina modulam as respostas imunológicas em leucócitos mononucleares (LOFFREDA et al. 1998; HONORIO-FRANÇA et al., 2013; MORSHEDI et al., 2013; PIRES-LAPA et al., 2013; DAYAKAR et al. 2016). Desse modo, essa população celular foi utilizada para verificar o possível impacto do excesso de peso materno sob a atividade funcional dessas células.

Os fagócitos mononucleares do colostro foram incubados com partículas de Zymosan., que por ser um derivado fúngico, possui $\beta$-glucanas em sua composição que se liga nos fagócitos via receptores Dectin-1, receptores Toll-like (TLR) e Myd88 (fator de diferenciação mielóide 88), além de ativar o fator de transcrição NF-kB, dando início ao processo de fagocitose e ativação de estresse oxidativo (BROWN et al., 2003; UNDERHILL, 2003; ELCOMBE et al., 2013; JIANG et al., 2013; CAMILI et al., 2018).

Neste estudo, o Zymosan induziu a resposta inflamatória, na qual foi verificada um menor índice de fagocitose e de liberação de EROS no grupo com sobrepeso e obesidade prégestacional. Os hormônios adiponectina, leptina e melatonina restauraram o índice de fagocitose a valores semelhantes ao do grupo eutrófico. Contudo, a associação da adiponectina+leptina teve destaque, dado que foi o único tratamento capaz de restaurar no grupo excesso de peso, o percentual de fagocitose com respectivo aumento de EROS a valores semelhantes ao controle.

Na literatura científica não há informações sobre o índice de fagocitose de macrófagos do colostro humano, em função do excesso de peso materno. Porém, pesquisas que associam a atividade fagocítica e o excesso de peso corporal ilustram resultados controversos, alguns estudos descrevem uma redução no índice de fagocitose e no número de macrófagos com habilidade fagocítica em função do excesso de peso (LOFFREDA et al. 1998; HUNSCHE, HERNANDEZ e DE LA FUENTE, 2016), enquanto que outros sugerem aumento no índice de fagocitose (NIEMAN et al. 1999; MEANEY et al. 2016). 
Em relação a liberação de radicais livres, resultados controversos são descritos na literatura científica. Algumas pesquisas relatam que a obesidade está associada a elevação do burst oxidativo em macrófagos e neutrófilos (NIEMAN, 1999; NEGRO et al. 2017), enquanto que outras descrevem que a elevação do IMC não reflete em aumento de marcadores do estresse oxidativo (PAHWA, ADAMS-HUET e JIALAL, 2017), semelhante ao encontrado neste estudo. Possivelmente, as diferenças nos resultados dos estudos citados estão no tipo de amostras e nos diferentes agentes indutores de fagocitose utilizados.

Quanto ao tratamento dos fagócitos com os hormônios utilizados, sabe-que a adiponectina, apesar de ser conhecida por sua ação anti-inflamatória, decorrente da sua capacidade de estimular a expressão de marcadores de macrófagos de fenótipo M2. Ela também é capaz de ocasionar em macrófagos estímulos pró-inflamatórios (CHENG et al., 2012; LEE et al., 2018), por ativação de macrófagos da via clássica (M1 - pró-inflamatória) (CHENG et al., 2012; SANZ-GARCIA et al., 2014). Essa adipocina induz a ativação da enzima IkB Kinase, enzima responsável pela degradação da proteína inibitória kB e assim, consequente ativação do NF-kB, que no núcleo irá promover a liberação de citocinas pró-inflamatórias e o desencadeamento da resposta inflamatória (LEE et al., 2018).

Em relação a leptina, estudo demonstra que sua deficiência em animais ocasiona prejuízos na fagocitose, o que demonstra a importância dessa adipocina para o processo de fagocitose (MOORE et al., 2003). Seu mecanismo de ação envolve a ativação das vias de sinalização JAK/STAT, que induz a fagocitose, burst oxidativo e aumento da secreção de citocinas pró-inflamatórias (SHIRSHEV e ORLOVA, 2005). Estudos na literatura descrevem a ação da leptina na elevação da geração de EROS, contribuindo assim para a atividade microbicida de monócitos (PADRA et al. 2012; DAYAKAR et al. 2016; TEIXEIRA et al., 2017), semelhante ao verificado neste estudo. No entanto, ela também possui potencial de reduzir a formação de EROS, provavelmente, devido a ocorrência de uma dessensibilização em 
monócitos provenientes de indivíduos que se encontram num estado hiperinflamatório (SANCHEZ-POZO et al., 2003),

A respeito do hormônio melatonina, na literatura científica ainda não é totalmente esclarecida a ação da melatonina nos fagócitos segundo o índice de massa corporal. Nesse estudo, a melatonina elevou o índice de fagocitose independente do IMC materno prégestacional, sem restituir a liberação de EROS para o grupo excesso de peso.

A melatonina eleva os índices de fagocitose, inclusive ela aumenta a fagocitose induzida por partículas de Zymosan (PIRES-LAPA et al., 2013), além de elevar a capacidade do colostro na proteção a enterophatogenic Escherichia coli (EPEC), demonstrando assim, que a melatonina no colostro apresenta uma função essencial para proteção do recém-nascido nos primeiros dias de vida (HONORIO-FRANÇA et al., 2013; MORCELI et al., 2013).

Nos mamíferos, a melatonina atua principalmente via receptores acoplados à proteína G, denominados de MT1 e MT2. Ambos desencadeiam cascatas de eventos intracelulares, que envolve a inibição da produção do AMP cíclico ou liberação de cálcio. Outros sítios de ligação da melatonina estão relacionados a proteínas intracelulares como a calmodulina, enzima quinona redutase 2 (MT3), receptores nucleares $\mathrm{RZR} / \mathrm{ROR} \alpha$ relacionados a família do ácido retinóico (Von GALL, STEHLE e WEAVER, 2002; DUBOCOVICH e MARKOWSKA, 2005; TAN et al., 2007; HARDELAND et al., 2011; MARKUS, CECON e PIRES-LAPA, 2013; EMET et al., 2016).

Nas células mononucleares do colostro humano, durante a fagocitose do Zymosan, a melatonina age diretamente via receptor MT2 e contribui para aumentar a eficiência dos fagócitos por elevar a expressão de dectina-1, fundamental na resposta imunológica inata a fungos, mecanismo importante na fagocitose do Zymosan (PIRES-LAPA et al. 2013).

Neste estudo, apesar da melatonina ter aumentado a fagocitose, ela não aumentou a liberação de EROS pelas células mononucleares do colostro. 
De acordo com a literatura, a melatonina tem ação antioxidante, pela interação diretamente com uma variedade de espécies reativas de oxigênio e nitrogênio, protegendo as células contra danos moleculares (REITER et al., 2007). Por outro lado, ela é capaz de estimular a produção de espécies reativas de oxigênio sem ocasionar distúrbios na mitocôndria e de forma independente da estimulação de receptores MT1/MT2. Nos leucócitos, a melatonina pode induzir a liberação da fosfolipase A2, independente de cálcio (Ipla2), que reage com sítio de ligação da calmudolina e assim leva a produção de radicais livres (RADOGNA et al., 2009a; RADOGNA et al., 2009b).

No caso dos fagócitos mononucleares do colostro, a melatonina induz a liberação de ânion superóxido no decorrer da fagocitose de bactérias. No entanto, na presença de alterações metabólicas, como diabetes, a melatonina não eleva a liberação do ânion superóxido (HONORIO-FRANÇA et al., 2013; MORCELI et al. 2013). Similar ao encontrado nesta pesquisa, indicando assim uma atividade antioxidante da melatonina em casos de alterações metabólicas, como o excesso de peso.

No decorrer da resposta inflamatória, além da liberação de EROS que são importantes para atividade microbicida (DJORDJEVIC, 2004), os níveis de liberação de cálcio intracelular também são necessários no processo de ingestão de antígenos e no controle das etapas subsequentes envolvidas na maturação de fagossomos (NUNES e DEMAUREX 2010). O ajuste fino da homeostasia do cálcio intracelular por meio de proteínas anti- e pró-apoptóticas molda o sinal de cálcio e controla o processo de apoptose celular (PINTON et al., 2008).

Constatamos neste estudo que o excesso de peso materno pré-gestacional não influenciou nas alterações do cálcio intracelular e de apoptose das células mononucleares do colostro na presença de Zymosan.

Sabe-se que o excesso de peso está associado a elevação de apoptose em monócitos. Possivelmente, os aumentos nos níveis de ácidos graxos saturados, são capazes de ativar vias 
inflamatórias nessas células, principalmente, por elevar a atividade das caspases, causando liberação de citocinas inflamatórias e inflamassomas (PILLON et al., 2016). Diferente do verificado neste estudo, que ilustra a capacidade do colostro de manter o número de células viáveis, independente do IMC materno pré-gestacional.

No colostro mais de $90 \%$ dos fagócitos mononucleares são formados por células viáveis (MORES et al. 2015), enquanto que o índice de apoptose nesta população celular é de 6,75\% (HONORIO-FRANÇA et al., 2016). Fato que demonstra a disponibilidade de número significativo de células viáveis, para o desenvolvimento de uma possível resposta inflamatória.

Neste atual estudo, a melatonina reduziu os níveis de apoptose das células mononucleares do colostro, enquanto que a interação da adiponectina+leptina aumentaram a apoptose para o grupo com elevado IMC pré-gestacional.

A melatonina modula a apoptose em leucócitos via estimulação dos receptores MT1/MT2, promovendo a relocalização da proteína anti-apoptótica Bcl-2 à mitocondria (RAGDONA et al., 2015) e pode atenuar a resposta inflamatória com reflexo na redução na concentração de apoptose em macrófagos (CHEN et al., 2018).

No entanto, nessa pesquisa apenas a associação da adiponectina+leptina foi o tratamento que refletiu em maior índice de apoptose. Considerando que a adiponectina elevou os níveis de cálcio intracelular e quando associada a leptina (adiponectina+leptina) o nível de EROS elevouse, podemos sugerir que as adipocinas em conjunto induziram nos fagócitos mononucleares uma resposta mais efetiva, com mecanismo de associação dependente de EROS e do controle de cálcio intracelular, culminando dessa maneira no aumento dos níveis de apoptose. Provavelmente, essa associação potencializou a atividade microbicida desses fagócitos e assim, o consequente aumento verificado nos níveis de apoptose para o grupo elevado IMC. Esses resultados condizem com a literatura, a qual descreve que as adipocinas em conjunto intensificam a resposta celular, provavelmente pela ativação da via clássica do NF-kB, que 
regula os genes responsáveis pela produção da maior parte de EROS nas células (MORGAN e LIU, 2011).

Dessa forma, é importante salientar a necessidade da manutenção do equilíbrio dos hormônios reguladores do metabolismo no organismo materno, para uma adequada atividade funcional das células mononucleares do colostro humano. No entanto, temos que destacar que mesmo havendo diferenças nas respostas das células mononucleares em função do excesso de peso pré-gestacional, essas células proporcionam proteção imunológica ao lactente. Além do mais, é possível que as diferenças encontradas na atividade funcional das células mononucleares, seja um mecanismo de defesa materno-infantil para garantir ao lactente uma eficiente resposta imunológica. Visto que, essas células in natura, também estarão estão emergidas em um meio alterado de hormônios e estímulos variáveis segundo a presença de alterações metabólicas decorrentes do excesso de peso materno.

Assim, a amamentação deve ser incentivada. $\mathrm{O}$ aleitamento materno continua sendo uma importante estratégia de saúde pública para o combate da epidemia da obesidade, com potencial real de proporcionar efeitos protetores ao excesso de peso para o binômio mãe e filho (OZENOGLU et al., 2017; BELL et al., 2018; ORTEGA-GARCÍA et al., 2018) e no combate de infecções infantis (HONÓRIO-FRANÇA et al., 2013).

Dessa maneira, estudos que avaliem as ações e os níveis dos hormônios reguladores do metabolismo, do colostro e leite humano, podem trazer importantes contribuições para o desenvolvimento de novas estratégias frente a epidemia da obesidade e até mesmo no combate de infecções infantis. Seja por meio do incentivo ao controle de peso materno, ou medidas que utilizem o próprio colostro e leite materno como estratégia de intervenção. 


\section{CONCLUSÃO}

O excesso de peso materno pré-gestacional elevou as concentrações da melatonina do colostro e influenciou na atividade funcional dos fagócitos mononucleares do colostro humano.

Os estímulos de adiponectina, leptina e melatonina restaurou o índice de fagocitose para o grupo excesso de peso, a valores similares ao grupo eutrófico. A associação da adiponectina+leptina nos fagócitos mononucleares foi o tratamento mais eficaz para restituir o índice de fagocitose no grupo excesso de peso, com restauração dos níveis de espécies reativas de oxigênio e manutenção das concentrações de cálcio intracelular. Contribuindo assim, para uma atividade microbicida mais efetiva, que foi refletida no aumento do índice de apoptose.

A melatonina e leptina, restauraram o índice de fagocitose, sem elevação no índice de apoptose, indicando uma ação antioxidantes desse hormônio, que pode prevenir danos celulares, nas células do colostro de mulheres com excesso de peso.

Os dados em conjunto reforçam a hipótese de que a amamentação representa um caminho para beneficiar a saúde da criança. Assim, a promoção do controle de peso corporal, junto ao incentivo da amamentação a livre demanda, representam um econômico e sustentável caminho para o desenvolvimento de ações benéficas frente a redução do impacto do sobrepeso e da obesidade populacional. 


\section{REFERÊNCIAS}

Agil A, Navarro-Alarcón M, Ruiz R, Abuhamadah S, El-Mir MY, Vázquez GF. Beneficial effects of melatonin on obesity and lipid profile in young Zucker diabetic fatty rats. J Pineal Res. 2011;50(2):207-12.

Ahima RS, Prabakaran D, Mantzoros C, Qu D, Lowell B, Maratos-Flier E, Flier JS. Role of leptin in the neuroendocrine response to fasting. Nature 1996;382(6588):250-2.

Ahima RS, Antwi, DA. Brain regulation of appetite and satiety. Endocrinol Metab Clin North Am. 2008;37(4): 811-23.

Alonso-Vale MI, Andreotti S, Peres SB, Anhê GF, das Neves Borges-Silva C, Neto JC, Lima FB. Melatonin enhances leptin expression by rat adipocytes in the presence of insulin. Am J Physiol Endocrinol Metab. 2005;288(4):E805-E812.

Alonso-Vale MI, Peres SB, Vernochet C, Farmer SR, Lima FB. Adipocyte differentiation is inhibited by melatonin through the regulation of $\mathrm{C} / \mathrm{EBPbeta}$ transcriptional activity. $\mathrm{J}$ Pineal Res. 2009;47(3):221-7.

Andreas, N.J.; Hyde, M.J.; Gale, C.; Parkinson, J.R.; Jeffries, S.; Holmes, E; Modi N. Effect of maternal body mass index on hormones in breast milk: a systematic review. PLoS One. 2014;9(12):1-25.

Andreas NJ, Hyde MJ, Herbert BR, Jeffries S, Santhakumaran S, Mandalia S, Holmes E, Modi N. Impact of maternal BMI and sampling strategy on the concentration of leptin, insulin, ghrelin and resistin in breast milk across a single feed: a longitudinal cohort study. BMJ Open. 2016;6(7):1-9.

Armitage P, Berry G. The planning of statistical investigations. In: Statistical methods in medical research. 2.ed. Oxford, Blackwell, p.179-185, 1987.

Atalah SE, Castillo CL, Castro RS. Propuesta de um nuevo estandar de evaluacion nutricional em embarazadas. Rev Med Chile. 1997;125(12):1429-36.

Austin J, Marks D. Hormonal regulators of appetite. Int J Pediatr Endocrinol. 2009;2009:1-9. 
Aye ILMH, Powell TL, Jansson T. Review: Adiponectin - the missing link between maternal adiposity, placental transport and fetal growth? Placenta. 2013;S34:S40-S45.

Badillo-Suárez PA1, Rodríguez-Cruz M2, Nieves-Morales. Impact of metabolic hormones secreted in human breast milk on nutritional programming in childhood obesity. J Mammary Gland Biol Neoplasia. 2017;22(3):171-91.

Bell S, Yew SSY, Devenish G, Ha D, Do L, Scott J. Duration of breastfeeding, but not timing of solid food, reduces the risk of overweight and obesity in children aged 24 to 36 months: findings from an australian cohort study. Int J Environ Res Public Health. 2018;15(4):1-14.

Binns C, Lee M, Low WY. The Long-Term Public Health Benefits of Breastfeeding. Asia Pac J Public Health. 2016;28(1):7-14.

Bray GA, Kim KK, Wilding JPH. Obesity: a chronic relapsing progressive disease process. A position statement of the World Obesity Federation. Obes Ver. 2017;18(7):715-23.

Bronsky J, Mitrova K, Karpisek M, Mazoch J, Durilova M, Fisarkova B, et al. Adiponectin, AFABP, and leptin in human breast milk during 12 months of lactation. J Pediatr Gastroenterol Nutr. 2011; 52(4):474-7.

Brown GD, Herre J, Williams DL, Willment JA, Marshall AS, Gordon S. Dectin-1 mediates the biological effects of beta-glucans. J Exp Med. 2003;197(9):1119-24.

Brydon L, Petit L, Delagrange P, Strosberg AD, Jockers R. Functional expression of MT2 (Mel1b) melatonin receptors in human PAZ6 adipocytes. Endocrinology 2001;142(10):426471.

Burchiel SW, Edwards BS, Kuckuck FW, Lauer FT, Prossnitz ER, Ransom JT, et al. Analysis of free intracellular calcium by flow cytometry: multiparameter and pharmacologic applications. Methods. 2000;21(3):221-30.

Cagnacci A, Malmusi S, Zanni A, Arangino S, Cagnacci P, Volpe A. Acute modifications in the levels of daytime melatonin do not influence leptin in postmenopausal women. J Pineal Res. 2002;33(1):57-60.

Camilli G, Eren E, Williams DL, Aimanianda V, Meunier E, Quintin J. Impaired phagocytosis directs human monocyte activation in response to fungal derived $\beta$-glucan particles. Eur J Immunol. 2018;48(5):757-70. 
Cardinali DP, Hardeland R. Inflammaging, metabolic syndrome and melatonin: a call for treatment studies. Neuroendocrinology. 2017;104(4):382-97.

Catalano PM, Shankar K. Obesity and pregnancy: mechanisms of short term and long term adverse consequences for mother and child. BMJ. 2017;356:1-21.

Cawley J, Meyerhoefer C. The medical care costs of obesity: an instrumental variables approach. J Health Econ. 2012;31(1):219-30.

Cermakian N, Westfall S, Kiessling S. Circadian clocks and inflammation: reciprocal regulation and shared mediators. Arch Immunol Ther Exp. 2014;62(4):303-18

Chan D, Goruk S, Becker AB, Subbarao P, Mandhane PJ, Turvey SE, et al. Adiponectin, leptin and insulin in breast milk: associations with maternal characteristics and infant body composition in the first year of life. Int J Obes (Lond). 2018;42(1):36-43.

Chen Y, Zhao Q, Sun Y, Jin Y, Zhang J, Wu J. Melatonin induces anti-inflammatory effects via endoplasmic reticulum stress in RAW264.7 macrophages. Mol Med Rep. 2018;17(4):6122-9.

Cheng X, Folco EJ, Shimizu K, Libby P. Adiponectin induces pro-inflammatory programs in human macrophages and CD4+ T cells. J Biol Chem. 2012;287:36896-904.

Chirico, G.; Gasparoni, A. Immunologic components of human milk. Haematol Rep. 2006;2(10):27-30.

Chojnacki C, Walecka-Kapica E, Błońska A, Winczyk K, Stępień A, Chojnacki J. Serotonin and melatonin secretion in postmenopausal women with eating disorders. Endokrynol Pol. 2016;67(3):299-304.

Ciardelli L, Garofoli F, Stronati M, Mazzucchelli I, Avanzini MA, Figar T, et al. Human colostrum $\mathrm{T}$ lymphocytes and their effector cytokines actively aid the development of the newborn immune system. Int J Immunopathol Pharmacol. 2008;21(4):781-6

Cinti S. Adipose Organ Development and Remodeling. Compr Physiol. 2018;8(4)1357-31.

Cipolla-Neto J, Amaral FG, Afeche SC, Tan DX, Reiter RJ. Melatonin, energy metabolism, and obesity: a review. J Pineal Res. 2014;56(4):371-81. 
Cnattingius S, Villamor E. Weight change between successive pregnancies and risks of stillbirth and infant mortality: a nationwide cohort study. Lancet. 2016; 387(10018):558-65.

Coccurello R., Maccarrone M. Hedonic eating and the "delicious circle": from lipid-derived mediators to brain dopamine and back. Front Neurosci. 2018;12(271), 1-20.

Corbalán-Tutau D, Madrid JA, Nicolás F, Garaulet M. Daily profile in two circadian markers "melatonin and cortisol" and associations with metabolic syndrome components. Physiol Behav. 2014;123:231-5.

Dayakar A, Chandrasekaran S, Veronica J, Maurya R. Leptin induces the phagocytosis and protective immune response in Leishmania donovani infected THP-1 cell line and human PBMCs. Exp Parasitol. 2016;160:54-9

De Luca A, Frasquet-Darrieux M, Gaud MA, Christin P, Boquien CY, Millet C, et al. Higher leptin but not human milk macronutrient concentration distinguishes normal-weight from obese mothers at 1-month postpartum. PLoS One. 2016;11(12):1-11.

Dieterich CM, Felice JP, O'Sullivan E, Rasmussen KM. Breastfeeding and health outcomes for the mother-infant dyad. Pediatr Clin North Am. 2013;60(1):31-48.

Djordjević VB. Free radicals in cell biology. Int Rev Cytol. 2004;237:57-89.

Doneray H, Orbak Z, Yildiz L. The relationship between breast milk leptin and neonatal weight gain. Acta Paediatr. 2009;98(4):643-7.

Dong M, Zheng Q, Ford SP, Nathanielsz PW, Ren J. Maternal obesity, lipotoxicity and cardiovascular diseases in offspring. J Mol Cell Cardiol. 2013;55:111-6.

Dubocovich ML, Markowska M. Functional MT1 and MT2 melatonin receptors in mammals. Endocrine 2005;27(2):101-10.

Elcombe SE, Naqvi S, Van Den Bosch MW, MacKenzie KF, Cianfanelli F, Brown GD, Arthur JS. Dectin-1 regulates IL-10 production via a MSK1/2 and CREB dependent pathway and promotes the induction of regulatory macrophage markers. PLoS One 2013;8(3):1-15.

Emet M, Ozcan H, Ozel L, Yayla M, Halici Z, Hacimuftuoglu A. A review of melatonin, its receptors and drugs. Eurasian J Med. 2016;48(2):135-41 
Fagundes DLG, França EL, Gonzatti MB, Rugde MVC, Calderon IMP, Honorio-França AC. The modulatory role of cytokines IL-4 and IL-17 in the functional activity of phagocytes in diabetic pregnant women. APMIS. 2018;126(1):56-64.

Fernández Vázquez G, Reiter RJ, Agil A. Melatonin increases brown adipose tissue mass and function in Zücker diabetic fatty rats: implications for obesity control. J Pineal Res. 2018;64(4):1-10.

Field CJ. The Immunological components of human milk and their effect on immune development in infants. J. Nutr. 2005; 135(1):1-4.

Fields DA, George B, Williams M, Whitaker K, Allison DB, Teague A, Demerath EW. Associations between human breast milk hormones and adipocytokines and infant growth and body composition in the first 6 months of life. Pediatr Obes. 2017;12(Suppl 1):78-85.

Figueroa A, Agil A. Changes in plasma's oxidative stress and antioxidant activity, measured with melatonin levels, and its relationship to newborns from obese and diabetic pregnancies. J Diabetes Metab. 2011; S4(002):1-10.

França, EL, Nicomedes TR, Calderon IMP, Honório-França, AC. Time-dependent alterations of soluble and cellular components in human milk. Biol Rhythm Res. 2010;41(5):333-47.

França EL, Bitencourt RV, Fujimori M, Morais TC, Calderon IM, Honorio-França AC. Human colostral phagocytes eliminate enterotoxigenic Escherichia coli opsonized by colostrum supernatant. J Microbiol Immunol Infect. 2011a;44(1):1-7.

França EL, Morceli G, Fagundes DL, Rudge MV, Calderon IM, Honorio-França AC. Secretory IgA-Fca receptor interaction modulating phagocytosis and microbicidal activity by phagocytes in human colostrum of diabetics. APMIS. 2011b;119(10):710-9.

França-Botelho AC, Honório-França AC, França EL, Gomes MA, Costa-Cruz JM. Phagocytosis of Giardia lamblia trophozoites by human colostral leukocytes. Acta Paediatr. 2006;95(4):438-43.

Francisco V, Pino J, Campos-Cabaleiro V, Ruiz-Fernández C, Mera A, Gonzalez-Gay MA, et al. Obesity, fat mass and immune system: role for leptin. Front Physiol 2018;9:1-20.

Frisancho AR. Anthropometric standards for the assessment of growth and nutritional status. Ann Arbor, Michigan: Univesity of Michigan Press; 1990. 
Fujimori M, França EL, Fiorin V, Morais TC, Honorio-França AC, Abreu LC. Changes in the biochemical and immunological components of serum and colostrum of overweight and obese mothers. BMC Pregnancy \& Childbirth. 2015;15(166):1-8.

Fujimori M, França EL, Morais TC, Fiorin V, de Abreu LC, Honório-França AC. Cytokine and adipokine are biofactors can act in blood and colostrum of obese mothers. Biofactors 2017;43(2):243-50.

Garofalo RP, Goldman AS. Expression of functional immunomodulatory and antiinflammatory factors in human milk. Clin Perinatol. 1999;26(2):361-77.

Gridneva Z, Kugananthan S, Rea A, Lai CT, Ward LC, Murray K, et al. Human milk adiponectin and leptin and infant body composition over the first 12 months of lactation. Nutrients 2018;10(8):1-24.

Grosshans M, Vollmert C, Vollstaedt-Klein S, Nolte I, Schwarz E, Wagner X, et al. The association of pineal gland volume and body mass in obese and normal weight individuals: a pilot study. Psychiatr Danub. 2016;28(3):220-4.

Hafekost K, Lawrence D, Mitrou F, O'Sullivan TA, Zubrick SR. Tackling overweight and obesity: does the public health message match the science? BMC Med. 2013;11(41):1-8.

Hardeland R, Cardinali DP, Srinivasan V, Spence DW, Brown GM, Pandi-Perumal SR. Melatonin-a pleiotropic, orchestrating regulator molecule. Prog Neurobiol 2011;93(3):350-84.

Hirayama D, Iida T, Nakase $H$. The phagocytic function of macrophage-enforcing innate immunity and tissue homeostasis. Int J Mol Sci. 2017;19(1):1-14.

Honorio-França AC, Castro C, Hara P, Ormonde JVS, Nunes GT, França, EL. Human colostrum melatonin exhibits a day-night variation and modulates the activity of colostral phagocytes. J Appl Biomed. 2013;11(3):153-62.

Honorio França AC, Nunes GT, Gomes Fagundes DL, de Marchi PG, Fernandes RT, França $\mathrm{JL}$, et al. Intracellular calcium is a target of modulation of apoptosis in MCF-7 cells in the presence of IgA adsorbed to polyethylene glycol. Onco Targets Ther. 2016;9:617-26.

Horta BL, Victora CG, França GVA, Hartwig FP, Ong KK, Rolfe EL, et al. Breastfeeding moderates FTO related adiposity: a birth cohort study with 30 years of follow-up. Sci Rep. 2018;8(1):2530. 
Hunsche C, Hernandez O, De la Fuente M. Impaired Immune Response in Old Mice Suffering from Obesity and Premature Immunosenescence in Adulthood. J Gerontol A Biol Sci Med Sci. 2016;71(8):983-91.

Illnerová H, Buresová M, Presl, J. Melatonin rhythm in human milk. J Clin Endocrinol Metab. 1993;77(3):838-41.

IOM. Institute of Medicine (US) and National Research Council (US) Committee to Reexamine IOM Pregnancy Weight Guidelines; Rasmussen KM, Yaktine AL, editors. Weight gain during pregnancy: reexamining the guidelines. Washington, DC: National Academies Press; 2009.

Islam SK, Ahmed L, Khan MN, Huque S, Begum A, Yunus AB. Immune components (IgA, IgM, IgG immune cells) of colostrums of Bangladeshi mothers. Pediatr Int. 2006;48(6):543-8.

Jiang LI, Sternweis PC, Wang JE. Zymosan activates protein kinase A via adenylyl cyclase VII to modulate innate immune responses during inflammation. Mol Immunol. 2013;54(1):14-22.

Karamitri A, Jockers R. Melatonin in type 2 diabetes mellitus and obesity. Nat Rev Endocrinol. 2019;15(2):105-25.

Kato H, Tanaka G, Masuda S, Ogasawara J, Sakurai T, Kizaki T, et al. Melatonin promotes adipogenesis and mitochondrial biogenesis in 3T3-L1 preadipocytes. J. Pineal Res. 2015;59(2):267-75.

Katzer D, Pauli L, Mueller A, Reutter H, Reinsberg J, Fimmers R, et al. Melatonin concentrations and antioxidative capacity of human breast milk according to gestational age and the time of day. J Hum Lact. 2016;32(4):NP105-NP110.

Konsoulova PS, Nyagolova PV, Orbetzova MM, Simitchiev KK, Terzieva DD, Kaleva NN. Leptin, adiponectin, and leptin/adiponectin ratio in adolescents with metabolic syndrome. Int. J Pharm. 2016;4(5):1-6.

Kratzsch J, Bae YJ, Kiess W. Adipokines in human breast milk. Best Pract Res Clin Endocrinol Metab. 2018;32(1):27-38.

Kronborg H, Vaeth M, Rasmussen K M. Obesity and early cessation of breastfeeding in Denmark. Eur J Public Health. 2013;23(2):316-22. 
Kugananthan S, Gridneva Z, Lai CT, Hepworth AR, Mark PJ, Kakulas F, Geddes DT. Associations between maternal body composition and appetite hormones and macronutrients in human milk. Nutrients. 2017; 9(3):1-18.

LaRosa DF, Orange JS. Lymphocytes. J Allergy Clin Immunol. 2008; 121(2) S2:S364-9.

Lee $\mathrm{KH}$, Jeong J, Woo J, Lee $\mathrm{CH}$, Yoo CG. Globular adiponectin exerts a pro-inflammatory effect via I $\mathrm{B} / \mathrm{NF}-\kappa \mathrm{B}$ pathway activation and anti-inflammatory effect by IRAK-1 downregulation. Mol Cells. 2018;41(8):762-70.

Lee KK, Raja EA, Lee AJ, Bhattacharya S, Bhattacharya S, Norman JE, et al. Maternal obesity during pregnancy associates with premature mortality and major cardiovascular events in later life. Hypertension. 2015;66(5):938-44.

Lee YH, Mottillo EP, Granneman JG. Adipose tissue plasticity from WAT to BAT and in between. Biochim Biophys Acta. 2014;1842(3):358-69.

Lieberman MM, Sachanandani DM, Pinney CA. Comparative study of neutrophil activation by chemiluminescence and flow cytometry. Clin Diagn Lab Immunol 1996;3(6):654-62.

Liu Z, Gan L, Luo D, Sun C. Melatonin promotes circadian rhythm-induced proliferation through Clock/histone deacetylase 3/c-Myc interaction in mouse adipose tissue. J Pineal Res. 2017;62(4):1-14.

Liu K, Yu W, Wei W, Zhang X, Tian Y, Sherif M, et al. Melatonin reduces intramuscular fat deposition by promoting lipolysis and increasing mitochondrial function. J Lipid Res. 2018; M087619:1-50.

Loffreda S, Yang SQ, Lin HZ, Karp CL, Brengman ML, Wang DJ, et al. Leptin regulates proinflammatory immune responses. FASEB J. 1998;12(1):57-65.

Luo Y, Liu M. Adiponectin: a versatile player of innate immunity. J Mol Cell Biol. 2016;8(2):120-8.

Manna P, Jain SK. Obesity, oxidative stress, adipose tissue dysfunction, and the associated health risks: causes and therapeutic strategies. Metab Syndr Relat Disord. 2015;13(10):423-44.

Manzar D, Hussain ME. Leptin rhythmicity and its relationship with other rhythm markers. Biol Rhythm Res. 2011;42(2):163-80. 
Markus RP, Cecon E, Pires-Lapa MA. Immune-pineal axis: nuclear factor $\kappa \mathrm{B}$ (NF-kB) mediates the shift in the melatonin source from pinealocytes to immune competent cells. Int $\mathbf{J}$ Mol Sci. 2013;14(6):10979-97

Marseglia L, Manti S, D'Angelo G, Cuppari C, Salpietro V, Filippelli M, et al. Obesity and breastfeeding: the strength of association. Women Birth. 2015;28(2):81-6.

Marshall NE, Lau B, Purnell JQ, Thornburg KL. Impact of maternal obesity and breastfeeding intention on lactation intensity and duration. Matern Child Nutr. 2018;e12732:1-21.

Martin LJ, Woo JG, Geraghty SR, Altaye M, Davidson BS, Banach W, et al. Adiponectin is present in human milk and is associated with maternal factors. Am J Clin Nutr. 2006;83(5):1106-11.

Mattar R, Torloni MR, Beltrana AP, Mario M. Obesidade e gravidez. Rev Bras Ginecol Obstet. 2009;31(3):107-10.

Mayer-Davis EJ, Rifas-Shiman SL, Zhou L, Hu FB, Colditz GA, Gillman MW. Breastfeeding and risk for childhood obesity: does maternal diabetes or obesity status matter? Diabetes Care 2006;29(10):2231-37.

McMurray F, Patten DA, Harper ME. Reactive oxygen species and oxidative stress in obesity-recent findings and empirical approaches. Obesity (Silver Spring) 2016;24(11):230110 .

Meaney MP, Nieman DC, Henson DA, Jiang Q, Wang FZ. Measuring Granulocyte and Monocyte Phagocytosis and Oxidative Burst Activity in Human Blood. J Vis Exp 2016;12(115):1-8.

Miehle K, Stepan H, Fasshauer M. Leptin, adiponectin and other adipokines in gestational diabetes mellitus and pre-eclampsia. Clin Endocrinol (Oxf). 2012;76(1):2-11.

Mission JF, Marshall NE, Caughey AB. Pregnancy risks associated with obesity. Obstet Gynecol Clin N Am. 2015;42(2):335-53.

Mitchell S, Shaw D. The worldwide epidemic of female obesity. Best Pract Res Clin Obstet Gynaecol. 2015;29(3):289-99. 
Mitrova K, Karpisek M, Durilova M, Dragusin LG, Nevoral J, Bronsky J. Development of high-sensitive ELISA method for detection of adipophilin levels in human colostrum and breast milk. J Clin Lab Anal. 2014;28(4):255-60.

Mohamad M, Loy SL, Lim PY, Wang Y, Soo KL, Mohamed HJJ. Maternal Serum and Breast Milk Adiponectin: The Association with Infant Adiposity Development. Int J Environ Res Public Health. 2018;15(6):1-19.

Montanari T, Pošćić N, Colitti M. Factors involved in white-to-brown adipose tissue conversion and in thermogenesis: a review. Obes Rev. 2017;18(5):495-513.

Moore SI, Huffnagle GB, Chen GH, White ES, Mancuso P. Leptin modulates neutrophil phagocytosis of Klebsiella pneumoniae. Infect Immun. 2003; 71(7): 4182-5.

Morceli G, Honorio-França AC, Fagundes DL, Calderon IM, França EL. Antioxidant effect of melatonin on the functional activity of colostral phagocytes in diabetic women. Plos One.

2013;8(2):1-8.

Mores L, França EL, Silva NA, Suchara EA, Honorio-França AC. Nanoparticles of barium induce apoptosis in human phagocytes. Int J Nanomedicine 2015;10:6021-6.

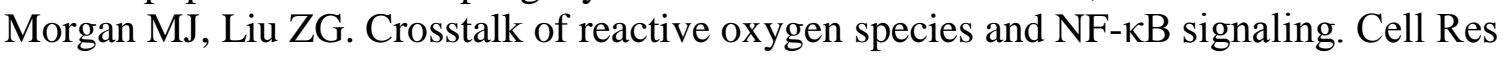
2011;21(1):103-15.

Morshedi A; Zarkesh-Esfahani SH, Behjati M. Effect of leptin on neutrophils phagocytosis and lymphocytes apoptosis challenge by listeria monocytogenes and Escherichia coli. Jundishapur J Microbiol. 2013;6(7):1-8.

Mouzon, SH, Catalo PC. Adiponectin: are measurements clinically useful in pregnancy? Diabetes Care. 2013;36(6):1434-6.

Negro S, Boutsikou T, Briana DD, Tataranno ML, Longini M, Proietti F, et al. Maternal obesity and perinatal oxidative stress: the strength of the association. J Biol Regul Homeost Agents. 2017;31:221-7.

Newburg D, Woo JG, Morrow AL. Characteristics and potential functions of human milk adiponectin. J Pediatr. 2010;156(2 Suppl):S41-6.

Newman G, Gonzalez-Perez RR. Leptin-cytokine crosstalk in breast cancer. Mol Cell Endocrinol. 2014;382(1):570-82. 
Ng M, Fleming T, Robinson M, Thomson B, Graetz N, Margono C, et al. Global, regional, and national prevalence of overweight and obesity in children and adults during 1980-2013: a systematic analysis for the Global Burden of Disease Study 2013. Lancet 2014;384(9945):766-81.

Nieman DC, Henson DA, Nehlsen-Cannarella SL, Ekkens M, Utter AC, Butterworth DE, Fagoaga OR. Influence of obesity on immune function. J Am Diet Assoc. 1999;99(3):294-9.

Nien JK, Mazaki-Tovi S, Romero R, Erez O, Kusanovic JP, Gotsch F, et al. Plasma adiponectin concentrations in non pregnant, normal pregnancy and overweight pregnant women. J Perinat Med. 2007;35(6):522-31.

Nunes P, Demaurex N. The role of calcium signaling in phagocytosis. J Leukoc Biol. 2010;88(1):57-68.

Ohashi K, Parker JL, Ouchi N, Higuchi A, Vita JA, Gokce N, et al. Adiponectin promotes macrophage polarization toward an anti-inflammatory phenotype. J Biol Chem.

2010;285(9):6153-60.

Ortega-García JA, Kloosterman N, Alvarez L, Tobarra-Sánchez E, Cárceles-Álvarez A, Pastor-Valero R, et al. Full breastfeeding and obesity in children: a prospective study from birth to 6 years. Child Obes. 2018;14(5):327-37.

Ozenoglu A, Sokulmez Kaya P, Asal Ulus C, Alakus K. The relationship of knowledge and breastfeeding practice to maternal BMI. Ecol Food Nutr. 2017;56(2):152-70.

Padra JT, Seres I, Fóris G, Paragh GJ, Kónya G, Paragh G. Leptin triggers $\mathrm{Ca}^{2+}$ imbalance in monocytes of overweight subjects. Neuropeptides 2012;46(5):203-09.

Pahwa R, Adams-Huet B, Jialal I. The effect of increasing body mass index on cardiometabolic risk and biomarkers of oxidative stress and inflammation in nascent metabolic syndrome. J Diabetes Complications 2017;31(5):810-13.

Park PH. Autophagy induction: a critical event for the modulation of cell death/survival and inflammatory responses by adipokines. Arch Pharm Res. 2018;41(11):1062-73.

Pevet P, Klosen P, Felder-Schmittbuhl MP. The hormone melatonin: animal studies. Best Pract Res Clin Endocrinol Metab. 2017;31(6):547-59. 
Pillon NJ, Chan KL, Zhang S, Mejdani M, Jacobson MR, Ducos A, et al. Saturated fatty acids activate caspase-4/5 in human monocytes, triggering IL-1 $\beta$ and IL-18 release. Am J Physiol Endocrinol Metab. 2016;311(5):E825-E835.

Pinto KA, Griep RH, Rotenberg L, Almeida MCC, Barreto RS, Aquino EML. Gender, time use and overweight and obesity in adults: Results of the Brazilian Longitudinal Study of Adult Health (ELSA-Brasil). PLoS One 2018;13(3):e0194190.

Pinton P, Giorgi C, Siviero R, Zecchini E, Rizzuto R. Calcium and apoptosis: ERmitochondria $\mathrm{Ca}^{2+}$ transfer in the control of apoptosis. Oncogene. 2008;27(50):6407-18.

Pires-Lapa MA, Tamura EK, Salustiano EMA, Markus RP. Melatonin synthesis in human colostrum mononuclear cells enhances dectin-1-mediated phagocytosis by mononuclear cells. J Pineal Res. 2013;55(3):240-6.

Pontes GN, Cardoso EC, Carneiro-Sampaio MM, Markus RP. Injury switches melatonin production source from endocrine (pineal) to paracrine (phagocytes) - melatonin in human colostrum and colostrum phagocytes. J Pineal Res. 2006;41(2):136-41.

Pontes GN, Cardoso EC, Carneiro-Sampaio MM, Markus RP. Pineal melatonin and the innate immune response: the TNF-alpha increase after cesarean section suppresses nocturnal melatonin production. J Pineal Res. 2007;43(4):365-71.

Proença AR, Sertié RA, Oliveira AC, Campaña AB, Caminhotto RO, Chimin P, Lima FB. New concepts in white adipose tissue physiology. Braz J Med Biol Res. 2014;47(3):192-205.

Pourahmad J, Salimi A. Isolated human peripheral blood mononuclear cell (PBMC), a cost effective tool for predicting immunosuppressive effects of drugs and xenobiotics. Iran $\mathbf{J}$ Pharm Res. 2015 Autumn; 14(4): 979.

Radogna F, Paternoster L, De Nicola M, Cerella C, Ammendola S, Bedini A, et al. Rapid and transient stimulation of intracellular reactive oxygen species by melatonin in normal and tumor leukocytes. Toxicol Appl Pharmacol. 2009a;239(1):37-45.

Radogna F, Sestili P, Martinelli C, Paolillo M, Paternoster L, Albertini MC, et al. Lipoxygenase-mediated pro-radical effect of melatonin via stimulation of arachidonic acid metabolism. Toxicol Appl Pharmacol. 2009B;238:170-7. 
Radogna F, Albertini MC, De Nicola M, Diederich M, Bejarano I, Ghibelli L. Melatonin promotes Bax sequestration to mitochondria reducing cell susceptibility to apoptosis via the lipoxygenase metabolite 5-hydroxyeicosatetraenoic acid. Mitochondrion 2015;21:113-21.

Ramsay JE, Ferrell WR, Crawford L, Wallace AM, Greer IA, Sattar N. Maternal obesity is associated with dysregulation of metabolic, vascular, and inflammatory pathways. J Clin Endocrinol Metab. 2002;87(9):4231-7.

Ralston J, Brinsden H, Buse K, Candeias V, Caterson I, Hassell T, et al. Time for a new obesity narrative. Lancet 2018;392(10156):1384-6.

Reiter RJ. The ageing pineal gland and its physiological consequences. Bioessays 1992;14(3):169-75.

Reiter RJ, Tan DX, Terron MP, Flores LJ, Czarnocki Z. Melatonin and its metabolites: new findings regarding their production and their radical scavenging actions. Acta Biochim Pol 2007;54(1):1-9.

Richardson MP, Ayliffe MJ, Helbert M, Davies EG. A simple flow cytometry assay using dihydrorhodamine for the measurement of the neutrophil respiratory burst in whole blood: comparison with the quantitative nitrobluetetrazolium test. J Immunol Methods. 1998;219(12):187-93.

Rogero MM, Calder PC. Obesity, inflammation, toll-like receptor 4 and fatty acids. Nutrients. 2018;10(4):1-19.

Sánchez-Pozo C, Rodriguez-Baño J, Domínguez-Castellano A, Muniain MA, Goberna R, Sánchez-Margalet V. Leptin stimulates the oxidative burst in control monocytes but attenuates the oxidative burst in monocytes from HIV-infected patients. Clin Exp Immunol. 2003;134(3):464-9.

Sanz-Garcia C, Nagy LE, Lasunción MA, Fernandez M, Alemany S. Cot/tpl2 participates in the activation of macrophages by adiponectin. J Leukoc Biol 2014;95:917-30.

Sato M, Kanikowska D, Iwase S et al. Seasonal differences in melatonin concentrations and heart rates during sleep in obese subjects in Japan. Int J Biometeorol 2013;57:743-48.

Savino F, Liguori SA, Fissore MF, Oggero R. Breast milk hormones and their protective effect on obesity. Int J Pediatr Endocrinol. 2009; 2009:p.1-8. 
Savino F, Lupica MM, Benetti S, Petrucci E, Liguori SA, Cordero Di Montezemolo L. Adiponectin in breast milk: relation to serum adiponectin concentration in lactating mothers and their infants. Acta Paediatr. 2012;101(10):1058-62.

Severin R, Sabbahi A, Mahmoud AM, Arena R, Phillips SA. Precision medicine in weight loss and healthy living. Prog Cardiovasc Dis. 2019; S0033-0620:1-26.

Sharma AJ, Dee DL, Harden SM. Adherence to breastfeeding guidelines and maternal weight 6 years after delivery. Pediatrics. 2014;134 Suppl 1:S42-9.

Shirshev SV, Orlova EG. Molecular mechanisms of regulation of functional activity of mononuclear phagocytes by leptin. Biochemistry (Mosc). 2005;70:841-7.

Stewart FM, Freeman DJ, Ramsay JE, Greer IA, Caslake M, Ferrell WR. Longitudinal assessment of maternal endothelial function and markers of inflammation and placental function throughout pregnancy in lean and obese mothers. J Clin Endocrinol Metab. 2007;92(3):969-75.

Sun J, Gao Y, Yao T, Huang Y, He Z, Kong X, et al. Adiponectin potentiates the acute effects of leptin in arcuate Pomc neurons. Mol Metab. 2016;5:882-91.

Szewczyk-Golec K, Woźniak A, Reiter RJ. Inter-relationships of the chronobiotic, melatonin, with leptin and adiponectin: implications for obesity. J Pineal Res. 2015;59:277-91.

Tan DX, Manchester LC, Terron MP, Flores LJ, Reiter RJ. One molecule, many derivatives: a never-ending interaction of melatonin with reactive oxygen and nitrogen species? J Pineal Res. 2007;42:28-42.

Tan DX, Manchester LC, Fuentes-Broto L, Paredes SD, Reiter RJ. Significance and application of melatonin in the regulation of brown adipose tissue metabolism: relation to human obesity. Obes Ver. 2011;12:167-88.

Taylor PD, Samuelsson AM, Poston L. Maternal obesity and the developmental programming of hypertension: a role for leptin. Acta Physiol (Oxf). 2014;210(3):508-23.

Teixeira TM, Costa DC da, Resende AC, Soulage CO, Bezerra FF, Daleprane JB. Activation of Nrf2-antioxidant signaling by 1,25-dihydroxycholecalciferol prevents leptin-induced oxidative stress and inflammation in human endothelial cells. J Nutr. 2017;147:506-13. 
Trend S, de Jong E, Lloyd ML, Kok CH, Richmond P, Doherty DA, et al. Leukocyte populations in human preterm and term breast milk identified by multicolour flow cytometry. PLoS One. 2015;10(8):1-15.

Underhill DM. Macrophage recognition of zymosan particles. J Endotoxin Res 2003;9:17680 .

van Zyl S, van der Merwe LJ, van Rooyen FC, Joubert G, Walsh CM. The relationship between obesity, leptin, adiponectin and the components of metabolic syndrome in urban African women, Free State, South Africa. SAJCN. 2017,30(3):68-73.

von Gall C, Stehle JH, Weaver DR. Mammalian melatonin receptors: molecular biology and signal transduction. Cell Tissue Res 2002;309:151-62.

Whitaker R C. Predicting preschooler obesity at birth: the role of maternal obesity in early pregnancy. Pediatrics. 2004;114(1):e29-36.

WHO. Fact sheet: obesity and overweight. February, 2018. http://www.who.int/newsroom/fact-sheets/detail/obesity-and-overweight (accesso em 27 Out, 2018).

Young BE, Patinkin ZW, Pyle L, et al. Markers of oxidative stress in human milk do not differ by maternal BMI but are related to infant growth trajectories. Matern Child Health $\mathrm{J}$ 2017;21:1367-76.

Zhang Y, Proenca R, Maffei M, Barone M, Leopold L, Friedman JM. Positional cloning of the mouse obese gene and its human homologue. Nature 1994;372:425-32. 
ANEXOS 
ANEXO 1 - QUESTIONÁRIO

\section{FICHA PARA COLETA DE DADOS INDIVIDUAIS}

Projeto: "Aleitamento materno: influência do sobrepeso e obesidade materna sobre componentes imunológicos do colostro humano".

Pesquisador Responsável: Prof. Dr. Luiz Carlos de Abreu

Pesquisadora executante: Tassiane Cristina Morais

\section{DADOS DA PACIENTE}

Nome:

Paciente $\mathrm{n}^{\circ}$

Data:...................

Registro.

Data de nascimento:...................

$R G$

Qual o seu endereço (rua, $\mathrm{n}^{\circ}$, cidade, CEP):

Telefone para contato

Qual é sua nacionalidade?

Cor: Branca ( ) Parda ( ) Negra ( ) Amarela ( )

\section{Estado civil}
( ) casada
( )divorciada
( )solteira
( )amasiada
( )viúva

Escolaridade: Qual a sua escolaridade:

Hábito de fumar: Nunca fumou ( ) Parou de fumar ( ) há quanto tempo?.

Por quanto tempo fumou?.

$\mathrm{N}^{\mathrm{o}}$ de cigarros/dia.

Tipo: ( )cachimbo ( ) charuto ( ) palha ( ) papel com filtro ( ) outros

Convive com fumante? Sim ( ) Não ( )

Local: ( )casa ( )trabalho ( )outros

$\mathrm{N}^{\circ}$. de pessoas?. .Quantas horas/dias? 


\section{Consume bebida alcoólica?}

Quanto?

Usa algum tipo de drogas? Sim（ ） Não（ ）

Tipo: ( )maconha ( )cocaína ( )craque ( )outros

Vias de administração: ( )inalatória ( )endovenosa ( )

outras Já usou? Sim（ ） Não（）

Quanto tempo?

Parou há quanto tempo?

Contato com substâncias tóxicas? Sim ( ) Não ( )

Quais?.

Por quanto tempo (meses)?

Período sem contato com a (s) substância (s) (meses):

Possui algum tipo de doença? Sim ( ) Não ( )

Qual(is)?
Não ( )

Mais de 7 doses/sem ( )

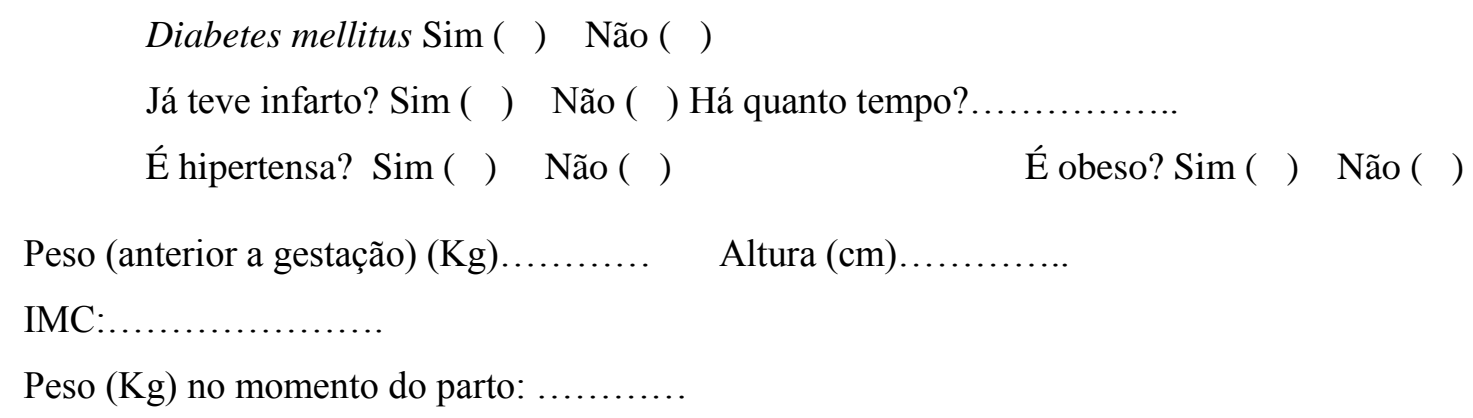

Diabetes mellitus Sim ( ) Não ( )

Já teve infarto? Sim ( ) Não ( ) Há quanto tempo?.

É hipertensa? Sim ( ) Não ( ) É obeso? Sim ( ) Não ( )

Peso (anterior a gestação) $(\mathrm{Kg}) \ldots \ldots \ldots \ldots$ Altura $(\mathrm{cm})$

IMC:.

Peso (Kg) no momento do parto:

Toma medicamento? Sim ( ) Não ( ) Qual(is)? Em que dosagem?

Profissão: Há exigência de esforço físico? Sim ( ) Não ( )

Pratica exercício físico? Sim ( ) Não ( )

Com que freqüência?

\section{HISTÓRICO FAMILIAR}

\section{Possui algum parente com:}

$\begin{array}{lll}\text { Diabetes Mellitus ( ) } & \text { Obesidade ( ) } & \text { Hipertensão ( ) } \\ \text { Doença cardiovascular ( ) } & \text { Hipercolesterolemia ( ) } & \text { Outros ( ) }\end{array}$

Quem? 


\section{HISTÓRIA GESTACIONAL}

Gestação: Pariadade:

Abortos:

..Cesáreas:

DUM: DPP:

IG (Ultrassom) IG (DUM)

Pré-natal: Sim ( ) Não ( ) $\quad \mathrm{N}^{\circ}$ de consultas?

Intercorrências durante a gravidez: ( )náuseas ( )vômitos ( ) dor abdominal ( )dor para urinar ( )corrimentos ( ) sangramento ( )outros

Doenças durante a gestação: Sim ( ) Não ( ) Tipo?

Tratamento: Sim ( ) Não ( ) Qual?

Fatores de risco para HIV? Sim ( ) Não ( )

DADOS DO CARTÃO DE PRÉ-NATAL:

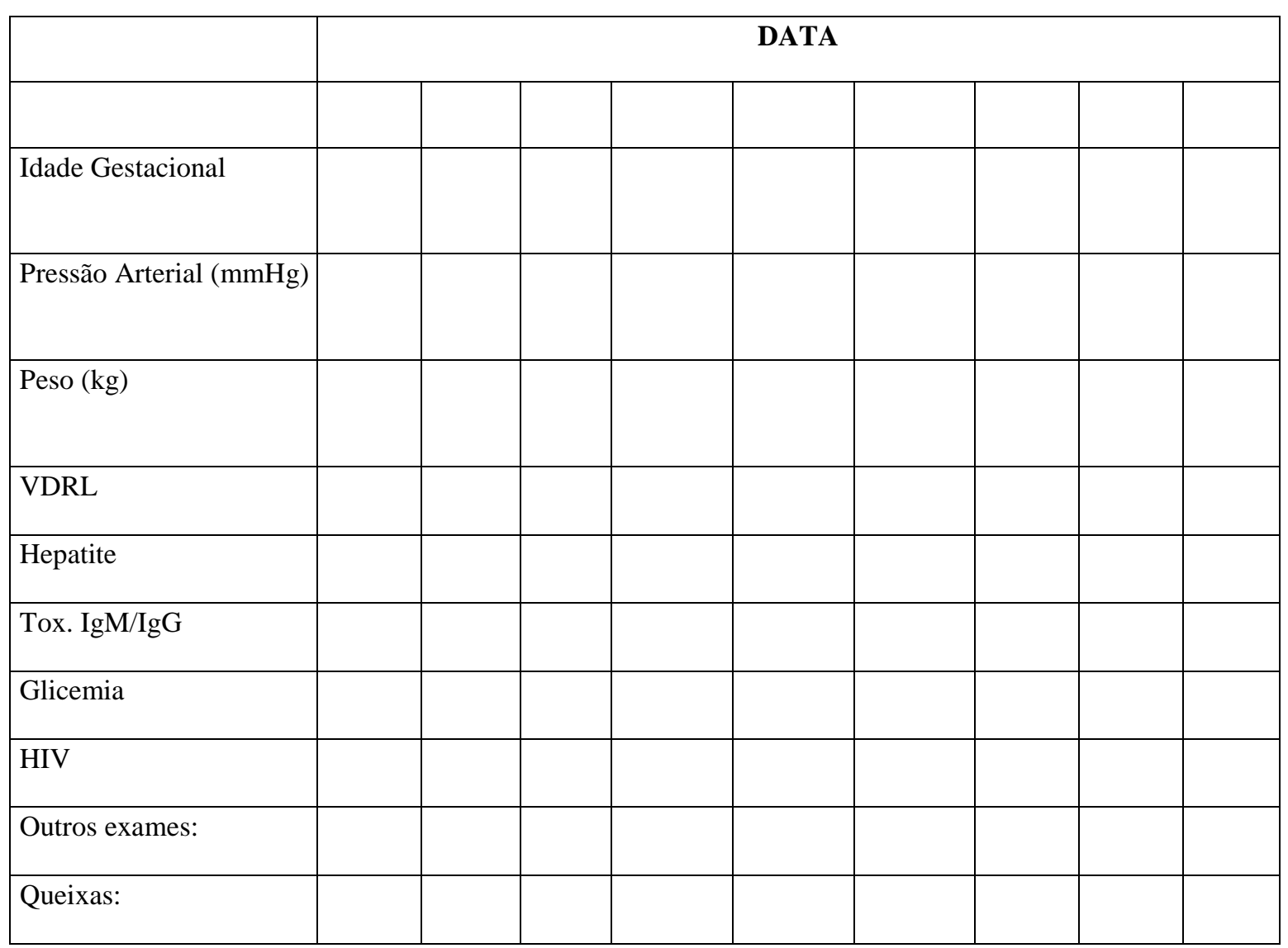




\section{DADOS DO RECÉM-NASCIDO (RN)}

Data de Nascimento:

Tipo de parto: ( )normal ( )cesária ( )fórceps ( )outros

Sinais de sofrimento fetal? Sim ( ) Não ( )

Qual?.......

Mecônio: Sim ( ) Não ( )

Tipo: ( )fluido ( ) moderado ( ) espesso

Apgar: 1' .5

New Ballard (NB):

Sexo:.....Peso:

Estatura:

PC:

PT:

PA:

Classificação do RN: ( ) PIG ( ) AIG ( ) GIG

Necessidade de reanimação: ( ) máscara ( )ventilação sob pressão ( ) intubação

( ) drogas Quais drogas?

Anomalias ou malformações: Sim ( ) Não ( )

Quais? 


\title{
ANEXO 2 - TERMO DE CONSCENTIMENTO LIVRE ESCLARECIDO
}

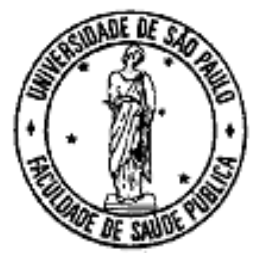

\author{
UNIVERSIDADE DE SÃO PAULO \\ FACULDADE DE SAÚDE PÚBLICA
}

\section{TERMO DE CONSENTIMENTO LIVRE E ESCLARECIDO}

\section{I - TÍTULO DA PESQUISA: ATIVIDADE FUNCIONAL DE CÉLULAS MONONUCLEARES DO COLOSTRO DE MÃES COM SOBREPESO E OBESIDADE E O PAPEL DOS AGENTES IMUNOMODULADORES: ADIPONECTINA, LEPTINA E MELATONINA.}

1. Justificativa e objetivos: Prezada senhora, como já lhe foi informado, o excesso de peso materno pode ocasionar alterações no organismo diminuindo os mecanismos naturais de defesa. É possível que isto influencie na qualidade do leite materno que protege a criança contra infecções. Por este motivo, para o desenvolvimento deste projeto, será necessário a coleta de leite materno (colostro) para avaliarmos se o excesso de peso influencia na atividade das células do leite humano, que são um dos mecanismos de proteção do bebê. A coleta do colostro será realizada por ordenha manual, sendo um processo indolor, apresentando incômodo ou não. Caso a senhora não queira participar da pesquisa, você tem todo o direito de se recusar. Caso comece na pesquisa e depois deseje desistir, também estará garantida a assistência prestada por esta unidade de saúde para você e sua criança.

2. Procedimentos que serão utilizados e propósitos, incluindo a identificação dos procedimentos que são experimentais: Será coletado uma amostra de colostro para realização de experimentos laboratoriais para determinar algumas das atividades anti-infecciosas do leite humano.

3. Desconfortos e riscos esperados: $\mathrm{O}$ desconforto ocasionado à senhora será pequeno. A coleta do colostro não causa dor, pode apresentar incômodo ou não. O risco apresentado é mínimo e não há nenhum risco ao recém-nascido. Em caso a senhora relatar qualquer incômodo, a coleta do colostro será interrompida imediatamente.

4. Benefícios que poderão ser obtidos: Não há benefício direto para a senhora, pois trata-se de estudo com análise laboratorial e somente no final do estudo poderemos concluir a presença de algum benefício. No entanto, acredita-se que o benefício a ser obtido será um melhor conhecimento sobre a influência do excesso de peso na qualidade do leite materno. Este conhecimento, favorece o desenvolvimento de condutas futuras que poderão beneficiar os pacientes evitando maiores riscos aos recém-nascidos.

\section{II - OBSERVAÇÃO:}

$\checkmark$ Atendendo a resolução CNS 466/12, este Termo de Consentimento Livre e Esclarecido é elaborado em duas vias, devidamente assinadas pelo pesquisador, uma via deste termo será entregue ao participante da pesquisa e a outra ficará sob a guarda pesquisador.

$\checkmark$ A senhora terá acesso, a qualquer tempo, às informações sobre procedimentos, riscos e benefícios relacionados à pesquisa, inclusive para diminuir eventuais dúvidas.

$\checkmark$ A senhora terá direito de retirar seu consentimento a qualquer momento e deixar de participar do estudo, sem que isto traga prejuízo à continuidade da assistência.

$\checkmark$ Disponibilidade de assistência, por eventuais danos à saúde, decorrentes da pesquisa. 
$\checkmark$ Se for detectado, algum problema de saúde previamente ao início da pesquisa, a senhora será encaminhada ao Sistema Único de Saúde (SUS) para o tratamento.

$\checkmark$ Se houver intercorrência de saúde decorrente da pesquisa, a senhora será atendida no Hospital Universitário da USP, São Paulo-SP, segundo o critério de assistência do mesmo. Se houver necessidade de atendimento de maior complexidade, a encaminharemos ao SUS.

$\checkmark$ A senhora terá total confidencialidade, sigilo e privacidade dos dados deste estudo.

$\checkmark$ A duração prevista da pesquisa é de 4 anos, mas o material será coletado apenas uma vez.

III - INFORMAÇÕES DE NOMES, ENDEREÇOS E TELEFONES DOS RESPONSÁVEIS PELO ACOMPANHAMENTO DA PESQUISA, PARA CONTATO EM CASO DE INTERCORRÊNCIAS CLÍNICAS E REAÇÕES ADVERSAS:

\section{NOME DOS PESQUISADORES ENVOLVIDOS:}

Pesquisadora executante: Tassiane Cristina Morais - tassi.morais@usp.br

Pesquisador responsável: Prof. Dr. Luiz Carlos de Abreu - luizcarlos@usp.br

Faculdade de Saúde Pública - Universidade de São Paulo: Endereço: Av. Dr. Arnaldo, 715 CEP:01.246-904 - São Paulo/SP. Telefone: 3061-7703.

Em caso de dúvida a senhora também pode entrar em contato com o Comitê de Ética em Pesquisa da Faculdade de Saúde Pública da Universidade de São Paulo, situado à Av. Dr. Arnaldo, 715, Cerqueira César - CEP 01246-904, São Paulo, SP - Telefone: (11) 3061-7779 / e-mail: coep@ fsp.usp.br e/ou Comitê de Ética em Pesquisa do Hospital Universitário da USP, situado à Av. Prof. Lineu Prestes, 2565 - Cidade Universitária - CEP: 05508-000 - São Paulo, SP - Telefone: (11) 3091-9457 / e-mail: cep@ hu.usp.br .

\section{IV - INFORMAÇÕES DO PACIENTE}

Nome do paciente:

Documento de identidade $\mathbf{N}^{\circ}$ :

Data de nascimento: ............................................

Endereço: Cidade:

... Número: Bairro:

CEP: Telefone: DDD ( )

V - ENCERRAMENTO DO TERMO DE CONSENTIMENTO LIVRE E ESCLARECIDO

"Declaro que, após convenientemente esclarecido pelo pesquisador e ter entendido o que me foi explicado, consinto em participar do presente projeto de pesquisa."

SÃO PAULO - São Paulo, de $. .201 . . . . . .$. 
ANEXO 3 - PARECER CONSUBSTANCIADO DO COMITÊ DE ÉTICA

\author{
FACULDADE DE SAÚDE \\ PÚBLICA DA UNIVERSIDADE \\ DE SÃO PAULO
}

\title{
PARECER CONSUBSTANCIADO DO CEP
}

\section{DADOS DA EMENDA}

Título da Pesquisa: ATIVIDADE FUNCIONAL DE CÉLULAS MONONUCLEARES DO COLOSTRO DE MÃES COM SOBREPESO E OBESIDADE E O PAPEL DOS AGENTES IMUNOMODULADORES: ADIPONECTINA, LEPTINA E MELATONINA.

Pesquisador: TASSIANE CRISTINA MORAIS

Área Temática:

Versão: 3

CAAE: 46643515.0 .0000 .5421

Instituição Proponente:Faculdade de Saúde Pública da Universidade de São Paulo - FSP/USP

Patrocinador Principal: Financiamento Próprio

\section{DADOS DO PARECER}

Número do Parecer: 1.420 .479

\section{Apresentação do Projeto:}

Trata-se de emenda ao projeto anteriormente aprovação no Comitê de Ética em Pesquisa da Faculdade de Saúde Pública da Universidade de São Paulo- FSP/USP, com o título de "Aleitamento Materno: influência do sobrepeso e obesidade materna sobre

componentes imunológicos do colostro humano". A proponente justifica adequadamente a emenda e propõe três modificações: mudança no título do projeto, ampliação da amostra e mudança do local de coleta de dados.

\section{Objetivo da Pesquisa:}

Avaliar a influência do sobrepeso e obesidade sobre a atividade funcional de células mononucleares do colostro de mães com sobrepeso e obesidade e o papel dos agentes imunomoduladores: adiponectina, leptina e melatonina.

\section{Avaliação dos Riscos e Benefícios:}

Os riscos decorrentes da participação da pesquisa são mínimos e envolvem o uso do material biológico (colostro) para fins científicos, estando garantido sigilo da identidade da nutriz, livre de coação ou conflito de interesses da instituição ou de pessoas envolvidas no projeto. As coletas respeitarão os protocolos técnicos

Endereço: Av. Doutor Arnaldo, 715

Bairro: Cerqueira Cesar CEP: $01.246-904$

UF: SP Município: SAOPAULO

Telefone: (11)3061-7779 Fax: (11)3061-7779 E-mail: coep@fsp.usp.br 


\section{FACULDADE DE SAÚDE PÚBLICA DA UNIVERSIDADE DE SÃO PAULO}

Continuação do Parecer: 1.420 .479

dos serviços envolvidos. As nutrizes serão previamente informadas e o material somente será coletado ou utilizado sob o consentimento em formulário específico.

Os benefícios estão descritos adequadamente.

Comentários e Considerações sobre a Pesquisa:

As modificações feitas na versão anteriormente aprovada foram pontuais e justificáveis, no intuito de adequá -la ao novo local de coleta e garantir as estimativa das variáveis de interesse. Foram anexados a plataforma, os formulários exigidos pelo novo local de coleta de dados (HU/USP).

Considerações sobre os Termos de apresentação obrigatória:

TCLE adequado

Termo de anuência da instituição adequado

Recomendações:

Conclusões ou Pendências e Lista de Inadequações:

Pela aprovação

Considerações Finais a critério do CEP:

Este parecer foi elaborado baseado nos documentos abaixo relacionados:

\begin{tabular}{|c|c|c|c|c|}
\hline Tipo Documento & Arquivo & Postagem & Autor & Situação \\
\hline $\begin{array}{l}\text { Informações Básicas } \\
\text { do Projeto }\end{array}$ & $\begin{array}{l}\text { PB_INFORMAÇÕES_BÁSICAS_642610 } \\
\text { E11.pdf }\end{array}$ & $\begin{array}{c}30 / 12 / 2015 \\
00: 50: 15\end{array}$ & & Aceito \\
\hline Outros & $\begin{array}{l}\text { CARTA_DE_JUSTIFICATIVA_DA_EME } \\
\text { NDA.pdf }\end{array}$ & $\begin{array}{c}30 / 12 / 2015 \\
00: 48: 06\end{array}$ & $\begin{array}{l}\text { TASSIANE } \\
\text { CRISTINA MORAIS }\end{array}$ & Aceito \\
\hline Outros & Anuencia_CPesq_Tassiane.pdf & $\begin{array}{c}30 / 12 / 2015 \\
00: 42: 52\end{array}$ & $\begin{array}{l}\text { TASSIANE } \\
\text { CRISTINA MORAIS }\end{array}$ & Aceito \\
\hline Outros & TERMO_DE_ANUENCIA.pdf & $\begin{array}{c}30 / 12 / 2015 \\
00: 41: 21\end{array}$ & $\begin{array}{l}\text { TASSIANE } \\
\text { CRISTINA MORAIS }\end{array}$ & Aceito \\
\hline $\begin{array}{l}\text { Declaração de } \\
\text { Instituição e } \\
\text { Infraestrutura }\end{array}$ & Decl_Infraestrutura_Pesq_Tassiane.pdf & $\begin{array}{c}30 / 12 / 2015 \\
00: 39: 17\end{array}$ & $\begin{array}{l}\text { TASSIANE } \\
\text { CRISTINA MORAIS }\end{array}$ & Aceito \\
\hline Outros & \begin{tabular}{|l|} 
Declaracao_sobre_Beneficios_da_Pesq \\
uisa versao 3101 2014.pdf
\end{tabular} & $\begin{array}{c}30 / 12 / 2015 \\
00: 37: 22 \\
\end{array}$ & $\begin{array}{l}\text { TASSIANE } \\
\text { CRISTINA MORAIS }\end{array}$ & Aceito \\
\hline Outros & \begin{tabular}{|l|l|} 
Declaracao_Compromisso_Pesquisador \\
versao 3101 & $2014 . p d f$ \\
\end{tabular} & $\begin{array}{c}30 / 12 / 2015 \\
00: 36: 27\end{array}$ & $\begin{array}{l}\text { TASSIANE } \\
\text { CRISTINA MORAIS } \\
\end{array}$ & Aceito \\
\hline Cronograma & CRONOGRAMA_DE_EXECUCAO.pdf & $\begin{array}{c}30 / 12 / 2015 \\
00: 31: 04\end{array}$ & $\begin{array}{l}\text { TASSIANE } \\
\text { CRISTINA MORAIS } \\
\end{array}$ & Aceito \\
\hline Orçamento & Orcamento_Financeiro_versao_31_01 & $30 / 12 / 2015$ & TASSIANE & Aceito \\
\hline
\end{tabular}

Endereço: Av. Doutor Arnaldo, 715
Bairro: Cerqueira Cesar
CEP: $01.246-904$
UF: SP
Municipio: SAOPAULO
Telefone: (11)3061-7779
Fax: (11)3061-7779
E-mail: coep@fsp.usp.br 


\section{FACULDADE DE SAÚDE PÚBLICA DA UNIVERSIDADE DE SÃO PAULO}

Continuação do Parecer: 1.420.479

\begin{tabular}{|l|l|c|l|c|}
\hline Orçamento & 2014.pdf & $00: 29: 12$ & MORAIS & Aceito \\
\hline Outros & INSTRUMENTO_DE_COLETA_QUESTI & $\begin{array}{c}30 / 12 / 2015 \\
00: 27: 37\end{array}$ & $\begin{array}{l}\text { TASSIANE } \\
\text { CRISTINA MORAIS }\end{array}$ & Aceito \\
\hline Outros & Cadastro_Protocolo_Pesquis_versao_31 & $\begin{array}{c}30 / 12 / 2015 \\
00: 25: 11\end{array}$ & $\begin{array}{l}\text { TASSIANE } \\
\text { CRISTINA MORAIS }\end{array}$ & Aceito \\
\hline $\begin{array}{l}\text { TCLE / Termos de } \\
\text { Assentimento / } \\
\text { Justificativa de } \\
\text { Ausência }\end{array}$ & TERMO_DE_CONSENTIMENTO_FSP_- & $\begin{array}{c}30 / 12 / 2015 \\
00: 22: 01\end{array}$ & $\begin{array}{l}\text { TASSIANE } \\
\text { CRISTINA MORAIS }\end{array}$ & Aceito \\
\hline $\begin{array}{l}\text { Projeto Detalhado / } \\
\text { Brochura } \\
\text { Investigador }\end{array}$ & Projeto_FSP_HU.pdf & & & \\
\hline Folha de Rosto & Folha_De_Rosto_Assinada.PDF & $\begin{array}{c}28 / 12 / 2015 \\
11: 20: 58\end{array}$ & $\begin{array}{l}\text { TASSIANE } \\
\text { CRISTINA MORAIS }\end{array}$ & Aceito \\
\hline
\end{tabular}

Situação do Parecer:

Aprovado

Necessita Apreciação da CONEP:

Não

SAO PAULO, 23 de Fevereiro de 2016

Assinado por:

Maria Regina Alves Cardoso

(Coordenador)

\footnotetext{
Endereço: Av. Doutor Amaldo, 715

Bairro: Cerqueira Cesar

CEP: $01.246-904$

UF: SP

Município: SAOPAULO

Telefone: (11)3061-7779

Fax: (11)3061-7779

E-mail: coep@fsp.usp.br
} 
São Paulo, 18 de março de 2016.

$I^{m o(a)} \cdot S^{r(a)}$

Tassiane Cristina Morais

Departamento de Saúde Materno-Infantil da Faculdade de Saúde Pública UNIVERSIDADE DE SÃO PAULO

REFERENTE: Projeto de Pesquisa "Atividade funcional de células mononucleares do colostro de mães com sobrepeso e obesidade e o papel dos agentes imunomoduladores: adiponectina, leptina e melatonina"

Pesquisador(a) responsável: Tassiane Cristina Morais

Orientador: Prof. Dr. Luiz Carlos de Abreu

CAAE: 46643515.0 .3001 .0076

Registro CEP-HU/USP: 1526/16

Prezado(a) Senhor(a)

O Comitê de Ética em Pesquisa do Hospital Universitário da Universidade de São Paulo, em reunião ordinária realizada no dia 18 de março de 2016 analisou o Projeto de Pesquisa acima citado, considerando-o como APROVADO, bem como o seu Termo de Consentimento Livre e Esclarecido.

Lembramos que cabe ao pesquisador elaborar e apresentar a este Comitê, relatórios parciais e final, de acordo com a Resolução n 466/2012 do Conselho Nacional de Saúde, inciso XI.2, letra "d".

O primeiro relatório está previsto para 18 de setembro de 2016.

Atenciosamente,

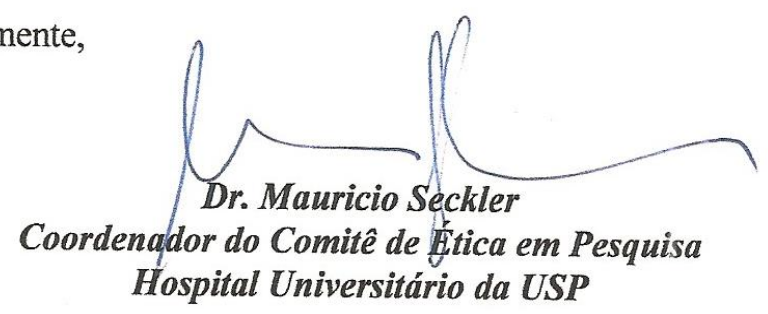


ANEXO 4 - VALORES BRUTOS DAS MÉDIAS E DESVIO PADRÃO DOS RESULTADOS DE FAGOCITOSE, ESPÉCIES REATIVAS DE OXIGÊNIO, NÍVEIS DE CÁLCIO INTRACELULAR E APOPTOSE.

Tabela 2 - Média e desvio padrão dos dados apresentados nos gráficos da sessão Resultados, referentes a atividade funcional dos fagócitos do colostro humano, segundo o estado nutricional pré-gestacional.

\begin{tabular}{|c|c|c|}
\hline Variáveis & $\begin{array}{c}\text { Eutrófico } \\
\text { (Média } \pm \mathrm{DP}) \\
\end{array}$ & $\begin{array}{c}\text { Excesso de Peso } \\
(\text { Média } \pm \text { DP }) \\
\end{array}$ \\
\hline \multicolumn{3}{|l|}{ Índice de Fagocitose (\% de células) } \\
\hline Células+Zy+meio 199 & $38,51( \pm 5,11)$ & $33,02( \pm 4,27)^{\#}$ \\
\hline Células+Zy+Adiponectina & $39,9( \pm 3,73)$ & $40,96( \pm 6,09)^{*}$ \\
\hline Células+Zy+Leptina & $36,81( \pm 3,84)$ & $39,06( \pm 3,82)^{*}$ \\
\hline Células+Zy+Melatonina & $42,72( \pm 2,96)^{*}$ & $40,62( \pm 2,28)^{*}$ \\
\hline Células+Zy+Adiponectina+Leptina & $40,61( \pm 3,74)$ & $41,12( \pm 1,94)^{*}$ \\
\hline Células $+Z y+$ Melatonina+Leptina & $39,73( \pm 4,64)$ & $39,74( \pm 4,04)^{*}$ \\
\hline \multicolumn{3}{|l|}{$\begin{array}{l}\text { Liberação de EROS (intensidade de fluorescência - } \\
\text { DHR123) }\end{array}$} \\
\hline Células+Zy+meio 199 & $20,07( \pm 6,58)$ & $15,32( \pm 1,87)^{\#}$ \\
\hline $\begin{array}{r}\text { Células }+Z y+\text { Adiponectina } \\
\text { Células }+Z y+\text { Leptina } \\
\text { Células }+Z y+\text { Melatonina } \\
\text { Células }+Z y+\text { Adiponectina+Leptina } \\
\text { Células+Zy+Melatonina+Leptina }\end{array}$ & $\begin{array}{l}13,70( \pm 3,43) \\
10,70( \pm 1,14) \\
18,88( \pm 4,96) \\
16,10( \pm 4,17) \\
16,40( \pm 1,82)\end{array}$ & $\begin{array}{l}14,42( \pm 1,60) \\
16,16( \pm 1,55)^{\# *} \\
14,19( \pm 3,92)^{\#} \\
17,56( \pm 2,41)^{*} \\
14,22( \pm 2,09)\end{array}$ \\
\hline \multicolumn{3}{|l|}{$\begin{array}{l}\text { Níveis de Cálcio Intracelular (intensidade de } \\
\text { fluorescência- FLUO-3 AM) }\end{array}$} \\
\hline $\begin{array}{r}\text { Células }+Z y+\text { meio } 199 \\
\text { Células }+Z y+\text { Adiponectina } \\
\text { Células+Zy+Leptina } \\
\text { Células }+Z y+\text { Melatonina } \\
\text { Células }+Z y+\text { Adiponectina+Leptina } \\
\text { Células+Zy+Melatonina+Leptina }\end{array}$ & $\begin{array}{l}2,54( \pm 0,56) \\
2,89( \pm 0,85) \\
2,51( \pm 0,47) \\
2,95( \pm 0,64) \\
2,53( \pm 0,72) \\
2,36( \pm 0,79)\end{array}$ & $\begin{array}{l}2,48( \pm 0,59) \\
3,64( \pm 1,08)^{\# *} \\
1,9( \pm 0,58)^{\# *} \\
3,38( \pm 1,39) \\
2,29( \pm 0,65) \\
2,43( \pm 0,67)\end{array}$ \\
\hline \multicolumn{3}{|l|}{$\begin{array}{l}\text { Índice de Apoptose (média da intensidade de } \\
\text { fluorescência de FITC-Annexin-V) }\end{array}$} \\
\hline $\begin{array}{r}\text { Células+Zy+meio } 199 \\
\text { Células }+Z y+\text { Adiponectina } \\
\text { Células+Zy+Leptina } \\
\text { Células+Zy+Melatonina } \\
\text { Células+Zy+Adiponectina+Leptina } \\
\text { Células+Zy+Melatonina+Leptina }\end{array}$ & $\begin{array}{l}0,82( \pm 0,11) \\
0,82( \pm 0,20) \\
0,80( \pm 0,32) \\
0,84( \pm 0,09) \\
0,85( \pm 0,11) \\
0,82( \pm 0,11)\end{array}$ & $\begin{array}{l}0,86( \pm 0,13) \\
0,87( \pm 0,29) \\
0,79( \pm 0,11) \\
0,73( \pm 0,06) \\
1,07( \pm 0,26)^{\#^{*}} \\
0,78( \pm 0,08)^{\#^{*}}\end{array}$ \\
\hline
\end{tabular}

Os resultatos foram avaliados por ANOVA, seguido de Teste de Tukey, os dados foram expressos em média $( \pm D P),\left(n=10\right.$ por tratamento e experimento), indicando: ${ }^{*}$ Diferença estatística $(p<0,05)$ em relação ao mesmo grupo tratado com meio 199 (controle negativo); ${ }^{\#}$ Diferença estatística $(\mathrm{p}<0,05)$ intragrupo (eutrófico x excesso de peso) considerando o mesmo tratamento. 


\section{CURRÍCULO LATTES}

Currículo do Sistema de Currículos Lattes (Tassiane Cristina Morais)

http://buscatextual.cnpq.br/buscatextual/visualizacv.do?id=K4750414U8

\section{Tassiane Cristina Morais}

Endereşo para acessar este CV: http://attes.cnpq.br/1323359812956537

Ultima a tualzaçöo do curícub em 11/05/2019

Doutoranda em Saúde Pública pela Faculdade de Saúde Pública da USP, Mestrado em Imunologia e Parasitologia básicas e aplicadas da Universidade Federal de Mato Grosso. Especialização em Farmácia Clínica. Graduação em Bacharelado em Farmácia, com habilitação em Análises Clínicas, pela Universidade Federal de Mato Grosso,Campus Universitário do Araquaia (2008), atuando principalmente nos seguintes temas: Epidemiologia de doenças crônicas não transmissiveis, Imunologia, Imunomodulação, Saúde-materno Infantil, e Obesidade. (Texto informado pelo autor)

\section{Identificação}

Tassiane Cristina Morais

Nome em citações bibliográficas

MORAIS, T. C.:Morais, Tassiane Cristina;Cristina de Morais, Tassiane

Endereço

Formação acadêmica/titulação 2015

Doutorado em andamento em Saude Publica (Conceito CAPES 6).

Universidade de São Paulo, USP, Brasil.

Título: ALEITAMENTO MATERNO: INFLUNÊNCIA DO SOBREPESO E OBESIDADE MATERNA SOBRE COMPONENTES IMUNOLÓGICOS DO COLOSTRO HUMANO

Orientador: (6) LUIZ CARLOS DE ABREU.

Bolsista do(a): Fundação de Amparo à Pesquisa do Estado de Săo Paulo, FAPESP, Brasil.

Palavras-chave: Colostro; Obesidade; Adiponectina; Leptina; melatonina.

2012-2014 Grande àrea: Ciências da Saúde

Mestrado em Imunologia e Parasitologia Básicas e Aplicadas. Universidade Federal de Mato Grosso, Barra do Garcas., UFMT, Brasil.

Titulo: FLUTUAÇốES TEMPORAIS NA CONCENTRAÇC̄OO DE CITOCINAS EM LEITE HUMANO,Ano de Obtenção: 2014. Orientador: (1) Eduardo Luzia França.

Bolsista do(a): REUNI, REUNI, Brasil.

Palavras-chave: Aleitamento Materno; citocinas; cronobiologia.

Grande área: Ciências Biológicas

$2013-2014$

Grande Area: Cências da Saúde / Área: Medicina / Subárea: Saúde Materno-Infantil.

Especialização em Farmácia Clinica. (Carga Horária: 420h).

Fauldade Montes Belos, FMB, Bras

Titulo: PREVALÊNCIA E PERFIL DE UNIVERSTTÁRIOS USUÁRIOS DE METILFENIDATO EM UMA INSTITUIÇÃ̃O DE ENSINO SUPERIOR NO MUNICÍPIO DE BARRA DO GARÇAS/MT.

Orientador: Marcelo Elias Pereira.

$2003-2008$ Graduação em Bacharelado em Farmácia.

Universidade Federal de Mato Grosso, IuniAraguaia, UFMT/IUNTARAGUAI, Brasil. Título: Uso de medicamentos em grupo de idosos na região de Barra do Garças-MT. Orientador: prof. ${ }^{\circ}$ Ms. Olegário Rosa de Toledo.

Formação Complementar

2018-2018

$2013-2013$

2011- 2011

$2010-2010$

2009-2009

2009-2009

2007-2007

2007- 2007

2007- 2007

$2007-2007$

$2007-2007$

2006- 2007

$2006-2006$

2006-2006

2006- 2006

$2006-2006$

$2005-2005$

$2005-2005$

2005-2005

2004-2005

$2004-2004$
Brazil: Advances in Medical Management of Obesity, (Carga horária: 8h)

Brazil: Advances in Medical Management of
WORLD OBESTY FEDERATION, WOF, Brasil.

$7^{\circ}$ Curso de Citometria de Fluxo. (Carga horária: $44 \mathrm{~h}$ ).

Instituto Adolfo Lutz, IAL, Brasil.

Cosmetologia: Desenvolvimento de Produtos Cosmétic. (Carga horária: 132h).

Instituto Racine, IR, Brasil.

Farmacologia Dermatológica na Prática Farmacêutica. (Carga horária: $30 \mathrm{~h}$ ).

Associação dos Farmacêuticos de Curtitiba e Regiäo, APRIMORE, Brasil.

Psicofarmacologia. (Carga horária: 80h)

Associação Brasilieira de Educação a Distância, ABED, Brasil.

Farmácia Hospitalar. (Carga horária: 60h).

Associação Brasileira de Educação a Distância, ABED, Brasil.

Extensão universitária em Detecção de Parasitoses Intestinais em crianças de. (Carga horária: 160h).

Universidade Federal de Mato Grosso, UFMT, Brasil.

Extensão universitária em Análise de parâmetros bioquimicos em idosos asil. (Carga horária: 160h).

Universidade Federal de Mato Grosso, UFMT, Brasi.

Extensão universitária em Detecçăo de Distưrbios Hematológicos em Idosos mor. (Carga horária: 190h).

Universidade Federal de Mato Grosso, UFMT, Brasi

Extensão universitária em ALEITAMENTO MATERNO: Um gesto que salva.... (Carga horária: 576h).

Universidade Federal de Mato Grosso, luniAraguaia, UFMT/IUNTARAGUAI, Brasil.

Farmácia Clinica e Atençăo Farmacêutica. (Carga horária: 81).

Sociedade Brasileira de Farmácia Hospitalar, SBRAFH, Brasil.

Extensão universitáría em ALETTAMENTO MATERNO: Um gesto que salva.... (Carga horária: 576h).

Universidade Federal de Mato Grosso, IuniAraguaia, UFMT/IUNIARAGUAI, Brasil.

Extensão universitária em Camapanha Sol e Saúde. (Carga horária: 80h),

Universidade Federal de Mato Grosso, IuniAraguaia, UFMT/IUNIARAGUAI, Bras

Extensão universitáría em V Semana do Idoso. (Carga horária: $90 \mathrm{~h}$ ).

Universidade Federal de Mato Grosso, IuniAraguaia, UFMT/IUNIARAGUAI, Brasi.

Princípios Básicos para Dispensação de Medicamento. (Carga horária: 12h).

SOLUÇÃO PLANEJAMENTO E Organizaçōes de Eventos, SOLUÇão, Brasil.

Curso de Injetáveis com Segurança. (Carga horária: 12h).

Universidade Federal de Goiás, UFG, Brasil.

INTERPRETANDO AS DOSAGENS HORMONAIS DE ROTINA. (Carga horária: 8h).

Congresso Brasileiro de Análises Clinicas, CBAC, Brasil.

ACONSELHAMENTO FARMACÊUTICO NA AUTO MEDICAC̄̃̃O RESP. (Carga horária: $8 \mathrm{~h}$ ).

Congresso Brasileiro de Medicamentos Genéricos, CBMG, Brasil.

CERDISCIPLINARIDADE - Fa

Congresso Brasileiro de Medicamentos Genéricos, CBMG, Brasi.

xtensão universitária en Educação em Saưde : Uma experiência. (Carga horária: $40 \mathrm{~b}$ ).

Universidade Federal de Mato Grosso, IuniAraguaia, UFMT/IUNIARAGUAI, Brasil.

Extensão universitária em Farmácia na Praia - Temporada Quarto Crescente. (Carga horária: 40h). 


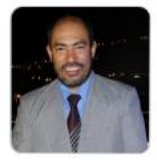

\section{Luiz Carlos de Abreu}

Bolsista de Produtividade em Pesquisa do CNPq - Nível 18

Endereço para acessar este CV: http://lbttes, cnpq.br/6796970691432850

Uitima atualzação do curríub em 23/04/2019

Livre Docente em Saúde Pública (FSP/USP). Pesquisador 1B do CNPq (luiz.abreu@pesquisador.cnpq.br). Chefe do Laboratório de Delineamento de Estudos e Escrita Científica do Centro Universitário Saúde do ABC(Santo André, SP, Brasil), da Fundação do ABC. Professor Adjunto da Escola Superior de Ciências da Santa Casa de Misericórdia de Vitória - EMESCAM. Vice-Presidente da Fundação Centro de Estudos do Crescimento e Desenvolvimento do Ser Humano. Editor-Chefe do Periódico Journal of Human Growth and Development. Visiting scholar at Graduate Entry Medical School in The University of Limerick, Irlanda. (Texto informado pelo autor)

\begin{tabular}{|c|c|}
\hline Nome & Luiz Carlos de Abreu \\
\hline Nome em citações bibliográficas & $\begin{array}{l}\text { Abreu LC; Abreu, LC; ABREU, Luiz Carlos de; de Abreu, Luiz Carlos; } \\
\text { Abreu; DEABREU, LUIZ CARLOS;ABREU, LUIZ CARLOS; Luiz Carlos } \\
\text { CARLOSDE; de Abreu L.C.; DE ABREU, L.C.;DE ABREU, LUIZZ C; DE } \\
\text { C.;ABREU, L. C.;ABREU, LUIZ; ABREU, LUIZ C. DE;LUiz C. de Abre }\end{array}$ \\
\hline \multicolumn{2}{|l|}{ Endereço } \\
\hline Endereço Profissional & $\begin{array}{l}\text { Faculdade de Medicina do ABC, Faculdade de Medicina do ABC. } \\
\text { Avenida Principe de Gales, } 821 \\
\text { Principe de Gales } \\
09060870 \text { - São Paulo, SP - Brasil } \\
\text { Telefone: (11) } 49937256 \\
\text { Fax: (11) } 49937256 \\
\text { URL da Homepage: Www.fmabc.br }\end{array}$ \\
\hline
\end{tabular}

Formação acadêmica/titulação

1999 - 2003

Doutorado em Ciências.

Universidade Federal de São Paulo, UNTFESP, Brasi.

Titulo: Impacto da fisioterapia neonatal em recém-nascidos pré-termo com doença pulmonar das membranas hialinas em ventilaçāo pulmonar mecânica e pós-reposição de surfactante exógeno, Ano de obtenção: 2003.

Orientador: (9) Paulo Hilário Nascimento Saldiva.

$2001-2001$

Bolsista do(a): Conselho Nacional de Desenvolvimento Cientfifico e Tecnológico, CNPq, Brasil.

Doutorado em Ciências.

Universidade Federal de São Paulo, UNIFESP, Brasil

com periodo sanduíche em Harvard School of Public Health (Orientador: John Godleski).

Titulo: Impacto da fisioterapia neonatal em recém-nascidos pré-termo com doença pulmonar das membranas hialinas em

ventilação pulmonar mecânica e pós-reposição de surfactante exógeno, Ano de obtenção: 2003.

Orientador: (1) Paulo Hilário Nascimento Saldiva.

$1996-1998$

Mestrado em Reabilitaçás.

Universidade Federal de Säo Paulo, UNIFESP, Brasil.

Titulo: Efeitos terapêuticos da fisioter apia pulmonar e motora em recém-nascidos pré-termo com hemorragia periventricularintraventricular,Ano de Obtenção: 1998.

Orientador: (6) Benjamin Israel Kopelman.

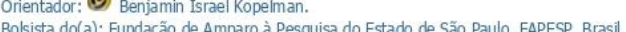

Palaviras-chave: Recém-nascido, hemorragia, fisioterapia, ultrasson.

Grande área: Ciências da Saúde

$2005-2007$

Setores de atvidade: Cuidado A Saúde das Populações Humanas.

Mestrado profissional em Terapia Intensiva.

Instituto Brasileiro de Terapia Intensiva, IBRATI, Brasil.

Instituto Brasileiro de Terapia linterisiva, 1BRAT1, Brasl.

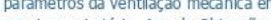

surfactante exógeno por va r

Bolsista do(a): Instituto Brasileiro de Terapia Intensiva, IBRATI, Brasil.

Bolsista do(a): Instituto Brasileiro de Terapia Intensiva, IBRATT, Brasil.

Grande área: Ciências da Saúde

Grande Area: Ciências da Saúde / Area: Fisioterapia e Terapia Ocupacional.

nal / Subárea: Neonatologia Pediatria.

$2008-2009$ res de atvidade: Saúde Humana.

Especialização em Saúde da Mulher no Climatério. (Carga Horária: $360 \mathrm{~h}$ ).

Faculdade de Saúde Pública da Universidade de São Paulo, FSP/USP, Brasil.

Titulo: Reposição de calcio como preditor de doença cardiovascular em mulheres no climatério.

Orientador: Arnaldo Augusto Franco da Siqueira.

Bolsista do(a): Núcleo de Estudos e Pesquisa à Saúde do ABC, NEPAS, Brasi.

$2005-2006$

Especialização em Fisioterapia Intensiva. (Carga Horária: 1600h).

Instituto Brasileiro de Terapia Intensiva, IBRATI, Brasil.

Titulo: Relação entre o desenvolvimento pulmonar e o controle neural da ventilação do recém-nascido.

Orientador: Miguel Nassif.

2018

Graduação em andamento em Serviço Social.

Universidade Paulista, UNIP, Brasil.

Titulo: Politicas Públicas de Acolhimento do trabalhador infantil: passo a passo da sua irradicação.

Orientador: Rodrigo Daminello Raimundo.

2009 interrompida

Graduaçăo interrompida em 2016 em Fisica.

Instituto Federal de São Paulo, IFSP, Brasil.

Ano de interrupção: 2016

Universidade Estadual Paulista Júlio de Mesquita Filho, UNESP, Brasil.

Título: Análise quantitativa da produção de serviços fisioterapêuticos na região do ERSA-48.

Orientador: Jaime de Oliveira Gomes. 
ARTIGO PUBLICADO

Journal: Cells (ISSN 2073-4409) - Fator de Impacto: 5,656 (2019).

\title{
Obesity as an Inflammatory Agent Can Cause Cellular Changes in Human Milk due to the Actions of the Adipokines Leptin and Adiponectin
}

\author{
Tassiane C. Morais ${ }^{1,2}\left(\right.$ D, Luiz C. de Abreu 1,2,3,*(D), Ocilma B. de Quental ${ }^{2}$, Rafael S. Pessoa ${ }^{2,4}(\mathbb{D}$, \\ Mahmi Fujimori ${ }^{2,4}$, Blanca E. G. Daboin ${ }^{2}$, Eduardo L. França ${ }^{2,4}(\mathbb{D}$ and \\ Adenilda C. Honorio-França $2,4, *$ CD \\ 1 Postgraduate Program in Public Health, School of Public Health, University of Sāo Paulo (USP), \\ Sāo Paulo, SP 01246-904, Brazil; tassi.morais@usp.br \\ 2 Laboratory of Scientific Writing, Department of Morphology and Physiology, Centro Universitário Saúde \\ ABC (FMABC), Santo André, SP 09060-870, Brazil; ocilmaquental2011@hotmail.com (O.B.d.Q.); \\ faelpessoa@gmail.com (R.S.P.); mahmi_fujimori@yahoo.com.br (M.F.); bgdaboin@yahoo.com (B.E.G.D.); \\ dr.eduardo.franca@gmail.com (E.L.F.) \\ 3 Postgraduate Program in Public Policies and Local Development, School of Sciences of Santa Casa de \\ Misericordia de Vitoria (EMESCAM), Vitória, ES 29045-402, Brazil \\ 4 Institute of Biological and Health Science, Federal University of Mato Grosso (UFMT), Barra do Garças, \\ Mato Grosso, MT 78600-000, Brazil \\ * Correspondence: luizcarlos@usp.br (L.C.d.A.); adenildachf@gmail.com (A.C.H.-F.); \\ Tel.: +55-(11)4993-7256 (L.C.d.A.); +55-663-405-5317 (A.C.H.-F.)
}

Received: 21 March 2019; Accepted: 7 May 2019; Published: 29 May 2019

\begin{abstract}
Adiponectin and leptin play roles in the hunger response, and they can induce the inflammatory process as the initial mechanism of the innate immune response. It is possible for alterations in the levels of these adipokines to compromise the functional activity of human colostrum phagocytes. Therefore, the objective of this study is to analyze the effects of adiponectin and leptin on colostrum mononuclear (MN) cells. Colostrum was collected from 80 healthy donors, who were divided into two groups: the control group and the high body mass index (BMI) group. MN cells were used to analyze phagocytosis by flow cytometry, and reactive oxygen species (ROS), intracellular calcium, and apoptosis were assessed by fluorimetry using a microplate reader. Adipokines restored the levels of phagocytosis to the high BMI group $(p<0.05)$, with a mechanism that is action-dependent on the release of ROS and intracellular calcium. However, adiponectin and leptin simultaneously contributed to better microbicidal activity, thus reflecting an increase in the apoptosis level $(p<0.05)$ in the high BMI group. Probably, the maintenance of the balance between adiponectin and leptin levels enhances the protection and decreases the indices of neonatal infection in the breastfeeding infants of women with high BMI values. Therefore, policies that support pre-gestational weight control should be encouraged.
\end{abstract}

Keywords: adiponectin; body mass index; colostrum; leptin; phagocytes; obesity; overweight; oxidative stress

\section{Introduction}

Obesity is considered a complex, recurrent, and progressive chronic disease. It can be characterized as an inflammatory condition involving elevated oxidative stress, and it is associated with other diseases [1,2] due to the risk of developing comorbidities such as asthma, musculoskeletal and sleep disorders, diabetes mellitus type 2, liver and kidney dysfunction, cardiovascular diseases, infertility, and cancer $[1,3,4]$. 